University of Louisville

ThinkIR: The University of Louisville's Institutional Repository

Electronic Theses and Dissertations

$5-2015$

\title{
I had to learn that on my own : successful first-generation, low- income college students from rural areas at an urban institution.
}

Aaron Phillips

University of Louisville

Follow this and additional works at: https://ir.library.louisville.edu/etd

Part of the Counseling Commons

\section{Recommended Citation}

Phillips, Aaron, "I had to learn that on my own : successful first-generation, low-income college students from rural areas at an urban institution." (2015). Electronic Theses and Dissertations. Paper 2003.

https://doi.org/10.18297/etd/2003

This Doctoral Dissertation is brought to you for free and open access by ThinkIR: The University of Louisville's Institutional Repository. It has been accepted for inclusion in Electronic Theses and Dissertations by an authorized administrator of ThinkIR: The University of Louisville's Institutional Repository. This title appears here courtesy of the author, who has retained all other copyrights. For more information, please contact thinkir@louisville.edu. 


\title{
I HAD TO LEARN THAT ON MY OWN: SUCCESSFUL FIRST-GENERATION, LOW-INCOME COLLEGE STUDENTS FROM RURAL AREAS AT AN URBAN INSTITUTION
}

\author{
By \\ Aaron Phillips \\ B.A., Eastern Kentucky University, 1999 \\ B.S., Eastern Kentucky University, 2003 \\ M.Ed., University of Louisville, 2006
}

A Dissertation Submitted to the Faculty of the College of Education and Human Development of the University of Louisville in Partial Fulfillment for the Degree of

Doctor of Philosophy in Counseling and Personnel Services

Department of Educational and Counseling Psychology, Counseling, and College Student Personnel

University of Louisville

Louisville, KY

May 2015 

I HAD TO LEARN THAT ON MY OWN: SUCCESSFUL FIRST-GENERATION, LOW-INCOME COLLEGE STUDENTS FROM RURAL AREAS AT AN URBAN INSTITUTION

\section{By}

Aaron W. Phillips

B.A. Eastern Kentucky University, 1999

B.S. Eastern Kentucky University, 2003

M.Ed. University of Louisville, 2006

A Dissertation Approved on

March 26, 2015

by the following Dissertation Committee:

Dr. Amy Hirschy, Chair and Advisor

Dr. Melissa Evans-Andris

Dr. Bridgette Pregliasco

Dr. Deborah Warnock 


\section{DEDICATION}

This dissertation is dedicated to my wife, Melanie, and my daughter, Lacy. They have made the ultimate sacrifice as I spent countless hours away from them in my office preparing my proposal and working on this study. While it has certainly been enjoyable and beneficial work, I can never repay those moments lost. My only hope is that they are and will continue to be as proud of this work as I am. 


\section{ACKNOWLEDGEMENTS}

First, I would like to thank all of the participants of this study. This work would literally have not been possible without their willingness to provide their stories as well as give of their time and effort. Also, I would like to thank my family including my wife, Melanie, daughter, Lacy, my in-laws, Susan and David, and my mother, the late Louanne Walker for their support and encouragement. If it were not for them, I would not have been able to accomplish all that I have.

Additionally, I would like to thank each member of my committee. I would like to thank Dr. Amy Hirschy as the chair of this committee for her continual work with me on getting my proposal ready and always providing helpful feedback that was always greatly appreciated. It is also because of her that I have a much better handle on APA citations. Next, I would like to thank my methodologist, Dr. Melissa Evans-Andris. Melissa’s continued efforts with me served to make my methodology much stronger in the end and in turn led to a better study. It was also through her qualitative method course work that I learned and honed my skills for qualitative research. Finally, I would also like to thank Dr. Bridgette Pregliasco and Dr. Deborah Warnock, who also provided some helpful and invaluable suggestions over the course of the study.

Likewise, I would like to give great appreciation to the many faculty members from whom I have taken course work over the last several years not already mentioned who have helped with my learning and development. This list includes Dr. Michael Cuyjet, Dr. Jeff Valentine, and Dr. Namok Choi. If any were accidently omitted from 
that list, I offer my sincerest apologies. I would also like to thank my supervisor, Dr. Margaret Pentecost. Although there were seldom instances where I let work on this dissertation interfere with my full time job, I very much appreciate the support during this endeavor. I would also like to offer tremendous thanks to my fellow colleagues and students who have provided support and encouragement over the years. This includes my comprehensive exam buddies, Joy Cox and Elizabeth Liebschutz-Roettger, as well as Tia Dumas who has "talked me off the ledge" metaphorically several times throughout my pursuit of not only the dissertation but this degree in general. I also cannot forget others such as Joe Goodman, Angela Duncan, and Laura Ulmer.

Many years before I set my sights on pursuing the doctoral degree, I was inspired by my high school sophomore English teacher, Mr. Judson Harmon. Over the years, Mr. Harmon would also become a good friend and mentor. Even though Mr. Harmon passed away on October $29^{\text {th }}$ of 2012, his inspiration, encouragement, and words of wisdom have stuck with me and continue to contribute to who I am today.

Finally, I would like to thank all of those who laid the groundwork prior to my study. I am greatly appreciative of all of the researchers and scholars who have contributed to the knowledge base on first-generation, low-income students. Their previous research, in large part, is what led me to pursue my study and generate ideas for development. 


\begin{abstract}
I HAD TO LEARN THAT ON MY OWN: SUCCESSFUL FIRST-GENERATION, LOW-INCOME COLLEGE STUDENTS FROM RURAL AREAS AT AN URBAN INSTITUTION
\end{abstract}

Aaron Phillips

March 26, 2015

First-generation and low-income college students have been at a greater risk of attrition and have graduated at lower rates compared to other students for some time. Despite this, however, there are first-generation and low-income students who have been successful and have graduated. Unfortunately, there has been a lack of research focused on successful students, particularly those who are also from a rural background. The purpose of this study is to reveal what strategies, practices, actions, and behaviors lowincome, first-generation students from a rural background employ and engage in to persist and be academically successful. A qualitative methodology was chosen for this study, and more specifically, interviews of study participants were conducted. Single participant interviews were conducted in order to maintain the strict confidentiality of the participants and to obtain information that occurred at previous points in time.

There were five major themes of the study. The first was the importance of the environment of the institution, followed the impact of one's first-generation and lowincome status on their campus experiences. Next, a third theme was the strengths participants brought with them to campus from a rural background, followed by the 
significance of participants building their own support networks on campus. Finally, participants reported a great deal of support to attend college from a variety of sources. Related findings included the need to build their own support network on campus and that a rural upbringing provides students with many assets and strengths that can be beneficial at the university. Related findings also included that the university is generally doing relatively well for students who are from first-generation and low-income backgrounds, although improvements can still be made. Finally, the study found that participants, overall, were involved and engaged on campus. Student affairs professionals and higher education administrators must look for ways to further increase the likelihood that first-generation, low-income students from rural areas will persist, be academically successful, and ultimately graduate. Essentially, understanding the unique characteristics such as strengths and assets as well as challenges and obstacles is paramount in working with this student population. 


\section{TABLE OF CONTENTS}

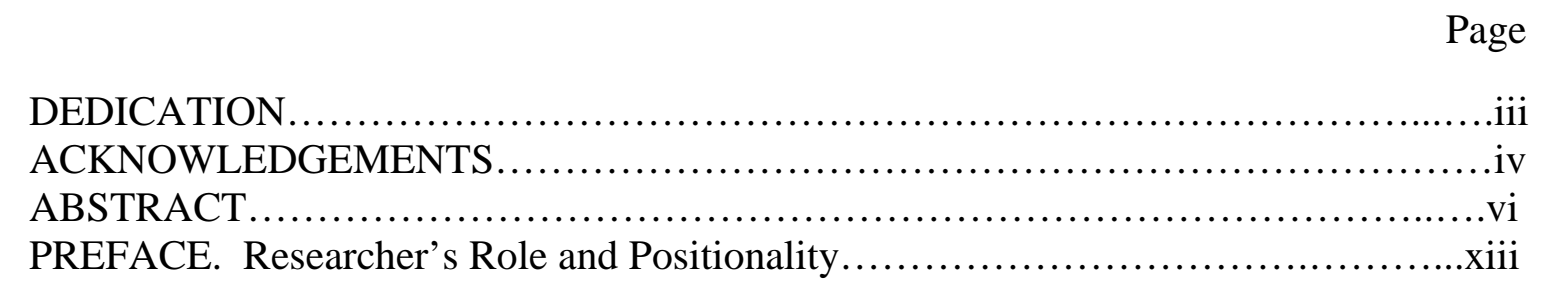

CHAPTER I. INTRODUCTION...............................................

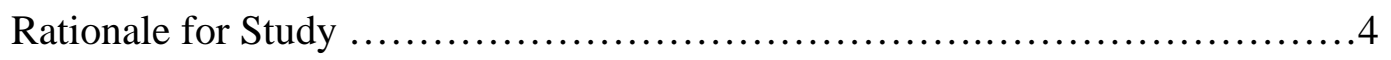

Kentucky............................................................

Student Characteristics................................................

Urban, Research Institution........................................

Completion and Graduation.............................................. 8

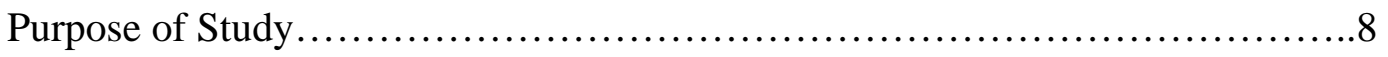

Conceptual Framework.....................................................10

Social and Cultural Capital...........................................11

Retention and Persistence.........................................16

Overview of Methodology .................................................20

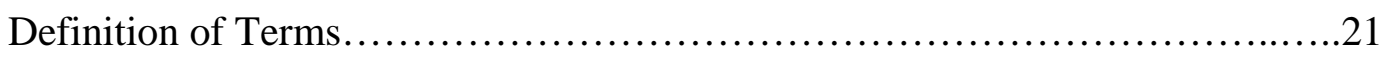

First-generation College Student........................................21

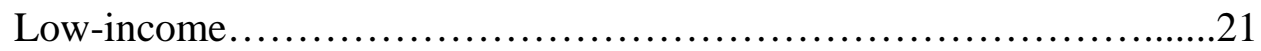

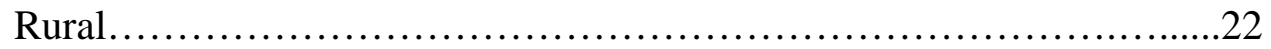

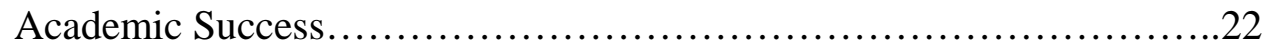

Preview of the Next Chapters............................................23

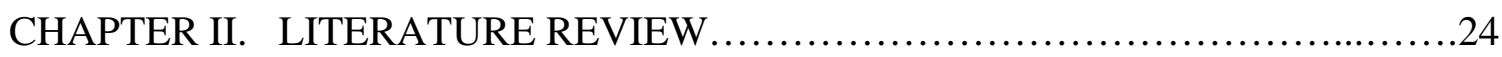

Characteristics of First-generation and Low -income College Students............24 


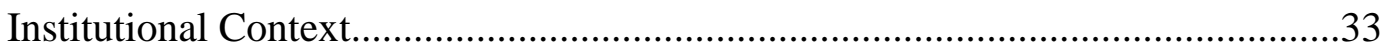

Why Class Matters........................................................

Significance of Rural Identity..............................................44

Family, Community, and Peer Support.......................................49

Significance of a Large, Urban Research Campus.................................60

College Access, Information, and Knowledge...............................64

Institutional Approaches and Obstacles......................................74

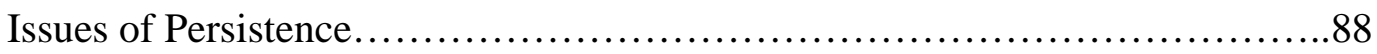

Focus on Completion and Graduation......................................91

Obstacles, Challenges, and the Importance of Higher Education..................94

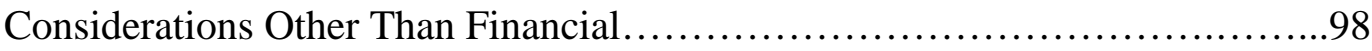

Further Exploration.....................................................103

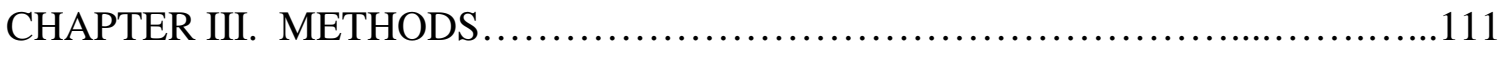

Qualitative Approach...................................................112

Nature of Design.......................................................114

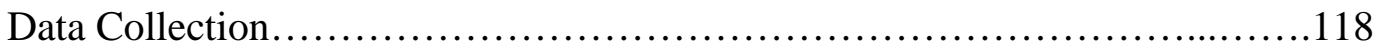

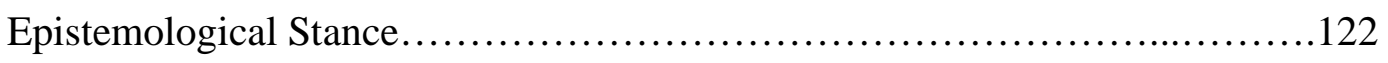

Description of the University of Louisville and City.............................124

Characteristics of Participants and Participant Selection...........................125

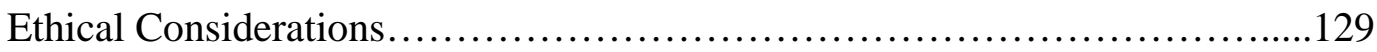

Confidentiality .................................................130

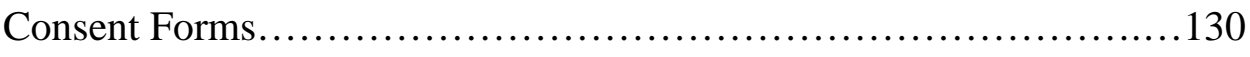

Potential Risks..................................................131

Precautions from Risk............................................131

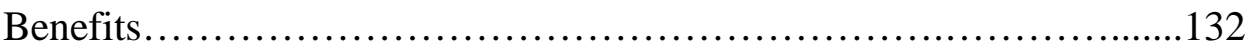

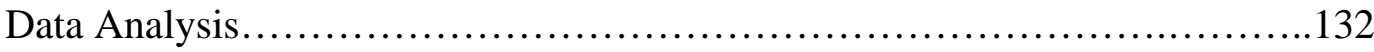

Quality Control.......................................................135 


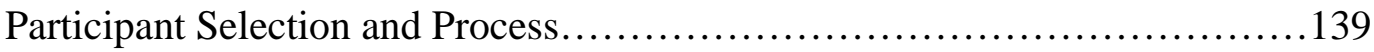

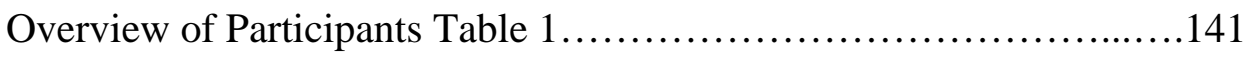

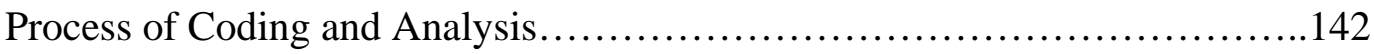

Major Themes.............................................................. 144

Support to Attend College............................................144

Parental and Family Support..................................144

Peer and Friend Support......................................146

Community Support......................................148

Importance of Environment and Atmosphere of the Institution...........149

The Positive Nature of the Campus Environment................150

Many Resources Available On Campus..................................151

Opportunities for Involvement on Campus......................153

Opportunities for Involvement can be Limited...................154

The Need for Greater Knowledge and Awareness for and about

First-generation and Low-income Students.....................155

Communication on Campus..................................159

Cardinal Covenant............................................160

Impact of First-generation and Low-income Status on Campus

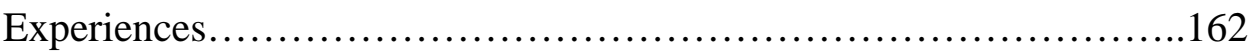

Statuses Serving as Impetuses for Success.....................162

Feeling Lost or Lacking Direction...............................164

Differences Noticed in Comparison to Classmates...............167

Continued Financial Challenges in College......................170

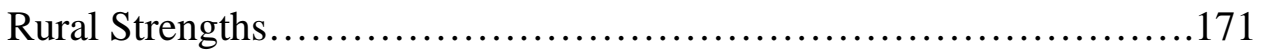

Rural Social Skills..........................................171

Work Ethic.................................................173 
Strong Sense of Community................................174

Building Your Own Support Network................................176

Lack of Reliance on Family or Others in Home Community.....176

Important Connections with Faculty and Staff on Campus.......177

Involvement on Campus and within the Community.............179

Making Informal Connections with Other Students on Campus.181

Taking Advantage of Resources...............................183

Chapter Four Conclusion..................................................184

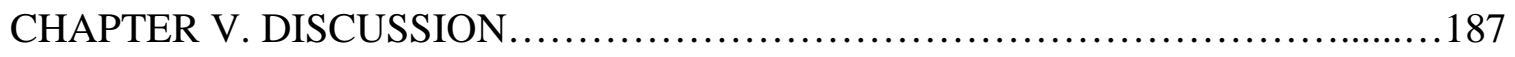

Research Questions....................................................187

Key Findings from the Study........................................ 188

Students Built Their Own Support Networks on Campus.................189

Rural Upbringing Provides Major Assets and Strengths.................193

The University is Generally Positive in regard to Low-Income

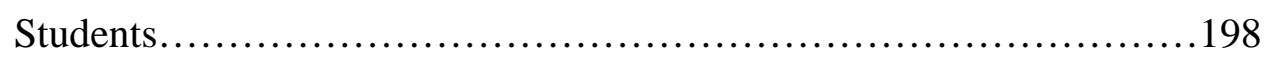

Participants are Heavily Involved and Engaged........................201

Differences among Participants............................................203

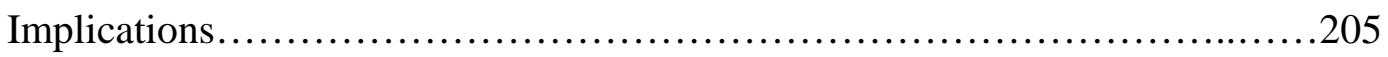

Implications for Practice............................................206

Offer Financial Assistance for Involvement......................206

Offer a Separate Orientation for First-generation Students........207

Offer Budgeting and Financial Workshops Aimed at Low-

Income Students.........................................208

Provide Training or Workshops for Faculty, Staff, and Other

Students........................................................209

Include and Provide More Information on Financial Aid.........211

Establishment of a Rural Student Organization..................211 
Offer More Opportunities for Family Members to Come to

Campus......................................................213

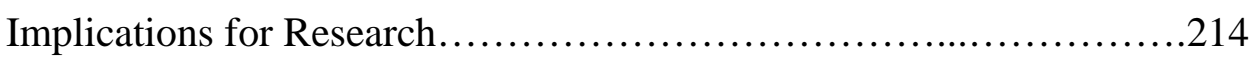

Quantitative Studies.........................................215

Comparing Research Universities to Other Types of Institutions............................................215

Further Exploration Needed on the Greatest or Greater

Factors of Influence....................................216

Qualitative Studies............................................217

Comparing Rural, First-generation, Low-income Students

to Urban, First-generation, Low-income Students.........217

More Research on Rural Students.......................218

Greater Focus on the Influence of Siblings for First-

Generation Students....................................219

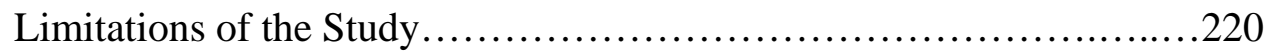

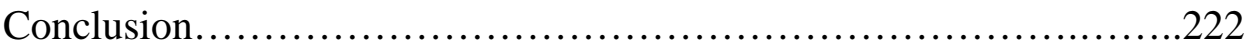

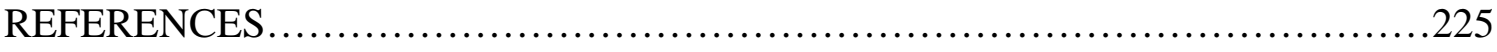

\section{APPENDICES}

A - Targeted E-mail to Cardinal Covenant and Trio Students...................261

B-E-mail to the General Student Population..............................263

C—Interview Questions.................................................265

D—Subject Informed Consent Document................................268

E—Posted Flier to Recruit Participants....................................272

F-Poverty Guidelines and TRIO Low-income Guideline Tables 2 \& 3........274

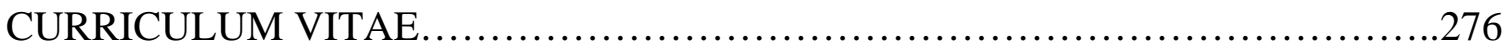




\section{PREFACE}

\section{Researcher's Role and Positionality}

Within qualitative research, the researcher is commonly referred to as the "human instrument” and is typically acknowledged as the primary instrument in any qualitative study (Lincoln \& Guba, 1985; Creswell, 2007). Because of this, it is extremely important for the researcher to reflect upon his or her own experiences, knowledge, bias, perceptions, and assumptions in regard to the phenomenon under study. One key way to address this is for the researcher to keep a reflexive journal, which according to Glesne (2006) may involve asking questions to one’s self as well as the research process throughout the study and recording such reflections, listening carefully to participants’ responses and potentially adjusting the interview if needed, and considering both the

sociocultural and political context in which the research is situated. Furthermore, Jones, Torres, and Arminio (2006) suggested these questions in guiding the researcher's reflection prior to engagement in data collection:

1.) Why is it I am engaged in the present study? What is it about me and my experiences that lead me to this study?

2.) What personal biases and assumptions do I bring with me to this study?

3.) What is my relationship with those in the study? (p. 125) 
Additionally, the primary reason why I am interested in studying this population is my own personal and emotional connection. While this can certainly be a potential strength, as Strauss and Corbin (1990) posited: "each of us brings to the analysis of the data our biases, assumptions, patterns of thinking, and knowledge gained from experience and reading” (p. 95). There are several techniques, however, a researcher can employ in managing these concerns: consider possible categories in developing precise questions; using words, phrases, and sentences to probe for meanings and reflect on assumptions; look at extremes of a dimension in thinking analytically rather than descriptively about data; using systematic comparisons early in the analysis to critically examine patterns of thinking; and being cognizant of absolute statements (Strauss \& Corbin, 1990; Beegle, 2000).

I grew up in a rural part of the state and although both of my parents went to college, we were by no means well off financially and most of those I grew up with had no intentions of going to college. Since I have begun working in higher education, one of my primary aims and missions is to improve the experience and find ways to support first-generation and low-income college students. Rager (2005) pointed out how important it is for qualitative researchers to take care in guarding against too much of an emotional connection or take proper precautions when this happens to occur. In her research on her dissertation focused on breast cancer patients she speaks of how in many ways their pain almost became her pain and this was something for which her studies and preparation did not prepare her. Qualitative research may by its very nature be emotionally draining and mentally exhausting due to personal connections made with 
participants in study. Often times the reason why they are under study may be due to an obstacle or challenge they are facing, one in which the researcher cares about immensely.

I was raised in McCreary County, a county with only a little over 18,000 residents according to the 2010 U.S. Census (U.S. Census Bureau, 2014). Furthermore, of six classifications based upon population statistics, McCreary County is in the lowest population classification of "noncore," defined as not having a city of 10,000 residents or more (Ingram \& Franco, 2013). Also, according the U.S. Census, just over 30\% of the counties' residents live below the poverty line (U.S. Census Bureau, 2014). In fact, McCreary County ranks as the $21^{\text {st }}$ poorest county in the nation and the fourth poorest (out of 120 counties) in the state of Kentucky (McCreary County Record, 2009). Those statistics alone may signal the environment from which I came, but they alone cannot paint the complete picture. I easily recall going to school with classmates who lacked running water, who only ate at school because they received free breakfast and lunch, and saw little point in graduating high school, much less attending college. At the time, I did not realize it, but that set the stage for my later wanting to do something about it. Growing up, I thought places like Harvard and Yale were only for the super wealthy and elite of society, and it was only when I moved to the Louisville area that I met students who qualified and enrolled in some of these elite institutions. This came as a complete shock since one rarely had a student from my high school attend a major university in the state such as the University of Louisville or the University of Kentucky, and only a small minority that would leave home to attend any institution of higher education. This said, I am sensitive to and understand some of the perspectives of students coming from rural backgrounds, those who are low-income and those who are first-generation. For many of 
these students, the only people with a college education they have likely ever met are the teachers at their school and the family doctor.

Within qualitative studies, it is also necessary for the researcher to acknowledge and address any previous relationships or power differentials with participants involved in the study. While I had previous contact with two or three participants prior to the study through my internship with Cardinal Covenant, our relationship was only as acquaintances at most and the vast majority of participants were unknown to me prior to the study. Also, although a university employee, I have no role as a supervisor or instructor, and have no role of influence over any of the participants, creating no conflict of interest. I now proceed to the findings of this study. 


\section{CHAPTER 1}

\section{INTRODUCTION}

Kentucky has the third highest rate of poverty in the nation and ranks $47^{\text {th }}$ in regard to bachelor degree attainment (U.S. Census Bureau, 2012). The rural areas of Kentucky fare even worse as much of Kentucky’s wealth is concentrated in more urban and metropolitan regions, while many rural areas within the commonwealth, particularly in eastern Kentucky, have poverty rates above 25\% (U.S. Census Bureau, 2012). A college education can certainly be one way to combat this concern, but even for those students from a disadvantaged background who make it to college, troubling issues may still be prevalent. In the 1992 movie, Scent of a Woman, Nicholas Sadler's character Harry quipped to his classmates in reference to an insincere offer to financially strapped classmate Charlie Simms to accompany them on an exorbitant Thanksgiving break trip, "It's customary on major holidays for the lord of the manor to offer drippings to the poor.” Harry's comment strikes at the core of a mentality permeating many circles in higher education. Although Charlie attends the prestigious Baird School on a scholarship allowing him financially to attend, the socioeconomic gulf between upper-class Harry and disadvantaged Charlie continues to influence the nature of Charlie's experience. The nuance of this takes place on many college campuses throughout the United States. Even when financial need is addressed, other concerns inherit within a university setting may 
severely hinder a low-income or first-generation student from successful completion of his or her undergraduate degree. Yet, some of these students succeed in spite of such challenges. The purpose of this study is to reveal what strategies, practices, actions, and behaviors low-income, first-generation students from a rural background employ and engage in to persist and be academically successful. The results of this study will benefit faculty, staff, and administrators who work with these student populations and those who face similar obstacles.

The U.S. invests in higher education because of the potential economic benefits, increased productivity, flexible workforce able to respond to a changing economy, and the increased standard of living, factors important to the nation and its citizens (Advisory Committee, 2002). Between the years 2008-18, approximately 22 million new college degree holders will be required to keep pace with the economy, yet estimates show a shortfall of about 3 million, or 300,000 each year. The Southern Regional Education Board (SREB) has called on its 16 member states to have $60 \%$ of their adult populations ages 25-64 to have post-secondary certificates, associate degrees, or bachelor degrees by the year 2025 (Spence, Blanco, \& Root, 2010). SREB also stated: “America’s economy will not flourish or be internationally competitive in the future without a better-educated and more skilled work force, and states will be unable to close their achievement gaps in education” (Spence et al., 2010, p. 2).

There are many benefits, however, that extend beyond solely the economic advantages of higher education. Baum, Ma, and Payea (2013) pointed out several benefits of higher education beyond the financial, both for the government (federal, state, and local) in regard to increased tax revenues, and for the individual who is not only 
more likely to be employed, but also have health insurance and pension benefits through his or her employer. Furthermore, they asserted that adults with higher levels of education are more active citizens in regard to volunteerism and civic participation as well as tend to lead healthier lifestyles leading to reduced health care costs (Baum et al., 2013). Attending college can also have a strong social effect because for many students, college will be the first place they encounter others who have dramatically different beliefs, values, backgrounds, and attitudes (Astin, 1977). McMahon (2009) also emphasized that higher education can have a wide range of social benefits that have not been typically measured or accounted for by many outside of academia. The financial benefits, however, can also not be overlooked. In 2002, while average earnings of those who had some college were only \$5300 more per year than those with a high school diploma, the average earnings of someone with a bachelor’s degree was $\$ 14,200$ more than someone with some college course work but had not completed a degree, and was $\$ 19,500$ more than someone with only a high school diploma (Cheeseman-Day \& Newburger, 2002).

While college access for those at-risk or disadvantaged has improved, there are still significant gaps between the haves and the have-nots in regard to completion and graduation rates and there are two factors that continue to limit the opportunity of a postsecondary education. One is social class, and the other, often ignored factor is geography or, one's location of origin. For years, research has indicated that urban, inner-city youth lack access to higher education compared to suburban youth, particularly for racial and ethnic minorities (Reid \& Moore, 2008; Piorkowski, 1983; Rendon, 1995; Yosso, 2005; Dennis, Phinney, \& Chuateco, 2005), but, what has not been as well-researched are the 
lack of college access and further obstacles if matriculation occurs rural youth may have experienced.

\section{Rationale for Study}

This study is being conducted for several reasons. First, low-income and firstgeneration students face significant obstacles to access, retention, and completion (Wyner, Bridgeland, \& Diulio, 2007; Bean, 2005; Ishitani, 2003). Second, students from rural areas may face even greater obstacles to college enrollment and completion (Abbott, 2006; Schutz, 2004; Elliott, 1989). Third, colleges and universities are increasingly challenged with engaging and developing minority, low-income, and first generation students, and while students whose parents went to college often have the social, cultural, and financial capital that promote success within a collegiate setting, those students who are the first in their families to go may be deficient in such resources (McGregor, et al.,1991; Lohfink \& Paulsen, 2005; Terenzini, Springer, Yaeger, \& Pascarella, 1996; Ramos-Sanchez \& Nichols, 2007; London, 1989; Tierney \& Venegas, 2009; Khan, 2008). Finally, much can be learned from academically successful students who are firstgeneration, low-income, and from a rural background that can be beneficial to other students from similar backgrounds and to institutions of higher education. One potential implication from the findings of this study include a greater understanding of firstgeneration, low-income students from a rural background including actions and behaviors enabling them to be successful within the academic environment, specifically at an urban, research institution. Another potential implication is to use that knowledge to improve practice, programs, and policy for the betterment of first-generation, low-income students from a rural background. Finally, a third potential implication is to encourage further 
research on first-generation, low-income students from a rural background so that more can be learned about this student population in the future.

Furthermore, there are several areas that need to be addressed in greater detail in regard to the rationale. First, the Commonwealth of Kentucky is a focal point since it is anticipated that the vast majority of participants in the study will originate from Kentucky. Second, there are several student characteristics addressed within the study including first-generation status, low-income self-identification, and identification from a rural background. Next, the study involves all participants from a rural background attending a large, urban, research institution. Finally, degree completion is addressed as the study focuses on students on the path to graduation.

\section{Kentucky}

An important consideration for this study is the location, more specifically the Commonwealth of Kentucky. The University of Louisville is located within Kentucky, and being a public institution, with significant differences between in-state and out-ofstate tuition, draw a majority of their students from within the Kentucky's borders. In fact, 73\% of the university’s population is comprised of in-state students ( $\mathrm{U}$ of $\mathrm{L}$ Institutional Research, 2014). Kentucky faces tremendous challenges in regard to educational attainment. According to Kelly (2011), there is a "long-held perception of Kentucky as a state with a poor system of education” (p. 14). It would be one thing if this was a stereotypical misrepresentation; however, the evidence reveals some truth to this assertion. As of the most recent U.S. Census, the national average for bachelor degree attainment or higher is $27.6 \%$, while only $21 \%$ of Kentuckians age 25 or older had earned a bachelor's degree or higher, ranking the state $47^{\text {th }}$ with only Arkansas, 
Mississippi, and West Virginia lagging behind and placing Kentucky more than six percentage points behind the national average (U.S. Census Bureau, 2012).

Education is not the only challenge within Kentucky, however. The national average for individuals below the poverty line is $13.9 \%$, while $18.6 \%$ of individuals in Kentucky live below the federal poverty line, ranking the state as $3^{\text {rd }}$ highest, with only Arkansas and Mississippi behind (U.S. Census Bureau, 2012). Furthermore, given this information, it can be surmised that Kentucky is facing some significant challenges. While poverty is of general concern throughout Kentucky, it is even more pronounced in rural areas. Of Kentucky’s 120 counties, 55 are at or greater than 20\% poverty for individuals, with all of the 55 counties being rural (U.S. Census Bureau, 2012). Perhaps even more disturbing, 11 of those counties have greater than 30\% poverty (U.S. Census Bureau, 2012). Educational attainment by geographic region also shows a disturbing trend within Kentucky. While the more populated urban areas of Lexington, Louisville, Owensboro, Bowling Green and northern Kentucky have college going rates, based on 2006 high school graduates, of greater than $50 \%$, the majority of rural counties in Kentucky have a college going rate of less than $50 \%$, and many with less than $40 \%$ (Kentucky Council on Postsecondary Education, 2009). Furthermore, the most urban counties in Kentucky, Fayette and Jefferson, have 35.6\% and 24.8\% of their adults 25 or over with at least a bachelor's degree, ranking them first and fourth respectively (Kentucky Council on Postsecondary Education, 2009). Comparatively, counties in the lower half of the spectrum have rates below 10\%, with all being rural (Kentucky Council on Postsecondary Education, 2009). One might say based upon the aforementioned evidence that originating from Kentucky could serve as an additional hindrance. To go 
one step further, originating from a rural county within Kentucky may serve as an even greater obstacle.

\section{Student Characteristics}

One of the criteria for inclusion in this study is first-generation status, a status which, alone, can at times create an obstacle. Orbe (2008) posited there are six primary and twelve secondary "dialectical tensions” that first-generation students face in their identity negotiation, with each primary tension being divided into two separate secondary tensions based upon their home versus campus environments. Another criterion for inclusion in this study is level of income. It is important to point out that even though there can be significant overlap, this is separate from one's first-generational status because not all first-generation students are low-income, and not all low-income students

are necessarily first-generation. Yet, a third major criterion for inclusion in this study is a rural identity. While some studies have pointed out the challenges and obstacles of the rural student population (Abbott, 2006; Kalmijn \& Kraaykamp, 1996; Schutz, 2004; Elliott, 1989), more research needs to be conducted revealing the strengths, attributes, strategies, positive actions, and beneficial behaviors of these students.

\section{Urban Research Institution}

It is also important to focus on the collegiate environment for these students, which interacts with one’s personal characteristics to shape experience (Lewin, 1936). While certain institutions (community colleges, small private colleges, etc.) may be easier for acclimation, they may not address the needs of all students within this population. For some, a larger research based university, or a university located in an urban setting, would be better. First, large, research universities offer a greater variety of degrees. 
Second, urban universities may offer greater opportunities for internships, practicums, and networking. Also, Goldrick-Rab (2006) found that students from a more socioeconomically disadvantaged background are more likely to have interrupted periods of enrollment when beginning at a community college and transferring between schools, and that the transfer, away from a four-year institution, is more likely to be to a community college as opposed to another four-year school than students from a higher income levels.

\section{Completion and Graduation}

Access, retention and persistence, and degree completion, are strongly repeated themes throughout the field of higher education. While all three (access, persistence, and completion) are important and tend to be the key talking points in higher education, "degree completion is the true bottom line for state legislators, parents, and most importantly, students” (Adelman, 1999). Therefore, it makes sense to focus on successful students to target those who are relatively close to completion and graduation.

\section{Purpose of Study}

For too long, research has focused on what first-generation and low-income students lack when they come to campus. Instead, having focused on the positives and strengths these students bring, Yosso (2005), through the lens of critical race theory, criticized deficit thinking and focused on the knowledge, skills, abilities, and various resources students of color possess. While her study focused specifically on students of color, her assertions regarding those positive attributes brought as well as her critical perspective in regard to deficit thinking are clearly also applicable to low-income, firstgeneration students, regardless of race or color. Her summation of the perspective of 
deficit thinking aimed at minority students is "students and families are at fault for poor academic performance because: (a) students enter school without the normative cultural knowledge and skills; and (b) parents neither value nor support their children's education” (p. 75), could very well also be a summation of deficit thinking aimed at firstgeneration and low-income students (who could very well be white). Again, the purpose of this study is to learn what strategies, practices, actions, and behaviors low-income, first-generation students from a rural background employ and engage in to persist and be academically successful.

While a great deal of research exists on low-income, first-generation students, much of it fits into the two following categories: quantitative comparisons between firstgeneration, low-income students and continuing generation, middle to upper-class students, and studies specifically on urban and/or racial/ethnic minority groups, which may be qualitative in nature but are narrow in scope, focusing on a specific group. While this study technically fits into the second category, rural, first-generation, low-income students who have successfully navigated and are near graduation at large, urban, research universities have rarely been studied. I chose to focus on first-generation, lowincome students from a rural background for three primary reasons. First, there is a dearth of literature available on first-generation, low-income students who are specifically from a rural background. Second, students from a rural background face certain obstacles other groups of students, even other groups of first-generation and lowincome students, may not. Finally, if first-generation, low-income students from a rural background are going to succeed economically, as previously mentioned, they cannot 
rely entirely upon community colleges, small, private institutions, or even regional universities as previously asserted.

The research questions that guide this study are:

1. What specific obstacles and challenges to their persistence and academic success do first-generation, low-income students from a rural background face at an urban research institution over the course of their enrollment?

2. What assets or strengths do first-generation, low-income students from rural backgrounds possess that could help them to be academically successful at an urban research institution?

3. What specific attributes of a large, urban research institution can be particularly challenging from a negative aspect or particularly beneficial from a positive aspect for a low-income, first-generation student from a rural background?

4. What actions and behaviors do first-generation, low-income students from a rural background engage in in combination with the practices of an urban research institution to promote and benefit transition and integration into the campus community?

\section{Conceptual Framework}

Any important study must include a conceptual framework that informs and guides one's research. The framework of this study includes the concepts of social and cultural capital, and also includes the issues of retention and persistence. This section will address those elements. 


\section{Social and Cultural Capital}

Bourdieu (1986) proposed the concept of three forms of capital: economic, social, and cultural. Also key to Bourdieu's theory was the notion of habitus, which Bourdieu (1977) viewed as “a system of lasting, transposable dispositions which...functions at every moment as a matrix of perceptions, appreciations, and actions” (pp. 82-83). Furthermore, Swartz (1997) held that these perceptions and actions are "derived from the predominantly unconscious internalization, particularly during early childhood, of objective chances that are common to members of a social class or status group” (p. 104). Finally, Horvat (2001) stated “in deciding which action to take and in carrying out an action in society, individuals listen to their own internalized interpretation of the rules which govern the field of interaction” (p. 207). In relation to the current study, a student's identity as first-generation, low-income, and from a rural background frames his or her interpretations and impacts how he or she sees oneself within the collegiate environment. Equally important to Bourdieu was the idea of "field.” According to Bourdieu (1984), the field consists of agents, the capacity for an individual to act, social positions, resulting from the interaction between rules of the field, habitus, and the agent's capital. One might view a college campus as a particular field where students have the ability to impact and influence their outcomes according to their habitus, or backgrounds and experiences influencing perspective and the levels of social and cultural capital they bring with them.

Oldfield (2007) defined cultural capital as “the knowledge, skills, education, and other advantages a person has that make the educational system a comfortable, familiar environment in which he or she can succeed easily” (p. 2). According to Lamont and 
Lareau (1988) this cultural capital can be rather confusing due to the myriad of definitions and explanations surrounding the phenomenon, but the pair sum up Bourdieu's original proposal as - cultural capital being an inherit quality upper and middle-class individuals bring with them into the social setting as early as young childhood, providing them with certain key advantages. The pair also defined cultural capital as- "institutionalized, i.e., widely shared high status cultural signals (attitudes, preferences, formal knowledge, behaviors, goods and credentials) used for social and cultural exclusion” (p. 156). Furthermore, Bourdieu (1986) divided cultural capital into three embodied strands: long lasting physical and mental dispositions, objectified cultural goods such as pictures, books, machines, etc., and institutionalized in terms of educational qualifications. Bourdieu (1986) defined social capital as relationships and connections, (i.e. group memberships), and also stated that all three forms of capital are closely linked and at times one form of capital can be converted to the other. Bourdieu's theory is relatable to first-generation, low-income students because often these students are deficient in all three forms of capital: social, cultural, and financial. Such students have numerous obstacles to overcome in the form of differences between their own culture and that of the university, differences involving the use of public vs. formal linguistic patterns as well as position within the family or community setting (Gos, 1995). Dumais and Ward (2009) suggested that a student who possesses greater degrees of cultural capital, particularly if he or she comes a from higher socio-economic status level, will receive more attention from teachers in the P-12 setting and, will receive better grades and also more encouragement to pursue higher education than a student who lacks the same degrees of cultural capital. Even when less privileged students possess degrees 
of such capital, they are not likely to receive the same rewards as those from a more privileged background because the capital appears more "studied and less natural” (Dumais \& Ward, 2009, p. 247). Their findings suggest that no matter how hard firstgeneration and low-income students work to overcome their potential deficits, many are not be able to achieve at the same levels as other students. Furthermore, in their study, Dumais and Ward (2009) found that the possession of greater degrees of cultural capital also positively impacted college enrollment. Similarly, yet another study found a significantly positive relationship between one’s degree of cultural capital and his or her educational attainment including college attendance (DiMaggio \& Mohr, 1985). In the same study, DiMaggio and Mohr (1985) also found that students involved in cultural pursuits throughout high school had an advantage going into college. Furthermore, the statement by Collier and Morgan (2007) regarding the experience related to the lack of cultural and social capital for first-generation (and low-income) students may be particularly apt:

"In contrast (to those students who are not first-generation), first-generation students typically possess relatively lower levels of college student expertise, in that, they cannot rely on parental advice to help them identify and resolve rolebased problems or to help them understand the university’s expectations. They come to the university with less understanding of student roles and less capacity to build their existing knowledge into genuine expertise” (p. 18).

Additionally, Berger (2000) applied Bourdieu’s concept of cultural capital to the issue of persistence, asserting that persistence is related to the congruence between a student's own cultural capital and that of the institution. Berger (2000) further elaborated 
stating institutions with higher levels of cultural capital have higher rates of retention and students with higher levels of cultural capital are more likely to persist. Furthermore, students with higher levels of organizational cultural capital are more likely to persist at institutions that likewise have higher levels of organizational cultural capital and students with low levels of organizational cultural capital are more likely to persist at institutions with lower levels of organization cultural capital (Berger, 2000). Lehmann (2007) applied Bourdieu's idea of habitus in looking at the persistence and enrollment patterns of Canadian first-generation students and supported Bourdieu's assertions by stating that those with adequate cultural and social capital felt like "fish in water," while many of the students in his studies "felt like fish out of water." Finally, Kuh and Love (2000) addressed one's cultural background and influences and how they relate to collegiate experience through eight propositions, four were perhaps most salient for first generation and low-income students. First, one's cultures of origin (or cultural backgrounds) mediate the importance attached to attending college and earning a college degree; second, the probability of persistence is inversely related to the cultural distance between the student's culture(s) of origin and cultures of immersion; third, students who traverse a long cultural distance must become acclimated to dominant cultures of immersion or join one or more enclaves; finally, the amount of time a student spends in one's cultures of origin after matriculating is positively related to cultural stress and reduces the chances they will persist (Kuh \& Love, 2000, p. 201).

As seen through the work of several researchers (Van Galen, 2000; Shields, 2002; Hsiao, 1992; London, 1989) first-generation and low-income students often come from backgrounds where education and a college degree are not priorities; students lack 
support from their families, there is a perceived lack of support, or families do not know how to support their student in college. Furthermore, the cultural distance between that of origin and immersion can be immense for these students and locating enclaves of students from similar backgrounds on campus can be challenging at best. Finally, the pressure to return home as much as possible can result in less time spent acculturating oneself to the campus environment.

The full appreciation of Bourdieu's work, however, can perhaps only be undertaken when one combines the ideas of social class and cultural capital with financial capital. The linkages between social class and cultural capital are not difficult to detect. Dumais (2002) asserted cultural capital is typically passed on by one's family, the acquisition of such capital is primarily dependent on one's social class, and higher income students are much more likely to participate in cultural activities. Often, however, while families of first-generation, low-income students are aware of their financial limitations, they are not cognizant of both their social and cultural disadvantages (Calkins, 2005). Social and cultural capital can sometimes be the most significant as these students leave their families and home communities with established relationships and connections for an environment that is foreign and operates on a separate currency on these two forms of capital. According to Tinto (2012), these students lack this shared knowledge regarding what it takes to be successful in college and the nature of the college experience. While economic capital can often be overcome with grants, scholarships, and employment, the social and cultural deficiencies can be more difficult to manage and overcome. 
Finally, Coleman (1988) defined social capital as existing of three forms: obligations and expectations, in which subject A does something for subject B and then subject B feels obligated to reciprocate, depending upon the trustworthiness of the social environment and the extent of the obligation; information channels, relying on information to provide a basis for action; and social norms. For first-generation students, obligations and expectations might come from family members who expect the student to stay home and work to help the family financially as re-payment for his or her upbringing, or could come from an institution by way of good grades and participation in campus culture for receipt of a scholarship or other financial awards. First-generation and low-income students could receive information about higher education opportunities (from family, school counselors, teachers, media, etc.) that are more limited or even misguided than for continuing generation students. Finally, social norms are often those expectations of behavior and action, which may lead to disconnect between a firstgeneration student's home life and life on campus. In two separate studies, London (1989 \& 1992) posited that students were often caught between both worlds and had to renegotiate relationships with family and friends back home, feeling varying degrees of conflict in the process.

\section{Retention and Persistence}

Vincent Tinto challenged the commonly held traditional belief that there was something deviant or inadequate about those students who did not persist (Tinto, 1987). Instead, Tinto (1987) chose to focus on what institutions should do for students in a series of calculated steps, stating “decisions to withdraw are more a function of what occurs

after entry than of what precedes it” (Tinto, 1993, p. 5). Tinto (1975) developed an early 
model "attempting to explain drop out as lack of integration into the social system of the college” (p. 92) and viewed the process of drop out as: "a longitudinal process of interactions between the individual and the academic and social systems of the college during which a person's experiences in those systems (as measured by his normative and structural integration) continuously modify his goal and institutional commitments in ways which lead to persistence and/or to varying forms of drop out” (p. 94).

Tinto's theory was originally designed to be applicable to all students, regardless of characteristics or personality traits, but it certainly has specific relevance for firstgeneration, low-income students as Tinto would later allude to this. As Tinto (1987) pointed out the rates of departure are highest for those of the lowest social status and among those who do persist and graduate, they are least likely to graduate on schedule. Tinto (1987) asserted that students who had experiences with and have acquired skills in coping with new environments will be more adept in their adjustment which is important since first-generation, low-income students from rural backgrounds often have not had the same level of such experiences.

Tinto (1987) noted that academic difficulty was one factor leading to departure and that poor academic preparation played a role in this, which is important since often students from disadvantaged backgrounds face this challenge (US Department of Education, 2001; Reid \& Moore, 2008; Brooks, 2005; Goldrick-Rab \& Pfeiffer, 2009). In terms of incongruence, first-generation students who lack this social and cultural capital may have more trouble navigating the conflicting demands of their collegiate and external environments and connecting one's self with the mainstream culture of the institution. Regarding isolation, Tinto (1987) emphasized the connection students can 
make with faculty which can be particularly problematic for first-generation college students who lack familiarity with collegiate culture as well as social and cultural capital.

Also, establishing contacts on campus may prove to be more difficult for students with external demands that Tinto (1987) referenced such as working more hours off campus, part-time enrollment, and living off campus, situations many first-generation students share (Pascarella, et al., 2004; Engle, Bermeo, \& O’Brien, 2006; Chen, 2005). While Tinto (1987) noted that separating oneself from his or her home community can be challenging for any student, the struggles for first-generation students can be greater given the stronger ties and influence they feel from friends and family and even more challenging when those family members and friends do not support the student's decision to attend college (London, 1989; Tinto, 1993; Khan, 2008). Rendon (1995) focused her research on minority student persistence at community colleges, finding two critical phases affecting the retention of first semester students that can be particularly problematic for first-generation and/or low-income students: making the transition to college and making connections to campus. Rendon (1995) stated that the first phase can be challenging for this student population because first-generation and low-income students deal with changing identities, are perceived by others on campus as different, leave old friends behind, break family codes of unity and loyalty, and live between two worlds. She also pointed out that for many, connecting socially and academically can also be challenging because often these students are unprepared for college, both academically and psychologically, feel lost in a strange academic environment, and lack a sense of direction, not even knowing the right questions to ask (Rendon, 1995). 
A contemporary of Tinto, Bean (2005), stated that there are nine themes related to retention: student's background, money and finance, grades and academic performance, social factors, bureaucratic factors, external environment, psychological and attitudinal factors, institutional fit, and finally, commitment and intentions. Several of these are particularly applicable to first-generation and low-income students. The first is institutional fit, in which Bean (2005) stated that a student is likely to fit in if he or she shares social and academic values with other students. This could be difficult for a student at a large university who is unsure of how to navigate thousands of other students to make these connections, and even more so for a student from a small, rural area. Furthermore, Bean (2005) asserted that economically disadvantaged students in particular may feel discriminated against and may not feel that they fit in at the institution. The second theme is academic, where Bean (2005) pointed out that there is often little expectation of faculty to exert much energy in lower-division courses, particularly at large universities. This can especially be detrimental to students coming from a rural area who have often attended small high schools where they received personal attention from high school faculty.

A third theme is social, in which Bean (2005) argued that the expectations of parents, siblings, and friends who have gone to college before them, and the information and encouragement they receive will impact the social connections they make. Students who are first-generation may not be able to rely upon such expectations, information, and encouragement. At first glance, while the bureaucratic factors Bean (2005) referenced broadly may seem to impact all students equally, the bureaucracy can be more intimidating to a student whose parents do not understand how to assist him or her in 
navigating the complex rules and regulations of an institution. Finally, a student's background is also clearly impactful for first-generation and low-income students as parents' education, college preparation, and lack of parental support place them at greater risk for attrition (Ishitani, 2003; Ishitani, 2006; Chen \& DesJardin, 2008; McCarron, 2006; London, 1989; Shields, 2002; Kahlenberg, 2004; Bean, 1985.)

\section{Overview of Methodology}

A qualitative approach was chosen for this study in order to obtain in-depth responses from the participants, leading to a greater thickness and richness in detail of their experiences. More specifically, grounded theory, first espoused by Glaser and Strauss (1967) was selected since there is currently no theory explaining how firstgeneration, low-income students from a rural background overcome obstacles and challenges to persist and be academically successful. Interviewing was chosen as the method for data collection since I will primarily gathering information about previous actions and behaviors directly from the participants while also doing as much as reasonably possible to maintain confidentiality and to protect participant privacy. Interviews will take place on the campus of the University of Louisville and will last no longer than one hour. Participants will be purposefully sampled meeting the criteria of low-income, first-generation college student, from a rural background, have at least a 2.5 cumulative grade point average, and have at least earned 60 college credit hours. Participants will be provided a consent form prior to the interview that will be collected at the time of the interview. Interviews will be transcribed by the researcher and coded for analysis and interpretation of the data. Participant identity will be kept confidential throughout the study with all electronic records saved on a password protector in the 
locked office of the researcher and any hard copy records kept in a locked file cabinet in the locked office of the researcher. Participants will select or be assigned a pseudonym and names of locations or other individuals referenced indirectly will be masked. At the conclusion of the study, all materials and records will be destroyed.

\section{Definition of Terms}

First-generation college student: First-generation students have been defined in at least three ways: first, those for whom neither parent has obtained a college degree, but may have enrolled in college (Engle \& Tinto, 2008; US Department of Education, 2011; Hicks, 2003); second, those for whom neither parent has attended college (Chen, 2005; Nunez \& Carroll, 1998); and third, for whom either parent has attended college, but for less than one year (Barnett, 2004; Hertel, 2002; York-Anderson \& Bowman, 1991). For the purposes of this study, the definition of first-generation students is those for whom a parent may have attended college, but did not complete a four-year degree. Firstgeneration students may also be referred to as "first-gen" students throughout the study.

Low-income: For the purposes of this study, low-income is defined as $150 \%$ at or below the federal poverty guideline. This is the definition used by the Federal TRIO Programs, as well as the Cardinal Covenant program (a program that covers full tuition, books, room and board for eligible in-state students) on the campus of the University of Louisville for establishment of eligibility in regard to income. It should be noted, however, that of prime importance is whether or not the student self-identifies as a lowincome student. Please see Tables 1 and 2 for further information on the 2014 Federal poverty guidelines in Appendix G. Table 1 consists of the 2014 federal poverty guidelines while Table 2 consists of the low-income levels to qualify for eligibility for the 
federal TRIO programs. For example, if a family of four has a combined income of less than $\$ 23,850$, then they would be considered by low-income. By way of another example, if a family of four has a combined income of less than $\$ 35,775$, a student from that family would be eligible for participation in the federal TRIO programs. While firstgeneration status alone is significant, it does not tell the complete story, as lower income students are often typically required to finance as much as $70 \%$ of their family's annual income in order to attend college at a public research institution (Haycock, Lynch, \& Engle, 2010).

Rural: The U.S Census Bureau marks percentages of urbanized area within counties in the U.S. (U.S. Census Bureau, 2010). Urbanized is defined by US Census Bureau (2010) as an area of 50,000 people or more which classifies (within the Commonwealth of Kentucky) as the cities of Louisville, Lexington, Covington, Bowling Green, and Owensboro as urbanized areas. While this was a helpful guide, determining rural versus urban status was primarily based upon how the student defined his or her community growing up, with census bureau definitions being secondary. For example, if a student came from a northern Kentucky county, close to the urbanized area of Covington, yet, defined him or herself as coming from a rural area, he or she will be considered as a student from a rural background. Or if a student had lived most of his or her life in a rural area and identified as coming from a rural area, but moved to Louisville late in their high school years, he or she would also qualify.

Academic success: Inevitably, there are varying measures of academic success and not one correct answer. A 2.5 grade point average (GPA) was chosen, and while some may argue GPA is not the only way to measure academic success, it may be the only way to 
measure it across disciplines at a large research university. Furthermore, it is a measuring tool for graduate schools, and Pascarella et al. (2005) estimated undergraduate grades have "a modest positive impact” on being employed full time early in one’s career in a position appropriate to one's bachelor's degree. A 2.5 GPA has been chosen because while different colleges at the University of Louisville use different GPA's for "good standing," a 2.5 GPA is the most common at the university.

\section{Preview of Next Chapters}

The following chapters comprise the remainder of this dissertation. First, chapter two reviews relevant literature; second, chapter three outlines the methodological approach for the study; next, chapter four addresses significant themes and patterns uncovered by the research and concisely tie those findings together; finally, at the conclusion, the fifth chapter consists of limitations of the study, major findings, and suggestions for research and practice moving forward. 


\section{CHAPTER 2}

\section{LITERATURE REVIEW}

This chapter will focus on important areas of previous research related to this study. First, characteristics of first-generation and low-income students are addressed. Equally important, socioeconomic class as an important element to this study is discussed. Further research related to the significance of rural identity is then addressed. Likewise, there is also a discussion of the influence of family, community, and peer support followed by the exploration of the significance of attending a large, urban, research institution. Furthermore, there is an inclusion of the overview of research on college access, information, knowledge, and academic preparation. Correspondingly, there is a discussion regarding institutional approaches and obstacles, followed by a discussion on the issues of persistence. Following is an examination of the concerns regarding completion and graduation subsequently continued by a review of the obstacles, challenges, and the importance of higher education. Finally, considerations that impact the issues of access, matriculation, retention, and completion are explored.

\section{Characteristics of First-generation and Low-income College Students}

First-generation college students undergo some of the same challenges and obstacles as other students, but also have some of their own distinct struggles. According 
to Gibbons and Shoffner (2004) there are five key areas where first generation students differ in regard to characteristics from other college students: lack of parental experience with the college application process, how a student prepares for college both personally and academically, why they choose to attend college (almost solely as a means to obtain a good job), personal experiences, and their overall personality traits.

In like manner, one study found first-generation students completed fewer credit hours, studied less, took fewer courses in the natural sciences, math, and arts/humanities, had lower college grades, and worked more hours per week (Pascarella et al., 2003). Further research by Brachman (2012) found that first-generation students are less likely to be involved in various academic or social collegiate experiences such as study groups, student organizations, and using support services. Equally important, Inman and Mayes’ (1999) study of students at community colleges found that first-generation students are more likely to believe they can work long hours at a job and still be academically successful in college and cite location as much more of a deciding factor in where to enroll than do other students. Furthermore, Padron's (1992) focus of first-generation students at Miami-Dade Community College found they lacked an understanding of expectations within higher education, faced unsupportive parents and siblings, and were inadequately prepared academically. While academic preparation can help, even those who are prepared can still struggle. According to an achievement report, high-achieving low-income college students are far less likely to graduate from college compared to their higher income peers by a rate of $59 \%$ to $77 \%$ respectively and even among those who do graduate, substantially fewer when compared to upper-class students will matriculate to graduate school (Wyner, Bridgeland \& Diulio, 2007). Correspondingly, in Lehmann’s 
(2007) qualitative study, first-generation students reported not fitting in, not able to relate to more affluent students with college educated parents, and not persisting to graduation despite solid academic performance. Additionally, Orbe (2008) believed two of the primary tensions: individual versus social identity and stability versus change identity were particularly important in understanding the experiences of first-generation students. Although Orbe was not explicit as to why this is the case, it is certainly possible that, at least for traditional age first-generation students, this may the first time in their lives they are experiencing such an extreme contrast and tension between their expectations of themselves and the expectations others have for them in regard to success.

The reasons for focusing on first generation students specifically are clear as since 1995, this population has comprised about $34 \%$ of the total student population at fouryear universities (Choy, 2001), and in a more recent examination still hovers at about one third of the entire college student population (Institute for Higher Education, 2012). Also, first generation and low-income college students are important to focus on as one national study revealed $95 \%$ of $8^{\text {th }}$ graders who had a parent that attended college actually attended themselves, while only $56 \%$ of $8^{\text {th }}$ graders who did not have a parent that attended college enrolled (Ingels, Curtin, Kaufman, Alt, \& Chen, 2002). The firstgeneration aspect potentially could be most salient, as Bean (2005) asserted that a parent's education consistently had the largest influence on retention compared to parental occupation or income, and that parental exposure provides the additional social and cultural capital which benefits interaction with the institution and adjustment to college. Also, college graduates who have shown the ability to navigate the system and graduate can serve as a role model for their children. Finally, some researchers 
(Pascarella, Wolniak, Pierson, \& Terenzini, 2003) divide the parents of these student populations into three groups: those who have a four-year degree, those who attended college but did not graduate, and those who never attended. Their study found those students whose parents had some college but no degree were more similar to firstgeneration students whose parents never enrolled than to students whose parents have degrees, lending support for how first-generation students are defined in this study (Pascarella et al., 2003).

Another finding was being first generation reduced one's odds of graduating in a 4-5 year period from $51 \%$ to $32 \%$ and that first-generation students are 4.4 times more likely to drop out by their second year as opposed to those students whose parents were college educated (Ishitani, 2003). Similarly, in a later study, despite the focus of many institutions on the first-year of enrollment, Ishitani (2006) also found that first-generation students face their greatest risk of attrition their second year, being 8.5 times more likely than their continuing generation counterparts to drop out. Formerly, Ishitani and DesJardins (2002) found that a mother's education may be of particular significance as students whose mothers had attained an undergraduate degree were 57\% more likely to persist to the third year than those students whose mothers had not. To add to this, only 7.5\% of students eligible for Pell Grants obtained a bachelor's degree within six years of initial enrollment at their institution (Tinto, 2012). Furthermore, Chen and DesJardin (2008) found while $22 \%$ of high-income students dropped out of college, $38 \%$ of their low-income peers did in their longitudinal study of six years. Another longitudinal study by McCarron (2006) found that even when level of income is controlled for, $69 \%$ of firstgeneration students had not obtained a bachelor’s degree within eight years after initial 
college matriculation and also found that as high school sophomores only about $40 \%$ of those students aspired to achieve a bachelor's degree. Finally, one national survey found that first-generation college students had less favorable perceptions of college, lower levels of academic and social engagement as well as lower levels of overall integration, particularly when it came to diverse college experiences (Pike \& Kuh, 2005).

Ultimately, one can clearly see that, at least up to this point, first-generational status can place a student at risk for greater attrition. All of this being stated, however, studies regarding parental influence have had mixed results. In fact, in one study, Shields (2002) found having a parent who attended a university helped students feel more prepared for the university experience, but that second-generation students felt no more successful than first-generation students, nor did the influence seem to impact GPA or levels of stress, which had been predicted by the researcher(s). To be clear though, this was only one study, compared to many multiple studies that state otherwise. Most research shows first-generation college students come into higher education at a substantial disadvantage and face many obstacles that place them in significant danger for dropping out of college. For example, Wang and Castaneda-Sound (2008) discovered that first-generation students had lower levels of academic self-efficacy, have more somatic or physical symptoms, and tend to experience higher levels of academic difficulty than other students. That same study (Wang \& Castaneda-Sound, 2008) also found that self-esteem was the single most important predictor of a first-generation student's psychological well-being. As has already been mentioned, there is much research out there that provides a thorough account of why this is the case. 
Pascarella, Pierson, Wolniak, and Terenzini (2004) pointed out that typically research on first-generation college students has focused on three distinct stages: the college choice process and ability to access higher education, the transition from high school to postsecondary education, and the persistence of these students along with eventual degree attainment. When it comes to entry level characteristics, some studies have found that those low-income students of greatest risk tended to be female, have lower levels of educational aspiration, have parents with less than a high school education, commute to campus, stop out and return to school later, need remedial coursework, have lower GPA's at the end of their first year, and are more likely to take classes part-time (Engle, Bermeo, \& O’Brien, 2006; Chen, X., 2005). In fact, while taking classes part-time may not seem like an obvious concern, another study found that about $90 \%$ of first-generation, low-income students who persisted to graduation within the time frame of the study were enrolled in a full course load their first semester (Yizar, 2010).

Further research reveals that first-generation students have been found to take fewer AP courses, score lower on college entrance exams such as the ACT and SAT, have lower GPA's after their first year and are more likely to take remedial course work (US Department of Education, 2001). Once on campus, the challenges and obstacles often are not any easier for the first-generation college student. CIRP (Cooperative Institutional Research Program) data has revealed that there is a consistently large gap for self-rating of leadership ability with first-generation students rating themselves lower than their continuing generation peers (Saenz, V.B. et al., 2007). Furthermore, in a qualitative study by Collier and Morgan (2007) first-generation students were more likely 
to report that time management was a significant concern, felt they had fewer resources, particularly outside of campus, and were less likely to understand the importance or purpose of the syllabus. The same study revealed first-generation students had different perspectives and interpretations of faculty verbal and non-verbal cues and expected greater specificity and clarity when it came to instructions about writing academic papers (Collier \& Morgan, 2007). While one might argue that these could be concerns for any students, the research aforementioned simply points out that these issues may be more pronounced for first-generation students.

Another study of personality characteristics of first-generation students found that they had lower levels of self-esteem, did not feel as socially accepted, and perceived themselves as significantly less creative than those students whose parents had attended college (McGregor, Mayleben, Buzzanga, Davis, \& Becker, 1991). Furthermore, a study focused on low income students found they are less likely to be involved with other students or experiences on campus (Terenzini et al., 2001). Additionally, separate studies found that first-generational students were more at risk if they were Hispanic, of lowerincome, and had weaker cognitive skills (Lohfink \& Paulsen, 2005; Terenzini et al., 1996).

In regard to motivation to attend college, Bui (2002) found that first-generation students are more likely to report pursuing higher education to help their families out financially after college, gain respect or status, and bring honor to their families while also expressing a greater fear of failure in college, have more worries about financial aid, and feel they will need to put more time into studying than continuing generation students. Furthermore, another study found that first-generation students have a lower 
self-efficacy and are less likely to believe they will succeed in college, and even those first-generational students who do believe they will succeed academically, tend to underperform other students in terms of GPA (Ramos-Sanchez \& Nichols, 2007). Similarly, Strayhorn (2006) found other factors influencing a student's GPA are time elapsed between high school completion and college matriculation, time needed to complete one’s degree, and number of institutions attended. In fact, further research reveals that first-generation students may struggle with the issue of time management, studying, and test taking because of family responsibilities (Payne, 2007; Shields, 2002). Finally, even when controlling for such factors as academic preparation, first-generation students were less likely to persist than their continuing generation counterparts and while some differences did disappear for first-generation students who took academic rigorous courses in high school, they were still more likely to stop out or downward transfer than other students (US Department of Education, 2001).

While much of the information regarding first-generation and low-income students is not positive; however, some findings are optimistic. In one study, Hicks (2005) found that first-generation students were more enthusiastic about living their life and making important life choices than were other students and also found first-gen students were in some ways more academically motivated. In another study comparing first-gens to continuing generation students at an HBCU (Historically Black College or University), Hicks and Murphy (2006) found that first-generation students did not differ from their peers in regard to highest level of education they hoped to achieve, GPA, or the possibility of graduating with honors. Furthermore, Hicks and Murphy (2006) state that such high expectations first-generation students have may contribute to a resiliency 
which allows them to persevere. The researchers were careful to note, however, that the results could be due in part to the nature of the environment at an $\mathrm{HBCU}$, and may not necessarily be transferrable to other institutions (Hicks \& Murphy, 2006). Likewise, further research by Smith (2011) found that many first-generation students from a lowincome background expressed a level of determination to succeed that in some cases contradicted their perceived abilities. Smith (2011) also came to the conclusion that attributes such as self-determination and personal motivation of these students can help them to overcome barriers such as a lack of family support as well as a lack of knowledge about college processes. Additionally, Steinmetz (2008) discovered many students who had grown up in relative poverty identified as middle-class until arrival at an elite institution in the south. Furthermore, Steinmetz (2008) found some first-generation students felt they were more qualified to be at their institution because of their hard work and had gained admission to the institution even though they lacked the same access to certain academic and leadership advantages. Equally important, students in this study also failed to identify with various social representations of the poor, instead identifying primarily with the middle class and seeing themselves as upwardly mobile (Steinmetz, 2008).

In contrast to much of the research revealed, additional evidence supports the notion there were no differences between first-generation students and continuing generation students in regard to academic or social adjustment to college, and that there was also no difference between first-generation students and continuing generation students in terms of their overall GPAs (Strage, 1999). It is certainly important to point out, however, that this is a single study that contradicts a multitude of studies that state 
otherwise. It should also be emphasized that contradictory studies, often do not capture the tales of first-generation and low-income students who did not persist. Finally, in her qualitative study, Rodriquez (2003) found that despite the negative characteristics that have been well researched regarding first-generation students, there were several positive traits that surfaced through her interviews such as individuals being singled out in a positive way at a young age and given "special status." This gave them a strong sense of self-confidence, having one individual who was a strong, positive influencing force, and a particular drive within them to lead an activist life to remove the barriers they had experienced (Rodriquez, 2003). In essence, it has been established that there are significant obstacles for low-income and first-generation students, but there are also students who go against the trend, those who stand out and are successful. In summation, the need to focus on first-generation and low-income students is significant as historically they have been at a greater risk of attrition and less likely to graduate. While firstgeneration and low-income have been popular topics, the notion of class, however, is often either overlooked or ignored.

\section{Institutional Context}

There are a variety of resources and services available at the University of Louisville for all students from tutorial services, to career services, and many others. For low-income and first-generation students specifically there are two programs on campus: Cardinal Covenant and TRIO. I have included a chart on page 140 that indicates, in part, if participants were recipients or involved with either of these programs. In order to be eligible for Cardinal Covenant, which is solely and uniquely a program at the University of Louisville, the students must be at or below $150 \%$ of the federal poverty line and a 
resident of Kentucky. The students must also meet the minimum admission requirements to the university and submit an essay by the established deadline of January $15^{\text {th }}$, with the purpose of the essay being to "help the University of Louisville understand from the student's perspective how receiving Cardinal Covenant will assist them in reaching their full potential as a student at the University of Louisville and citizen of the Commonwealth of Kentucky” (U of L Office of Financial Aid web site, 2015). Cardinal Covenant was established in 2007 and was the first program of its kind in Kentucky with the purpose of making college attainable for the $22.6 \%$ of Kentucky families living at or below 150\% of the federal poverty level (U of L Office of Financial Aid web site, 2013). The program fulfills a promise by the University of Louisville to award students who meet the eligibility criteria with enough financial assistance to meet the costs of their tuition, room, board, and books and graduate debt free as long as they graduate within four years and remain Pell Grant eligible (U of L Office of Financial Aid web site, 2013). Cardinal Covenant students are assigned an "Ambassador" as freshman and they are required to meet with their Ambassador once a week for their first semester. It is important to note, however, that the Ambassador program just finished its third year and has not been in existence since the inception of the program. This is important to note that some of the students who are recipients of Cardinal Covenant that participated in the study began prior to the start of the Ambassador program and were not able to take advantage of this opportunity.

The Federal TRIO Programs are outreach and student service programs designed to assist low-income and first-generation students from middle school through graduate level programs offering tutorial services, career and college preparation, among 
additional services (U.S. Department of Education, 2014). The program differs from Cardinal Covenant in that a student does not apply to receive direct funding under these programs, and serves students throughout the United States, not just the University of Louisville (U.S. Department of Education, 2014). The program's stated mission is to: "increase retention and graduation rates by offering academic, financial, and personal support.” (U of L TRIO Student Support Service web site, 2015). In order to be eligible for participation in TRIO, federal regulations require that participants must be either a low-income student, meeting federal income eligibility guideline requirements, must be a first-generation college, defined where neither parent/guardian has graduated from a fouryear institution by the time of the student's $18^{\text {th }}$ birthday, or that the participant have a documented disability (U of L TRIO Student Support Service web site, 2015). Participants receive a variety of services (and in fact are required) including the opportunity to participate in programming and events, meet with a support specialist, and further intervention from the support specialist if the student goes on academic probation (U of L TRIO Student Support Service web site, 2015). Furthermore, according to the program's web site (2015), they also provide a one-on-one tutoring, assistance with applying to graduate school, academic success workshops, information on applying for financial aid, scholarship opportunities, and professional mentoring.

It is important to note that while participants in my current study were not directly asked if they were recipients or participated in either program, recipients, particularly with Cardinal Covenant, were quick to attribute at least some of their success to the program. Another significant advantage of students being engaged in one of these 
programs is that staff members within the program also serve as invaluable resources for connecting these participants to other beneficial resources and services on campus.

\section{Why Class Matters}

Why does class matter? The story of rags to riches, of an individual originating from humble beginnings to achieve success and amass great fortunes is often told, however these are extreme examples and millions of Americans living in poverty will likely never advance in regard to their socio-economic status. While stating that "education is the great equalizer" may be naïve and too simplistic, education can certainly be a significant factor in helping one to advance and move up the social class ladder rungs. Furthermore, Pascarella and Terenzini (1991) stated: “completion of a bachelor's degree is typically the single most important educational rung on the socioeconomic attainment ladder” (p. 575). Also, while many Americans might have images of those living in poverty as lazy, and this can sometimes be applicable just as it is for those who are middle or upper class, the vast majority of the nation's poor are women surviving on low wage employment and children. In fact, while there are 72 million children under the age of 18 in the United States, using the federal poverty threshold and defining low-income as less than $200 \%$ of that threshold, 32.3 million children (45\%) live in low-income families (Addy, Engelhardt, \& Skinner, 2013). Children, of course, cannot help the station they are in or the socio-economic status in which they are born into, and with many women now heading single-parent households, we live in a time when many might argue it takes two incomes financially manage a household. For those living in poverty education can move them upward. Since this is 
the case, we must help those children who will need a college education to better their lives and put an end to generational poverty.

Ultimately, while college can sometimes be assumed for many middle and upperclass students, it is not always a given for lower income and working-class students. In his ethnographic study, Moss (2003) found that many of the low-income white high school students in his study did not see much of a benefit from education and that since their parents and peers did not value education, likewise neither did the students. Even among those students who did express a desire to attend, they were often uncertain about whether or not they would ultimately enroll and how they would pay for it if they did (Moss, 2003). Another longitudinal study found that only one demographic characteristic was significantly associated with degree completion: socio-economic status (Adelman, 2006).

Once again, why is this significant, why does it matter? As Rank (2005) poignantly states: "Poverty casts its shadow upon the majority of our citizens at some point during their lives” (p. 3), and while those words are haunting, many Americans might scarcely believe them to be true. The fact remains, however, that since the early 1970's an increasing number of working families are falling below the poverty line, in addition to the inner cities, rural areas have become more and more economically isolated, and the gap between the rich and poor has widened (Rank, 2005).

In fact, while race and gender are often popular topics, class is often overlooked, at least until recently, with the common misconception that the United States has been a relatively classless society. Additionally, class has been overlooked or undervalued as a student characteristic compared to race and gender for much too long. While 
discrimination based on race, ethnicity, gender, and religion, etc. is a violation of the law and generally not socially accepted, discrimination based upon class and use of the term "white trash" is almost applauded and often encouraged (Sullivan, 2003). Furthermore, DiMaria (2006) asserted that while institutions often celebrate many types of differences, that differences of class are not typically celebrated because it can upset the ideals of the institution.

In the same fashion, while many want to marginalize those who in some way experience economic misfortune, the fact remains, however, that the United States has the highest rate of poverty and income inequality among Western industrialized nations (Rank, 2005). Furthermore, Rank (2005) identified three major reasons why poverty, and as a result class, have tended to be ignored historically in this country: the notion of individualism tends to work against a sense of community and caring for others, a focus on self-reliance where issues such as poverty and class are seen as one's individual responsibility and not that of the collective, the view that the U.S. is still a land of opportunity available to all. Even when other student predictors were referenced, religious background received greater attention with only brief mention of one's "social background” and parents' education level (Astin, 1977). Even more recently, in Thelin’s 2011 A History of American Higher Education, class was not mentioned, and socioeconomic factors were seldom referenced.

Furthermore, Paulsen and St. John (2002) stated that focusing on social class in higher education represents a departure from the mainstream research on college students, further elaborating that most theories on student outcomes assume students have geographic, social, and economic mobility and opportunities when the fact remains that 
many of today’s students do not. The pair further stated that: “Although higher education research has given only limited consideration to the role of social class, it has long been evident that class plays an important role in education and attainment and should be considered when critically examining educational policy” (Paulsen \& St. John, 2002, p. 195). Finally, Susan Borrego (2008), at the time the Vice President for Planning and Enrollment Management at California State University in Dominguez Hills stated succinctly that: "there is little consciousness about how class affects campus climates and individual lives," going on also to state that often what confuses the issue, making it a rather complex topic are the "multiple definitions of class, disagreement about the significance of class background, and ambiguity about class categories” (p. 1).

In moving forward with this notion, in her book "Where We Stand," bell hooks (2000) referred to our nation as a class-segregated society, afraid to think about the issue of class and that race and gender are often used as ways to deflect attention away from class. Likewise, Gladieux and Swail (1999) also pointed out that gaps in who attends college based upon socioeconomic status continue to remain the "primary contributor to the social and economic stratification of American society" (p. 180). Most research, and that more recently, would indicate, however, that class should be examined. For example, Titus (2006b) found that a student's socioeconomic status is a useful characteristic in explaining college completion at four-year institutions and that as one's level of income moves upward, there is a greater chance of degree completion within a six year time frame, with only $46 \%$ of the lowest income students graduating compared to $71 \%$ of the highest level of income students. 
Correspondingly, In Swimming Against the Tide: The Poor in American Higher Education, Terenzini, Cabrera, and Bernal (2001) posited that by the ninth grade, most students had developed both occupational and educational expectations related to their income levels. Additionally, they also found that while only $11 \%$ of high school students from the higher income group had not enrolled in college the fall semester following graduation, nearly half (48\%) of those students in the lowest income group had not enrolled (Terenzini, et al., 2001). While some may argue race and class are tightly linked, other evidence supports that the association is are fairly weak (Pascarella et al., 2001) and low-income whites still constitute about two thirds of all low-income students in college (Hoxby \& Avery, 2013). Furthermore, Rank (2005) found that by age 75, more than half of all white Americans will have spent one or more of their adult years below the poverty line, pointing out that poverty is an event experienced by all racial groups and not something that can easily be dismissed as a condition of a marginalized group. Finally, in the book Shape of the River, Bowen and Bok (1998) contended students benefit in multiple ways as undergraduates through exposure to all types of diversity, including that of class, such as appreciation of differences of others, becoming more active community members, and being able to successfully interact with others from diverse backgrounds. What makes class diversity sometimes difficult to detect is that often poverty and hardship can exist beyond what the naked eye can be visually observed.

While many may argue that economic hardship has always been a fact of life for minorities, evidence based upon several measures is pointing to increasing difficulties of white Americans. According to hooks, an African-American,: "poverty in the white 
mind is primarily black,” (p. 4) and it is difficult for blacks to think about class because it "disturbs the illusion of racial solidarity” (p. 8), but the realities point to class being culturally significant. According to 2013 figures, more than 30 million white Americans fell below $100 \%$ of the federal poverty line, accounting for about $65 \%$ of the nation's destitute (US Census Bureau, 2013). Furthermore, while ethnic minority children comprise a large percentage of those children living in poverty in the U.S., about 4.2 million white children live in poverty (National Center for Children in Poverty, 2007). Finally, according to hooks (2000), the hidden face of poverty in this country are the untold stories of millions of poor white people and "the white poor make up the vast majority of poor in our society,” (p. 115), which is particularly true in the rural and suburban areas. While the focus of the dissertation is not solely on white students, it is anticipated that many of the participants will be white, given the populations statistics for Kentucky, particularly in rural areas (US Census Bureau, 2012). Therefore, it is important to dispel images that poverty must be a certain color, race, or ethnicity.

In like manner, Terenzini, Cabrera, and Bernal (2001) also found in their review that when students receive parental encouragement, when parents have high expectations and there is strong academic preparation, students are more likely to pursue a college education. While these concepts may seem rather obvious, these are all factors where class plays a significant role, with lower income students often deficient. Some also continue to see the issue as black/white, as a racial issue alone, however, some research would suggest otherwise. In one study as early as the 1980's, cultural resources had increased at a faster rate for Black children than White children and Blacks as a whole were catching up to white America in this regard (Kalmijn \& Kraaykamp, 1996). Few, 
perhaps, have stated the issue more poignantly than William Julius Wilson, a Harvard professor specializing in race and poverty, when he said: "It's time America comes to understand that many of the nation’s biggest disparities from education and life expectancy are due to poverty and are increasingly due to economic class and position” (Yen, 2013).

In fact, much of the reason class is often ignored is based upon self-interest. According to Howard Zinn (1999), while one percent of the nation owns about one third of the wealth, the other portion of the wealth is distributed in such a way to turn the remaining 99 percent against one another. Also consider Zinn wrote this in 1999 and as wealth continues to become more concentrated in the hands of the wealthiest Americans (Levine, 2012), the 99 percent to which he refers continually and increasingly are fighting against each other for a smaller percentage. According to hooks (2000) another reason why discussions regarding class are strongly discouraged is that throughout the latter $20^{\text {th }}$ century, and now into the early $21^{\text {st }}$ century, mass media have presented the rich as generous, benevolent, hard-working, model citizens, while living simply is never celebrated and poor people who lead meaningful lives are rarely acknowledged. What this has led to is a society that has gradually moved away from widespread communal concern for social justice and welfare to notions of individual accountability and selfcentered materialism (hooks, 2000). Another repercussion is that many of the poor and working class have adopted the thoughts and value of the ruling upper-class and ideologically join with them in promoting and protecting the class interests of the wealthy (hooks, 2000). 
Class can particularly develop as an issue for students in college. In considering the popular society myth of a "classless society," many young people may come to college with little exposure to notions of class, regardless of whether they are upper, middle, or lower-income. One study of all white students from low-income backgrounds found that both students at elite private institutions and state public universities tended to downplay the role of their social class as an important factor in influencing their career paths, citing characteristics such as motivation and determination as playing a more significant role (Seider, 2008). This is the idea known as "pushing class aside” (Seider \& Aries, 2004), and further points to the notion we as a nation continue to blind youth toward the realities of class disparities. Having grown up in rural Kentucky, hooks (2000) speaks of her first interactions with those from the upper-class culture when she went to college, an experience that led to her first conscious thoughts about the notion of class.

Furthermore, when one considers that hooks' experiences were over four decades ago, prior to the aforementioned shift in societal focus she references, differences between students can seem even more pronounced when harsh realities are dealt with as opposed to images displayed and dispersed through television and the internet. Furthermore, hooks (2000) described youth culture at the time of her writing as centered on consumption where all of one's worth is determined by material possession. Finally, in her ethnographic study, Weis (1992) found that not only were there race related tensions, but also class tensions as well involving middle-class faculty and working-class students. While researchers have found is that class is often underplayed when compared 
to other demographics, further strengthening the argument that it should be a focal point of scrutiny.

\section{Significance of Rural Identity}

Historically, research on retention has moved from the general to the specific; Berger (2000) asserted that students from different income groups are more or less likely to be retained at varying types of institutions and we had reached an age where we should focus on these interactions as opposed to those studies focused at the macro-oriented level. Since Berger's assertion was well over a decade ago, it could be well said we are now well into the stage. First-generation students, and more specifically those firstgeneration students from rural backgrounds, are certainly one of those groups worth studying. In building upon the work of other researchers, Reid and Moore (2008) listed five areas where first-generation students differ from their continuing college generation peers: lack of assistance from parents who lack knowledge regarding the process; poor academic preparation at inferior secondary schools; poor academic preparation due to parents not understanding the significance of taking challenging courses while in high school; selecting a school that is close to home that may be a poor fit for purely financial reasons; and different personality traits. While this problem can be dramatic for any firstgeneration student, and in fact Reid and Moore's study focused on urban students, it can be particularly challenging for students from a rural background for several reasons.

First, there may be few options, particularly when it comes to four-year institutions that are close to a rural student's home. Since first-generation and lowincome students are often more apt to select institutions close to home (Lohfink \& Paulsen, 2005), further limiting a rural student's opportunities. Second, rural students 
have fewer community resources outside of the school upon which they can rely. Since first-generation students are often at a disadvantage when it comes to parental experience with higher education and at an academic deficit when it comes to preparation, external resources are paramount. Third, rural students may have less exposure to possible careers and therefore may make more choices based upon a lack of information. Therefore, in addition to the challenges that an urban first-generation student faces, a rural student may face those same obstacles with a few more to compound the problem.

Correspondingly, one of those additional challenges is that a college education is often not viewed as an asset in some rural communities, and can sometimes be viewed as the exact opposite (Abbott, 2006). Abbott (2006) additionally pointed out that while rural low-income students face some of the same challenges and obstacles many urban minority youth do, their situation can be made more difficult by geographical and cultural isolation as well the fallout from "stagnant local economies" (p. 28). Whiting (1999) also observed both from her previous position as a high school English teacher in a small, rural community as well as her role as an education professor at the state’s flagship university that rural students were often left out of the discussion on diversity but were also at great risk of attrition due to the clashing cultural environments between their rural upbringings and the university setting. Another study found that rural residents have less cultural capital than do urban residents (Kalmijn \& Kraaykamp, 1996). To make matters worse, while a significant amount of research has focused on first-generation and lowincome college students, relatively little published material has focused specifically on those students from a rural background. This being stated, as early as 1947, the Truman Commission recognized regional variations impacted one's access to higher education, 
finding that those from rural areas had far fewer opportunities to pursue a post-secondary education. In fact, of the barriers referenced by the Truman Commission almost seven decades ago, the two that have lacked legislative or significant societal action have been the issues of class and geographical origin. Furthermore, one study found that firstgeneration students are more likely to originate from a small town (15\%) and rural area (18\%) versus their continuing generation counterparts (10\%) (U.S. Department of Education, 2001).

While several dissertations specifically focused on rural college students (Hodsdon, 2012; Yoder, 2007; Schutz, 2003; Maples, 2000; \& Blevins, 2004), there is a lack of published scholarly articles on the topic. In one of the few published studies that exists of students from a rural, agricultural background, Schutz (2004) found these students considered college much later in high school than did other students, experienced more resistance to attend from their fathers than their mothers, lacked knowledge about college costs and available financial aid, lacked an understanding of the importance of relationship building and had difficulty adjusting to the academic rigors and expectations. Also in his study, many of these students from rural backgrounds found the environmental adjustment to campus and a larger community as anxietyproducing and while their identity as rural, agricultural students often served as a possible strength, it also produced a division and created tension within the general campus population (Shultz, 2004). The same study found that the large physical size of the campus, the close quarters of the dormitory rooms, the expansiveness of the classrooms, the breadth of the curricula, and the amount of money needed for school and living expenses tended to be overwhelming to rural students (Schutz, 2004). In fact, nearly all 
of the participants held a belief that they had to work harder before college than other students, creating a disharmony in relationship-building and perhaps the most significant theme of all: participants saw themselves as being "different from others" in the new college milieu; they were different because they were from rural areas, and because they were the first-generation in their families to attend college (Schutz, 2004).

In another similar study, Elliott (1989) found that rural students often lack the experiences and knowledge from their existing schemas to properly integrate and transition into the college environment. Equally important, Yarbrough (1996) surveyed college admission directors and high school principals at rural school districts in Mississippi and North Dakota, finding that based upon participants' perceptions, rural students made postsecondary decisions with little input or assistance from high school guidance counselors or admission representatives and often rural students opted to not enroll in college due to a lack of perceived benefit of higher education and insufficient financial resources. In 2006, the Chronicle of Higher Education spoke with several leaders from different regions of the United States finding that while challenges for rural students can vary depending upon one's region, there are some commonalities such as lack of academic preparation, cultural differences, and transportation issues. Furthermore, many schools in rural regions very likely do not have similar access to cultural resources as do schools in other areas (Dumais, 2002). This lack of cultural resources can hinder a student's ability for collegiate success. That being stated, there are other resources that can be utilized for rural students.

In modern times, the internet is likely the most widely utilized source for information and in rural areas this may be the only other source aside from school 
counselors and administrators. Research indicates that low-income students are less likely to have home internet access and more likely to attend schools with slower or more limited internet resources (Vargas, 2004). Furthermore, even when low-income students do have access to the internet, students may find financial aid sites particularly cumbersome and confusing, with one study indicating an average of five to seven months needed for completion of the Free Application for Federal Student Aid (FAFSA) and a lack of understanding on how to utilize school web sites to obtain financial aid information (Venegas, 2006). This would result in placing rural low-income students at even further risk of an inability to obtain college going information and resources. For many families in rural areas, schools provide the only internet access, which can be limited and deficient in relation to other geographical areas (Sheehy, 2011). In a recent report by the Federal Communication Commission (2012), nearly one fourth of the rural population lacks broadband service, about 14.5 million, and even among those who have access to service, millions more do not subscribe.

Even well qualified students in rural areas face daunting challenges that those in more metropolitan areas, despite similarities in class, might face. Institutions are often reluctant to travel to recruit one highly qualified student when they can target areas that garner larger pools of applicants as do urban or suburban areas; guidance counselors in rural area often lack connections with large or selective institutions, even if they have the time to devote to college advising; and often rural students may have additional geographical stigmas of being from certain areas and being thought of as a "hick" such as a student from West Virginia (Tyre \& Scelfo, 2003). In regard to geographical barriers, Turley (2006) found that first-generation college students were more likely than 
continuing generation students to have parents who encouraged them to apply only for colleges close to home, and since rural areas tend to have far fewer options than urban areas for higher education, which can further compound the problem for these students. Geographical barriers also serve as further evidence that because students in rural areas can be isolated from such information and opportunity, even when all other obstacles are pushed aside, the college knowledge barrier still serves as a major hindrance. Research which supports the distinct obstacles and challenges students from a rural, low-income and first-generation background face, provides support for the assertion that "institutions should develop their own instruments which fully capture the unique interactions between students and institutions” (Nora et al., 2005, p. 150). Finally, glimmers of hope do exist for rural, low-income students. In addition to the Robinson Scholars program at the University of Kentucky, which provides funding as well as academic and social development to students in 29 eastern Kentucky counties (University of Kentucky, 2014), there is also the Appalachian Scholars Program at Ohio University which offers 10 students from the 29 county Appalachian region a four-year renewable scholarship, annual book stipend, faculty guided research experience, and an alumni mentor (McDavis, 2010).

\section{Family, Community, and Peer Support}

While family, community, and peer support are important for most college students, they can be particularly crucial for students who are first-generation, lowincome, and from a rural background (Schutz, 2004; Logan, 2007; London, 1989; Piorkowski, 1983; Wells 2008-09). In fact, one study (Wang \& Castaneda-Sound, 2008) posited that the more family support a first-generation student received, the lower level of 
stress he or she would experience and that the more support from friends he or she perceived led to fewer psychological symptoms experienced.

While support for first-generation students can clearly come from not only those within a student's family unit or community, but also those at the college as well (Cushman, 2006), the support of those within a student's family, community, and peer group, particularly for a first-generation or low-income student is crucial. One study found that parental education level and peers' plans to attend college tended to have a greater influence on a college student's levels of persistence (Wells, 2008-09). While these findings should come as no shock and could certainly be applicable to almost any student, regardless of generational status, there is further literature supporting the significance of family, community, and peer support on the aspirations, matriculation, retention, and graduation of college students who are first-generation and originate from a lower socio-economic status. When examining first-generation students from a rural, agricultural upbringing, Schutz (2004) found that parental attitudes about going to college, or lack of attitudes, had a significant influence on the decision of students to go to college. Schutz (2004) also found that when support was offered by one or both parents, the decision was much easier for the participant, however, where one parent objected, the participant was conflicted and somewhat confused about his or her decision Logan (2007) posited that family involvement was immensely significant for firstgeneration students in their decisions to attend college and that female caregivers, particularly mothers and grandmothers, were particularly influential. Also, while college faculty can influence persistence, at least one study found the influence of peers and parents to be greater on persistence than that of the faculty (Bank, Slavings, \& Biddle, 
1990). Tinto (1975) noted as early as four decades ago that students from lower social classes exhibit higher rates of drop out even when taking into account intelligence and academic ability, and that those who persist in college are more likely to come from better educated families. Furthermore, Tinto (1975) surmised that social interaction with one's peers could either aid in persistence or help facilitate drop out depending upon the nature of that interaction. Thus, the influence of one’s family and peer group on success and persistence in higher education has been known for a long time (Engberg \& Wolniak, 2010; Terenzini, Cabrera, \& Bernal, 2001; Bouchard, 1994; Moore, 2003). Another advocating point for familial influence is while student achievements are clearly linked to family characteristics, the extent to which parents engage in positive practices that promote post-secondary education success is more important than a family's socioeconomic status (Becker, 1999).

In his brief autobiographical sketch, Richard Rodriquez (1974), spoke of the unease of returning home after he pursued higher education and obtained his doctoral degree, feeling a sense of guilt and a lack of connection with the culture and language with which he had originally grown. Although his parents may have been proud of his accomplishments, he notes the uneasiness that he sometimes felt: "I realize now how much more difficult and complicated was my progress into academic life for my parents, as they saw the cultural foundation of their family erode, than it was for me” (p. 19). Although Dr. Rodriquez wrote those words forty years ago about his experiences as a Mexican-American navigating his way through academic culture while feeling his connections with his own culture disappear, his experience is very familiar with that of first-generation students both white and minority. 
The emphasis that one's family, community, and peers have on college enrollment and success simply cannot be overstated. In fact, students who believe their roles as a student create hardships for the family, both financially and emotionally are less likely to persist than those with family members, friends, and others from the community who support their educational goal (Braxton \& Hirschy, 2005). Perna and Titus (2005) found that a student in general is more likely to enroll in college when the student has friends who plan to enroll, attend a high school where more students in general plan to enroll in college, when parents have frequent interaction with the school regarding academic related issues and when parents have discussions about educated related topics with the student. Furthermore, another study based on a nationally representative sample from the Educational Longitudinal Survey found the number of friends one has attending a four -year college increased the likelihood that the student would also attend a four-year institution and that a student is more likely to enroll if they have family members and peers that provide this encouragement (Engberg \& Wolniak, 2010).

As it relates to the family specifically, Adams, Ryan, and Keating (2000) stated we often ignore the role family can play and impact they can have once adolescents reach young adulthood and instead focus on other contexts such as peers, work, and school, however, their study of traditional aged college students in the mid-90's found the family remains influential even when students go away to college. In fact, in one qualitative study of first-generation students, they reported they believe their parents and family to be their strongest support systems (Mueller, 1997). Also, Engberg and Wolniak (2010) found that it is not just parental support, but that parental involvement with school 
organizations as well as with other parents positively influences the odds of a student attending a four-year school. Additionally, Terenzini, Cabrera, and Bernal (2001) found parental encouragement is a strong influencing force of a student's occupational and educational expectations, stating: "Parents are central players in the intergenerational legacies that are passed on and which shape children's educational attainment” (p. 41). As one might imagine, this begins much earlier than when a student arrives on a college campus. Lareau (1987) discovered there was both a difference in the quality and quantity of interactions between teachers and students when comparing two elementary schools where one was considered middle and upper class and the other working class, finding that parents who were middle and upper class had more frequent interactions, were more proactive in contacting teachers, and focused more on academic related issues. In the same study, there was also a difference in expectations and while most parents wanted their children to succeed academically, for working-class parents this meant graduating high school and for middle and upper-class parents this meant at least a college degree and often an advanced degree (Lareau, 1987).

Furthermore, according to 2005 CIRP data, a higher percentage (47\%) of firstgeneration students reported a very important reason for going to college was parents wanted them to go versus only $43 \%$ for continuing generation students. While the difference may seem low or insignificant, it is a complete reversal of the CIRP data a generation earlier (Saenz, V.B. et al, 2007). Also, a study utilizing NELS data from 1988 through 1994, found that students whose parents reported frequently discussing academic issues with their teenagers were more likely to enroll at both two-year and four-year institutions and that active participation by parents in post-secondary school guidance 
programs had a greater positive impact for those students who parents had lower levels of educational attainment (Kim \& Schneider, 2005).

Although institutional fit is not the only factor which contributes to student success, it certainly plays a key role. In one study, family encouragement was found to be the most significant variable impacting institutional fit among first-generation students (Bouchard, 1994). In fact, Bouchard (1994) asserted that institutional fit for a firstgeneration student is often more about what those students either bring or do not bring to campus with them while for continuing generation students, it is more about what happens to them once they are on campus. Potentially implied in this statement is that familial background and pre-college experiences determine a great deal. Finally, Rendon (1992), relating well to Rodriquez and recounting her own journey through higher education, recounted the frustration and anger of her mother regarding Rendon's decision to go to college, the pain of separation she felt when she transferred farther away from her local junior college, and the repeated attempts by her parents to have her quit school, give up her academic pursuits, and return home.

One study reported that students with parents who had not attended college are less able to convey college going messages to their children and are more likely to rely upon their school district to provide post-secondary information (Rowan-Kenyon, Bell, \& Perna, 2008). Another study of first-generation white males found parents neither encouraged nor discouraged college enrollment (Wilkins, 2014). The issue, however, can be rather complex and not straightforward, as one might imagine. In fact, while one study found that parents of first-generation students are much less likely to be involved with the college lives of their children (Shields, 2002), another study found that first- 
generation college students' families were supportive, but in different ways from other families which may be deemed more emotionally and practically supportive as opposed to financially in the form of providing money or physically in regards to visiting campus and participating in events such as orientation or family weekend (St Clair-Christman, 2011). Yet, in another study, London (1989) found students had a wide range of experiences with their families, from being made to feel guilty about leaving home, to being pressured into feeling that the student is not only accomplishing a goal for him or herself but for the entire family, to being weighed down by excessive family pressures and tensions taking time, energy, and focus away from school work and campus activities, and feeling different, set apart, and excluded from their family and home community due to the pursuit of a higher education. Additionally, London (1992) points out that matriculation to college often results in dissonance and separation from family, friends, and home communities and that navigating between and attempting to reconcile the two competing cultures can be challenging and distressing.

To further expound on the feeling of guilt, in her observations of urban, firstgeneration, low-income students, Geraldine Piorkowksi (1983) posited that such students often suffer from “survivor’s guilt” contemplating why they are succeeding when friends and family are not and focusing significant mental and emotional energies on others' traumatic experiences. What success in higher education often means for low-income and first-generation college students is discarding their cultural heritage and adopting a new identity that is entirely separate from the one they are leaving behind (Duffy, 2007). Furthermore, Van Galen (2000) asserted that "for working class and poor students, success in school often signals their distance and difference from those who love them" 
(p. 7). In fact, first-generation students often experience tension and a sense of displeasure with others in their home communities, having to re-negotiate relationships with friends and family (Hsiao, 1992). First-generation students have to often be selective about how much information they share with family and friends while gaining new perspectives on those close to them including viewpoints about how the student's matriculation has changed the dynamics of the relationship (Cushman, 2006). Finally, another concern by parents may be that their child will move away from what are considered to be traditional family values. Astin (1977) found students' religious behavior declines while hedonistic behavior increases after entering college. In rural areas particularly, with few socialization outlets, church is often a foundational source of support for many students, with religion play a strong and significant role in their lives and the lives of their families. The threat and danger for many of these parents, and potentially other family members, that their child/student will move away from those traditional values is very real.

Further complicating matters, the relationship between parental expectation and student action is not always direct and linear. Turley’s (2006) study found that parents who encouraged their children to apply for colleges close to home are much less likely to have graduated from college than parents who encouraged their children to move away from home and consider other options. Turley's (2006) study also found that students of parents who encouraged them to stay at home were also less likely to even apply for college as other students, the study strongly suggested that parents both directly and indirectly control to an extent whether or not their children will even go to college. The same study also found that students with parents who want them to stay at home are less 
likely to apply to multiple colleges and that a student's preferences tend to mirror that of their parents, which creates further limitations for students who already face significant obstacles (Turley, 2006). Communicative differences can also be at the heart of misunderstanding. Orbe and Groscurth (2004), examined communication practices through a co-cultural lens as first-gen students attempt to straddle the culture asking what co-cultural communication orientations and practices first-gen students utilize in their interactions with others and what differences may exist between their communicative patterns at home and at school. Previous research by Orbe (1996), focused on six factors (field of experience, perceived cost and rewards, abilities, preferred outcome, communicative approach, and situational context) which influence such communicative practices. Their 2004 study found that through first-gen communication on campus, students opted for one of three methods: nonassertive assimilation, assertive assimilation, and assertive accommodation; while communication at home tended to go along with one of three tracks as well: nonassertive assimilation, nonassertive and assertive separation, and assertive accommodation (Orbe \& Groscurth, 2004).

In one study, first-generation students were more likely to have friends and social support networks off-campus leading to a lack of "structural integration" to their institutions (Hertel, 2002). Additionally, there was a significant relationship found between family support and adjustment to college for low-income, first generation college students, particularly within the first fall semester (Moore, 2003). In one study even students who had a high degree of support and assistance from transition counselors within their high school, struggled to make it to college due in large part to pressure from family and friends to stay home (Arnold et al., 2008). 
Additionally, one study (Lobo, 2001) found friends and family lacked the knowledge of how to be supportive, felt that the student's studies were taking away valuable time that could be spent otherwise, and were often critical of the student when he or she struggled academically. Rondini (2010) concluded from her research that while familial relationships with first-generation students can create conflicts, pressures, and challenges, creating an "outsider status" both at home and within the campus community, at the same time, these same relationships can be a source of strength and support. In his research, DeLong (2003), found parents to be extremely supportive with many making great sacrifices to give their children an opportunity to get a college education. Despite this, however, many of these parents of first-generation college students were concerned that doing so might break the social bonds and ties their children had with the family and their home communities and while verbally expressing support for their children to go to college, sometimes their actions seemed counter-productive and rather in keeping with the normative values and behaviors of their family and community (DeLong, 2003). Another study found that first-generation high-ability and high-achieving females possessed a conscious knowledge that they were vastly different from their families in terms of interests, values, and of particular salience, views regarding gender roles (Speirs Neumeister \& Rinker, 2006). Finally, some family members may even feel scared or worried, as was the case with one first-generation student, Aileen, who rode the bus for over an hour from New Jersey to John Jay College of Criminal Justice in New York City, often getting home after midnight on most nights (Cushman, 2006). As it relates to this particular study, the same feeling could often apply to families of low-income, firstgenerational students from rural areas, sending their children off to school at a large, 
urban institution. The city of Louisville, for many in rural parts of the state from my personal experience, can be an intimidating place, one wrought with dangers and the unknown.

In addition to family and community support, there is also a strong influence from peer groups. In one study on a large, urban campus, researchers found peer groups, particularly at the micro-interpersonal level, impact a student's socialization and development (Antonio, 2004). Bean (1985) also found in another study that peer groups serve as the primary agents for socialization within the university setting, and that when peers outside of campus have a more significant influence on freshmen students, the students are much less likely to be socialized. Additionally, a separate study of ethnic minority first-generation students found that peer support was a stronger predictor of college grades and adjustment than was family support (Dennis, Phinney, \& Chuateco, 2005). A similar study found that while parental discussions regarding attending college were impactful, having friends that planned to go to college was the strongest predictor of college enrollment (Choy et al., 2000). Another study discovered based upon their results, when combined with a sense of self-efficacy, that social support may be particularly important for students who have few if any family members who have attended college (Phinney \& Haas, 2003). Unfortunately, for first-generation students, the influence of peers may not be positive, as in one study first-generation students were more likely than second-generation students to mention friends as a negative influence on their college success and persistence (Shields, 2002). Astin (1993) found that peer groups were by far the most influential source of a student's academic and personal development and that students tend to adjust values, behaviors, and academic plans in the 
direction of the dominant orientation of the peer group. What Astin focused primarily on, peers on campus, however, what if one remains attached to peers from the home community? Peer networks and close friends who go to college and are supportive a student's decision to matriculate are a welcome resource, whereas those peers not supportive can be a source of distraction in the least, and a source of attrition at worst.

\section{Significance of a Large, Urban Research Campus}

Another key focus of this study is success from this specific population on an urban, large, research university campus. Some might dispute this would make a difference at all. In fact, one study found that the contextual influence of institutional size had no relationship to student retention (ACT, 2004); it is important to note, however, this study looked at retention only and not the access for a student, nor did the study look at graduation or completion rates. Finally, and perhaps most importantly the study did not focus specifically on first-generation, low-income students, or, even more specifically, those from rural areas. Perhaps more significantly, Lewin (1936) asserted one's behavior is in conjunction with his or her interactions with a certain environment. So, succinctly, one's actions are not solely due to an individual's characteristics, such as rural, low income, or first-generational status, but also work in combination with the surroundings. Therefore, the success of this student may vary depending upon the institutional context. Some might argue that smaller institutions such as community colleges or private institutions might engender more success for students of this background, in fact one study found that rural community colleges can have some major advantages for rural students that a large urban research institution may not such as providing a sense of community inclusiveness, community pride, adding value, and town 
defining (Miller \& Tuttle, 2007). One study found that students with lower levels of traditional forms of social and cultural capital were less likely to persist from their first to second year at 4-year institutions than they were at community colleges (Wells, 2008). Community and small private colleges may offer a more intimate surrounding, similar to the home environments for many rural students.

Furthermore, while community colleges tend to be the common starting point for many first-generation and low-income students, Gladieux and Swail (1999) found that students attending less than four-year institutions do not receive the same economic rewards as those with a four-year degree. Additionally, while one of the great arguments in favor of community colleges has been the low cost and transferability of general education credits, some research has found that only approximately 10 percent of all lowincome students who start at a community college will transfer to a four-year institution (Dougherty \& Kienzl, 2006). Finally, Pascarella and Terenzini (1991) examined several studies and found that those individuals who had attended a large research university earned more than those who had attended a small, liberal arts college. In other words, if first-generation and low-income students want their best chance at success, it would seem at least that a fair percentage would need to enroll at a large, research university at some point in their educational career; unfortunately, one study found first-generation students are much less likely to enroll at a research university than continuing generation students (US Department of Education, 2001).

While low-income students are found in much greater numbers at two-year institutions, those students originating from the lowest income quartile are outnumbered at four-year institutions by students in the higher income quartile by about 10 to 1 
(Pascarella et al., 2001). This would certainly indicate that something is going on to limit those from low income from enrolling in public universities and could be compounded by originating from a rural area as well. Additionally, Reason (2009) asserted that one key focal area that should continually be emphasized for further examination is the importance of an institution's environmental context, believing that institutional type can largely influence whether or not a particular student persists. This lends credence to the argument that a student not accustomed to a large campus environment may have difficulty. In fact, large, urban institutions may have additional distractions away from campus that are detrimental to a students' academic well-being and sense of cohesion to the institution, particularly if the student is not accustomed to such distractions. Additionally, Astin (1977) found attending a large institution as opposed to a smaller one has a substantially negative impact on a student's chances to achieve in a wide variety of extra-curricular activities. Additionally, he also found large institutions received poorer ratings in the areas of classroom instruction and practicality of environment (Astin, 1977). Finally, Pascarella and Terenzini (1991) noted that attending a large institution can inhibit a student's level of social involvement, and as seen later through the work of Astin (1984) involvement can be a key piece to student success.

Furthermore, Collier and Morgan (2007) stated students at different types of institutions whether it is community colleges, elite private universities or large, public, urban universities must deal with different sets of expectations in order to be successful and that not only is the institutional context important, but students must also learn each professor's expectations. The assertion could then be plausibly made that large, urban institutions have more academic disciplines (for example the University of Louisville has 
business, engineering, medical, law, social work, education, arts and sciences, etc. colleges and schools) and therefore, have a greater variety among faculty temperamental and methodological approaches to teaching styles, leading to more challenges for any student, but particularly a first-generation or low-income student given their additional obstacles, to an overall acclimation and acquisition of the college student role. One study found most institutions with large numbers of low-income students that also had higher than average graduation rates were located in rural areas or small cities, making campus life and work on campus the center of the students' lives (Muraskin \& Lee, Wilner, \& Swail, 2004). So, not only can there be key advantages to attending a larger, research institution, but there can also be a different skill set required for academic success.

In one study which focused specifically on rural students transitioning to an urban campus, the participants were located outside of the United States, in Australia, and were of high school age at a boarding school, not in college (Bramston \& Patrick, 2007). Another study examined both institutional and student factors in explaining differences in transfer rates for low-income, first-generation students from Appalachia when it came to transferring from small, local community colleges to larger four-year institutions (Dykes, 2011). Although few studies have focused specifically on rural students, many of which have already been addressed in the preceding section, there are several studies that might offer implications for first-generation students from a rural background. One study utilizing CIRP (Cooperative Institutional Research Program) data from 1971 to 2005, found that first-generation students were more likely to consider close proximity to home a very important reason for choosing their institution, a phenomenon that has been increasing over time (Saenz, Hurtado, Barrera, Wolf, \& Yeung, 2007). Since many large, 
research universities are not typically located in remote rural locations, for example, in Kentucky the two largest institutions are located in the two largest cities of the state, Lexington and Louisville. This could have negative implications on enrollment of such students at these universities and also serve as an isolation mechanism for those firstgeneration, low-income rural students who have chosen to matriculate to these institutions. In fact, while there are a slightly higher percentage of first-generation, lowincome students enrolled at four-year public institutions versus private institutions, public institutions are lagging behind privates in regard to time-to-degree completion and overall graduation rates (National Association of Independent Colleges and Universities, 2011). Private institutions can also be preferable and easier to manage for firstgeneration college students because of the smaller class sizes, greater opportunity to interact with faculty and the greater opportunity for campus engagement and academic success (Saenz, et al., 2007). There is also some evidence that institutions which focus primarily on undergraduate teaching and have smaller class sizes have higher graduate rates of low-income students (Muraskin et al., 2004), two characteristics that are not typically characteristic of large, research universities. In other words, to sum it all up, challenges facing low-income, first-generation students from a rural background can be expounded and enumerated at large urban institutions. Of course, the first obstacle to overcome, to bring the student into the academic arena, is that of college access, information, and knowledge.

\section{College Access, Information, and Knowledge}

First generation college students are a population that remains underserved within the secondary school system (Gibbons \& Shoffner, 2004) and one of the major obstacles 
can be one of access to college alone. "Low-income eighteen-year-olds often do not have the resources, time, expectations, or educational preparation to pursue such a goal,” (Rank, 2005, p. 141). In fact, low-income students are more likely to attend poor quality elementary and secondary schools that spend less on education, are assigned to lesser qualified teachers, and expect less academically than are their higher income counterparts (Haycock, Lynch, \& Engle, 2010). Kahlenberg (2004) points out that at the most 146 selective institutions within the U.S., while about three quarters of the student population come from the top economic quartile, only about 3\% come from the bottom quartile. Astin and Oseguera (2004) also discovered the chances of student from a highly educated family, with at least one parent with a college degree, were three times more likely than a student with middle educated parents, with some college, and five times more likely than a first-generation student, whose parents had no college of enrolling at a highly selective institution. The pair further stated that American higher education had become much more stratified by 2004 than it had been 30 years earlier (Astin \& Oseguera, 2004).

One way for selective institutions, such as Harvard and Stanford, to attempt to combat this phenomenon has been to offer lucrative financial aid packages to students whose families earn under $\$ 40,000$ year (Vedantam, 2013). Despite this, many of these students are not taking advantage of such programs. The prevailing wisdom might be, particularly based upon much of the research here referenced, that since financial need would not be a concern, that lack of academic preparation or lack of cultural or social capital might be the culprits. Caroline Hoxby, an economist at Stanford, has found this is not the only or necessary most significant issue in that often these students, although 
academically talented and capable, are not from major metropolitan areas, may be the only such student in their high schools, and are not aware of these opportunities (Vedantam, 2013).

These issues are significant since research indicates graduating from a selective college or university can positively impact one’s earning potential, a phenomenon that has been increasing over time (Goldhaber \& Peri, 2007). Also, while affirmative action seemed to level the playing field for some, Kahlenberg (2004) noted that children of alums and those offering large donations are typically given even greater preference and that while affirmative action may have benefitted ethnic minorities from the middle and upper classes, it did little for those of lower incomes. Furthermore, Cabrera and La Nasa (2001) noted that while lower income students typically graduate from high school at rates similar to their higher income peers, the challenges often lie with students making application to college (a process involving just the act itself, but also requisite knowledge and access to information that lower income families often lack). One study revealed low-income students often made decisions about whether or not to attend an institution based upon limited or faulty information such as a fixation on a singular, highly competitive career such as fashion design, campus image and appearance, or in one case one student eliminated all public institutions entirely because an aunt once had a racist professor at a state university (Arnold, Fleming, Castleman, DeAnda, Wartman, \& Price, 2008). Finally, in one early study, done nearly four decades ago in 1975, Hearn (1984) concluded that those students who are higher income are much more likely to attend colleges and universities with both superior intellectual and material resources, further expanding the gap between low income and high income, and that social class was a 
greater factor in predicting school selection than were factors such as race, ethnicity, and gender.

Furthermore, one study in the late 1990’s asserted that lack of academic preparation was not as significant as some would claim, pointing out a gap of 20 percentage points in between high income "highly academically qualified” students and low income "highly academically qualified" students in terms of college attendance (Advisory Committee, Access Denied, 2001). The concern with this, however, is first, the study doesn't define what is meant by "highly qualified," which could refer to ACT/SAT scores, high school GPA, P-12 standardized test scores, or another unknown factor or grouping of factors. A second issue is the results focus on college-going rates, but not college completion rates, in other words, how successful are the low-income students, even when defined as "highly qualified" compared to the higher-income students also defined as such? A study completed by NCES (National Center for Education Statistics) found that high school academic preparation was related to a student's likelihood to persist in college with $87 \%$ of those who took rigorous academic course work persisting and only 62\% of those who did not (US Department of Education, 2001). Additionally, in two separate studies done later, one found that while $71 \%$ of those students in the lowest income level are considered not academically qualified, only $30 \%$ in the highest income level are not so, and in the second study the number of higher income students who were "highly qualified" was three times higher than lower income students (Kahlenberg, 2004). Furthermore, another study found first-generation college students were more likely to perceive themselves as less successful in adjusting to the academic demands of college and developing effective study skills than other students 
(Jean, 2010). Likewise, Bean (1985) found that pre-college academic preparation and level of academic integration once on campus accounted for most of the variance in GPA in one study. Additionally, Phillips and Chin (2003) state the education quality received by lower-income youth is substantially below that of their middle and upper-class counterparts. While ACT (2007) acknowledged the influence of nonacademic factors in their report, they also assert that of all the factors considered, prior academic achievement and cognitive ability surpass all other factors in their degree of influence on student persistence and success in college.

A large part of this concern may be that P-12 school policy and practices are often grounded with the assumption that all parents benefit from the social networks, academic facility and cultural capital that middle class parents have which is compounded by the fact students from lower-socioeconomic backgrounds are more likely to be taught by less experienced, less educated, and lesser paid teachers than those from higher socioeconomic levels (Van Galen, 2000). Rank (2005) also pointed out those growing up in lower-income neighborhoods (since public education is largely funded through local real estate taxes) go to schools with severely limited resources which in turn compromises a students' ability to go to college, much less be successful once they arrive. When comparing first-generation and second-generation students, first-generation students were more likely to indicate their high school did not prepare them for the amount and difficulty of academic work at the university level (Shields, 2002).

Furthermore, Cushman (2006), stated: "many first-generation college students notice that their classmates are much better prepared for demanding college work than they are.” Additionally, Gladieux and Swail (1999) cited several studies and data sources pointing 
to the fact that the secondary school curriculum is the most important factor regardless of race or financial aid in whether or not a student will attend college. Another study by Engberg and Wolniak (2010) found that the socio-economic status of the high school was a strong indicator of college enrollment, particularly when it came to four-year institutions. Finally, in examining whether or not one’s high school impacted and influenced enrollment, persistence, and graduation at a public research university concluded that students coming from high schools with a higher percentage of students receiving free lunch were less likely to persist (Johnson, 2008).

Reid and Moore (2008) found in their qualitative study of urban first-generation students that despite being excellent students in high school, their participants were not prepared for college-level coursework. CIRP data indicates that first-generation students report spending consistently less time on homework and studying, have lower high school GPA's, lower SAT scores, have lower expectations for their college GPA's, and rate themselves lower on intellectual self-confidence, math ability and writing ability than other students (Saenz, et al., 2007). In further research, Titus (2006B) found pre-college academic performance was a useful characteristic in explaining college completion at four-year institutions. High school mathematics scores have been found to be the greatest predictor of post-secondary education success for students from a low income background (Lee, Daniels, Puig, Newgent, \& Nam, 2008). Additionally, multiple studies have found (Choy, Horn, Nunez, \& Chen, 2000; Adelman, C., 2006;) that taking advanced mathematics in high school is highly correlated with college attendance and that often first-generation and low-income students are more likely to attend schools where such opportunities may not be available. 
While Adelman (2006) pointed out that many community colleges offer such opportunities for students and technology has somewhat closed the gap with online offerings, cost and awareness can still be significant obstacles and hindrances for firstgeneration and low-income students (Schutz, 2004; Yarbrough, 1996; Venegas, 2006; Tierney, 2009; Plank \& Jordan, 2001). Furthermore, Ishitani (2006) also found that academic preparation had a significant impact on the probability of a student graduating, particularly within a timely manner and Adelman (2006) asserted that academic intensity is the largest contributing factor to bachelor degree completion. In similar fashion, additional research supports the idea that the strongest predictors of both college persistence and degree attainment are prior academic achievement and course selection in high school (ACT, 2007). Furthermore, the strongest non-academic factor is the influence of one's level of academic discipline, further stating that gaps in college success are significantly reduced across both ethnic and socioeconomic lines when students are prepared upon matriculation with the necessary academic and non-academic skills (ACT, 2007). While academic preparation is certainly not the only obstacle these students face, it can certainly be one of the major hurdles. ACT (2007) found that students who complete a rigorous college preparatory program in high school are not only more likely to remain in high school, score higher on their ACT exams, and enroll in college, but they also are more likely to be prepared for college level coursework, to not need remedial coursework, achieve a first year cumulative GPA of a 3.0 or higher, persist, and ultimately earn their college degrees.

As alluded to, another key challenge first-generation college students face is information about higher education, including the cost and opportunities involved (Perna, 
2006). While one study critical of the continuing existence of such barriers posited the barrier of lack of financial aid information was a thing of the past (Advisory Committee, Access Denied, 2001), another study found that financial aid by itself does not directly influence persistence and should only be considered as one factor among many that influences academic and social integration on campus (Cabrera, 1992). Additionally, while there may be no lack of information, having the resourcefulness and capability to seek out and find appropriate information about financial aid can be in short supply even among those with college educated parents. Subsequently, Tierney (2009) found through a multi-state review of financial aid opportunities that often low-income students are not knowledgeable about various forms of financial aid available. Yet another study found that often teens from lower income backgrounds and their parents make postsecondary decisions based upon incomplete and inaccurate information about cost, financial aid, and procedural steps necessary to be taken to matriculate to college (Plank \& Jordan, 2001). A series of focus groups in California of low-income students found that since colleges and universities have almost entirely shifted financial aid information and communication online, this may have further expanded the inequalities for high- and low-income students with many low-income students lacking the instrumental knowledge of how to check the status of financial aid applications, scholarship applications, and financial aid awards (Venegas, 2006). Also, one investigation of various college enrollment programs across five separate states concluded that such programs lacked "philosophical coherence, systematic and intentional policy development and program clarity and distinctiveness” (Perna, Rowan-Kenyon, Bell, Thomas, \& Li, 2008, p. 263), furthermore finding that only about $41 \%$ of programs are specifically targeted to students from low income 
backgrounds. One can easily see how this complexity could be confusing and cumbersome for any parent, student, teacher, or school counselor, but even more so for first-generation and low-income students who may not be as familiar with navigating the process having parents who have not been to college or attending secondary schools that may be inferior to schools of their middle and higher income counterparts.

Additionally, the concern has become so paramount and the application process for financial aid so long and cumbersome to hinder college enrollment that a program was initiated for H\&R Block professionals to assist low and moderate income students with completion of the FAFSA (Bettinger et al., 2007). That being stated, with loans becoming an increasing option, many first generation low-income students are adverse to the idea of going into debt for a college education (Somers, Woodhouse \& Cofer, 2004; Brooks, 2005). Also, Beegle (2000) found students from low-income backgrounds are many times averse to taking out student loans because they lack an understanding of the future earning power that comes with a college degree and thus fail to grasp how to pay back thousands of dollars in debt. Lack of information is not limited to financial aid, but also includes the ability of students to make connections between career goals and educational requirements as well as basic admission procedures which may include taking the ACT/SAT, understanding the importance of admission and financial aid deadlines, and understanding the significance of taking college preparatory course work (Vargas, 2004). Using NELS data, Plank and Jordan (2001) found that the direct effects of a student's income level was diminished regarding college attendance when measures such as guidance, information, and direct action were employed by both parents and school administrators. Knowledge about college, however, is not only an issue at the 
level of access and pre-matriculation, but can extend throughout the enrollment period as well. Students who have had parents with college educations are more likely to be familiar with higher education through family members’ academic histories and are also more likely to have more appropriate approaches for dealing with both faculty and administrators through parental coaching (Collier \& Morgan, 2007).

Furthermore, student affairs and other higher education professionals understand that being successful in college is not solely about deciding to attend and being academically and financially able, but also in selecting the appropriate school that fits the needs and interests of the student. Unfortunately, low-income and underrepresented student are much less likely to have access to knowledge on how to research and properly select an institution that meets their social, academic, and emotional needs further compounded by the problem that many of these students are located in school districts where school counselors are limited due to budgetary constraints, dealing with large caseloads of students, and are not as well trained to be of appropriate assistance in the process (Vargas, 2004). Additionally, through her research, McDonough (1997) found students' college choices were shaped by a complex myriad of factors that encompassed both family and school influences, finding parents of higher income students were much more likely to be involved and proactive. She also found that secondary schools where they attend are more apt to take a multi-level approach to college planning through utilization of technology, teachers, other students, alumni, and counselors whereas by comparison lower income students' parents often lacked the knowledge about the college choice and decision making process and that schools only provided basic, minimal information to students (McDonough, 1997). In summation, research shows that income 
gaps narrow when students have not only the necessary prior academic achievement and preparation in order to be successful in college, but also the related and relevant nonacademic factors as well (ACT, 2007).

\section{Institutional Approaches and Obstacles}

Provided a first generation, low-income student matriculates to college, he or she continues to face obstacles. Although first-generation parents can be supportive, they often do not know how to best provide that support; first-generation students often feel different or set apart from other students, find it difficult to balance the demands of family life and being a college student, cannot rely on parents for assistance with expectations, and face inadequate preparation while in high school (Nichols, 2004). In one study of students from a lower income background attending the University of Pennsylvania, they reported experiencing an inability to participate in various activities on campus, inability to network, or join certain organizations, and when they were able to join had less engagement, sense of ownership, or interaction with other members of the group (Grcich, 2008). Also, Kim and Sax (2009) discovered as social class rises, so does student satisfaction with faculty interactions and that social class also seems, at least to some degree, to shape the nature of the relationship between student-faculty interactions and developmental outcomes. The same study also discovered that first-generation students are less likely to assist faculty on research projects for course credit, communicate with faculty outside of the classroom setting, and are less likely to interact with faculty during classroom time as well (Kim \& Sax, 2009). These challenges and obstacles faced by the student will continue to be addressed, but the primary focus of this section lies with what colleges and universities can do to offset these concerns. While 
Cushman (2006) offered advice for first-generation students on navigating through their college experiences such as involvement in student organizations, finding different ways to make friends, and looking for others who share commonalities, college and universities can also make use of this advice by creating and developing programs that make this process easier for the students.

So, what institutional obstacles do first-generation students face and what approaches are successful? In general terms, using data from the Beginning PostSecondary Longitudinal Study (BPS), Settle (2005) found that social capital variables, contact between the student and faculty member outside of the classroom environment, and student's fit with the social and academic environment of the campus are all strongly associated with first to second year persistence for first-generation student. Additionally, while one study found being a first-generation college does not impact graduation rates or overall GPA (Dumais \& Ward, 2009), many other studies do point to key differences and challenges for this population of students. In fact, Ishitani (2003) found that during the first year of enrollment, first-generation students are at a 71\% greater risk of departure than other students. Brooks (2005) asserted that the problem is no longer about access and while enrollment rates continue to climb, completion has become the greater concern, as students from less educated families are dropping out at much greater rates and attributes this to the lack of the "four pillars of cultural capital": academic competence (lack of academic preparation), practical competence (a desire to attend but not fully understanding the practical steps necessary), economic confidence (being more intimidated by college costs and less willing to go into debt), and social confidence (a lack of comfort at elite or large institutions where they perceive they don't fit). 
Furthermore, Kuh, Kinzie, Schuh, and Whitt (2005) identified two primary factors influencing student success and while one focused specifically on the student in regards to the amount of time and effort he or she chose to put into his or her studies as well as other activities on campus, the other placed the onus on the institutions stating that colleges and universities need to closely examine ways they allocate resources and organize learning opportunities as well as services for students. Although many institutions claim they do this, and for some it may come easy for the high-achieving, well prepared students of college educated parents, what about first-generation and lowincome students? Certainly some level of responsibility should be placed upon the student, but particularly for this group of students, it is up to each institution to provide the student with the necessary services and resources. Also identified by Kuh and others (2005) were 20 institutions to which they referred to as "gemstones" or also as "DEEP" schools, ones serving as role models for best practices and all sharing six common features: a "living" mission and "lived" educational philosophy, an unshakeable focus on student learning, environments adapted for educational enrichment, clearly marked pathways to student success, an improvement oriented ethos, and shared responsibility for educational quality and student success. Furthermore, Kuh and his team (2005) recognized several effective practices by these institutions promoting student success: challenging students academically, facilitating active and collaborative learning, promoting student-faculty interaction, creating and developing enriching educational experiences, and fostering a supportive campus environment. While Kuh and his researchers (2005) did not aim their book or focus their findings in regards to firstgeneration or low-income students specifically, it can certainly be argued that these 
practices and features would benefit this population of students as it would for the general student population.

Further research finds that high income students are three times more likely to complete a four-year degree than low-income students (Tinto, 2012). One concern may be a lack of confidence as Tinto (2012) indicated such students may not perceive themselves as possessing of the self-efficacy to be academically successfully, which relates back to the aforementioned research regarding academic preparation. Here, Tinto (2012) referenced Bandura’s (1986) social cognitive theory, in which individuals selfevaluate their past performances leading to a belief about whether or not one can successfully perform and manage future challenges. Not all obstacles are external, however. Another specific issue related to this that many first-generation students face is the competing environments of their familial backgrounds and that of the university setting with these students often perceiving lower levels of family support as well as a lower degree of importance placed on college by their parents and other family members (Khan, 2008).

In his study of low income students at four-year institutions, Walpole (2003) found even after nine years of initial matriculation to college such students continued to have lower incomes than students from a higher income background, were less likely to pursue graduate school than their higher income peers, and contributes this to a difference in cultivation of social and cultural capital that continues even on the college campus. One of the obstacles, unfortunately, is simply a lack of an organized social support system which focuses on the specific social challenges low-income students will face (Howard, 2001). This points to where campus environments can have a significant 
impact. Furthermore, one study found first-generation students involved in a Freshman Empowerment Program, which required students to meet weekly during the second half of the semester in peer groups with student directed discussions focusing on issues such as academics, college resources, and adjustment to postsecondary life, had statistically significant higher GPA's and higher retention rates than first-generation students not involved in the program (Folger, Carter, \& Chase, 2004). Pascarella, et al. (2004) also found that when variables such as cognitive development, educational degree plans, parental income, academic motivation and high school GPA were controlled for, firstgeneration students still selected institutions less academically selective, completed significantly fewer credit hours over a three year time span, were less likely to live on campus, more likely to work more hours per week, had lower levels of extracurricular involvement, and had significantly lower GPA's than those students who were not firstgeneration.

Thayer (2000) asserted strategies designed for general campus populations without taking the characteristics and circumstances of first-generation and low-income students into consideration will likely not be beneficial to this specific group of students and by contrast strategies aimed at first-generation, low-income students can serve to benefit the larger campus population. One study found that first-generation and lowincome college students felt disempowered and marginalized by their university, finding such students felt like outsiders because of their cultures and experiences which were so vastly different from that of the academic culture, also many felt the faculty looked down upon them, were not available, were not academically supportive, and had extreme difficulty in connecting with other students to form a community on campus (Lobo, 
2001). Cole (2008) found many first-generation college students who left did so for reasons that were not necessarily academic or financial and found many left due to a perceived lack of support and encouragement from others in regard to their educational pursuits, did not feel a connection with the university, did not embrace the notion they were doing something worthwhile, and did not have overall positive feelings about their environment. It is important for institutions to establish programs aimed specifically at first-generation and low-income students. One such example is Project Challenge at Emporia State University which helps first-generation students set goals, increase selfawareness by offering tutoring, mentoring, leadership courses, and counseling workshops, ultimately leading to higher GPA's for those first-generation students involved in the program (Barnett, 2004; Emporia State University web site, 2013). So, what else can institutions do to retain and graduate these at-risk students? One study found the two largest contributors of institutional fit for first-generation students that were directly related to the institution were positive course experiences and student staff interaction (Bouchard, 1994). Some common elements among institutions that have large numbers of low-income students but yet higher than average graduation rates include (but are not limited to): intentional academic planning, small class sizes, special programs for students who are academically at-risk, a dedicated faculty, developmental/remedial education, courses to ease with the freshman transition, have modestly selective admissions, and offer a wealth of academic support (Muraskin et al., 2004). Both Bergh (2008) and Astin (1993) found that interaction with faculty was largely influential for an undergraduate student’s development. Furthermore, Bergh (2008) also found that flexibility in course and degree program requirements, course 
delivery methods, positive reinforcement, and feedback were positive motivators for those first-generation college students who had been successful. He also suggested that college administrators help new first-generation students to utilize pre-arrival materials and programs, inform such students of available services, work with faculty in regards to better training on their roles and teaching styles, and make use of more experienced successful students who originate from similar backgrounds and can help the incoming students begin to realize the same success (Bergh, 2008).

Another study found low-income and first-generation college students benefitted from educational practices which heavily involved them in collaborative learning and high levels of interaction with the faculty while also finding the greatest influence on student outcomes were their perceptions of the campus environment in terms of levels of both academic and non-academic support (Filkins, 2002). Since often first-generation and low-income students can be some of the lower performing students in P-12 settings, an important discovery is the benefit the taking college credit courses, as long as students are adequately prepared and properly supported, while still in high school can have for middle and low achieving students (Karp \& Hughes, 2008). The same study made the assertion that, as a result, it is imperative for secondary and post-secondary institutions to work collaboratively and cooperatively with each other to promote the success of such students (Karp \& Hughes, 2008).

Additionally, Miller and Tatum (2007) discovered family history knowledge is an indicator of the support low-income, first-generation students receive from their families and therefore recommended as a result that both academic and student affairs professionals work to incorporate activities which allow such students to reflect upon 
their histories, and when it comes particularly to academic content that which can make meaning through personalization. Furthermore, another study found institutions with higher than expected graduation rates and large numbers of low-income students have designated key faculty and staff members to serve as "first responders" which assist students in navigating through the institution, have high levels of involvement and engagement in various activities and programs, have well developed first-year programs, and are actively engaged in efforts to improve instruction in introductory courses (Engle \& O’Brien, 2007). While a "first responder” could conceivably be anyone on campus, academic advisors can obviously play an important role. Cushman (2006) recommended advisors as a great place for first-generation students to begin to enlarge their circle on campus of networking. Furthermore, Payne (2007) posited that academic advisors can alleviate some of the tension and alienation first-gen students feel while attempting to balance two often competing cultures. Advisors can help first-gen students in a variety of ways from simply listening to their struggles, being knowledgeable about community and campus resources, and establishing rapport leading to an overall more positive experience (Payne, 2007). In another study of institutions with large numbers of low-income students yet higher than average graduation rates, one commonality was intrusive advising which often required the student to meet with his or her advisor several times during the semester, both faculty and professional advisors, and these institutions often offered an intensive annual training for faculty advisors (Muraskin et al., 2004).

Another way that institutions can benefit those who are first-generation and lowincome is through learning communities. Learning communities can promote academic success, provide intensive mentoring and advising, and also help to engage students with 
faculty and other students on campus (Spence et al., 2010). According to Braxton and Hirschy (2005), learning communities can lead to strong academic and social integration with peers and faculty and increase the chances a student will persist. Additionally, Engstrom and Tinto (2008), found first-generation, low-income students at two-year institutions benefitted from involvement in learning communities in basic skills courses by being more engaged at all levels, more positive in their perceptions of the encouragement they experienced on campus, and were significantly more positive in their estimated intellectual gains. Engstrom and Tinto (2008) also determined that these students were more likely to persist than those not involved in learning communities finding that such communities provided a safe and supportive environment (something the students noted as lacking prior to their experiences), did not perceive their course work as "remedial" because faculty utilized collaborative and active learning strategies in an integrated and coherent curriculum, and that the learning community served as an invaluable connection to important campus support services. Engstrom and Tinto (2008) also found that students who were academically underprepared were more likely to be "significantly engaged" in a variety of activities on campus, perceive themselves as having experienced more encouragement, support, and intellectual benefit, and were more likely to persist to the following academic year. In one national survey of over 1000 first-generation students residing on campus, Inkelas (2007) found those who lived in a living-learning community were more likely than those first-generation students in a traditional residence hall to perceive an easier academic and social transition to college contributing such feelings to the usage of co-curricular residence hall resources such as workshops, peer counselors, and social activities and also finding that the higher 
perceived levels of support within the living-learning community environment positively impacted student outcomes.

In addition to the findings of both Inkelas and Engstrom, Thayer (2000) also cited institutional examples including Drexel, Colorado State, and Michigan State Universities where living learning communities have been beneficial to the outcomes of firstgeneration, low-income students. The University of Kentucky has established a living learning community for first-generation students which offers the students links to campus resources, social support networks, and a greater connection to faculty members (UK Undergraduate Housing and Residence Life web site, 2013). The University of Cincinnati has even gone as far as establish an off-campus residence specifically for first generation low-income students (Ramsey \& Peale, 2010). In addition to living-learning communities, one study found that engaging in community service was a significant indicator of academic success for first generation students (Ting, 2003) and another found that service learning served to facilitate positive social and academic interactions between faculty and first generation students potentially leading to academic success (McKay \& Estrella, 2008).

Additionally, Conley and Hamlin (2009) examined the impact of a justicelearning approach encompassing both a justice-orientated curriculum and a servicelearning focus on first-generation students, finding that while the group was small (only five students) and entirely female, the researchers felt strongly about the course outcomes in broadening the students' understanding of justice-oriented endeavors. Similar to the justice learning concept, in another study Yeh (2010) concluded that service learning can facilitate growth in academic, psychosocial, persona and spiritual, as well as 
sociocultural/sociopolitical dimensions for low-income and first-generation college students. Another step is a move toward peer mentoring programs. In one such program at California State University, $2^{\text {nd }}$ and $3^{\text {rd }}$ year first-generation college students are matched with freshman first-generation students for the purpose of supporting the mission of retention of these students, providing academic support, a sense of community and increased college knowledge for participants (Olivérez, 2013). Furthermore, Reid and Moore (2008) asserted how important it is for first-generation students to have opportunities to participate in groups with other first-generation students, be provided with information regarding academic and social support systems on campus, and be connected with an upper-class first-generation mentor.

Another qualitative study found that low-income students in the study, despite having attended high schools with strong college going expectations and numerous supports in place, reconsidered their decisions and wavered on their plans even after they had formally accepted offers of admission (Arnold et al., 2008). Furthermore, this study found a strong need for a summer bridge program, given the many obstacles and challenges these students faced, which emphasized: continued guidance and support from both college admission and high school personnel, continued assistance for students to find the best possible pathways for their skills, interests, and post-secondary goals, ongoing social and emotional support that socializes students to the college experience, and intensive and consistent financial aid guidance and assistance (Arnold et al., 2008). Also, Clauss-Ehlers and Wibrowski (2007) found that an EOF (Educational Opportunity Fund) program, a summer institute of six weeks, while having no significant impact on ethnic identity, helped to strengthen academic resiliency and increase social support from 
supervisors and peers. Additional research by Hicks (2002), led to his advocating for implementing the following: intensive support groups and an intensive orientation program, programs that involve parents of first-generation students, first-year experience courses that includes actions which combat the lack of academic preparation and support for first-generation students, and other programs providing additional support for firstgeneration students who may lack academic, personal, social, and parental support. In fact studies on summer bridge programs have been almost unanimous with positive results on student retention (Muraskin et al., 2004).

Some have also addressed the notion of greater partnerships between secondary schools and post-secondary institutions. One thought is that of "early colleges" which allow high school juniors and seniors to take college classes for dual credit, and this could be a way to better prepare first-generation and low-income students who have suffered from a lack of academic preparation (Abbott, 2006). Finally, in utilizing the tenets of hope theory, on the belief that hope is a significant predictor of positive outcomes, Williams and Butler (2010) asserted that strengths and positive attributes can be found to instill hope through focus groups, first-year experience courses and embedding such a philosophy with classroom practices. On the negative side, which should also be addressed in the case of a balanced overview, an extensive study found that American colleges and universities are organized according to middle and upperclass norms of independence, which creates an often disturbing mismatch between the interdependence norms of many first-generation and low-income college students (Stephens, Johnson, Fryberg, Markus, \& Covarrubias, 2012). Consequently, Oldfield (2007) asserted institutions need to take four key steps at improving the environment and 
the culture for first-generation and low-income students: develop strong support systems for these students, openly address social class issues on campus, diversify the social class origins of the faculty, and diversify the social class origins of the student body as well.

All of this being stated, there are some characteristics inherit within the firstgeneration, low-income student him or herself that may benefit and lead to success in a college environment. Byrd and MacDonald (2005) surmised that time management was just as important to the success of a first-generation college student as were academic skills and also the ability for such students to self-advocate and focus on a particular career goal was also significant, and perhaps most importantly, Byrd and MacDonald (2005), who primarily focused on non-traditional aged students, found such students perceived their life experiences and challenges as strengths rather than weaknesses, a finding which may be important for college administrators to acknowledge that be transposed to a more traditional age college students who has not gained such wisdom yet. In another study focusing specifically on high ability first-generation females, Speirs Neumeister and Rinker (2006) found that one key commonality among them was viewing themselves has having an emerging professional identity due in large part to involvement in extracurricular activities, friendships with high-achieving peers in their fields and early academic experiences. Additionally, Ting (1998) found that high school rank, leadership experience and community service were the largest predictors of academic success while standardized test scores were not predictive and overall, a combination of cognitive and psychosocial variables are effective in predicting success in college. Furthermore, in examining a group of first-generation white males, Wilkins (2014) found they had to be proactive about avoiding legal troubles because their family did not have the resources to 
leverage them if they did have such difficulties and that these men saw themselves as hard-working, goal-oriented, and independent.

Finally, although Richard Light's book: Making the most of college: Students speak their minds, was not focused specifically on first-generation or low-income students, there were some more general findings beneficial in guiding work with this population. First, Light (2001) set out to answer two broad questions: "What choices can students themselves make to get the most out of college?" and "What are effective ways for faculty members and campus leaders to translate good intentions to practice?” (pp. 23). Even among bright and talented students, Light (2001) asserted that it was up to faculty and administrators to help students make powerful connections between in-class and out-of-class activities, not to mention those who may face more significant challenges. Light (2001) further contended there are two symptoms, aside from poor grades, which serve as signs predictive of struggle: a student feeling isolated from the rest of the campus community, and the student's unwillingness to seek help from available campus resources. Once again, while Light's focus was primarily on students at Harvard, these symptoms can also be predictive for first-generation, low-income students as well and Light's broad research questions as solid guiding principles when undertaking any initiative with this population. All of this being stated, faculty and administrators must also recognize that any at-risk student comes to campus with certain impactful relationships, outside of the campus community, influencing success and persistence. Understanding how these relationships impact the student in various ways is paramount. 


\section{Issues of Persistence}

Historically, the issues of persistence and retention in postsecondary education have been viewed through a variety of lenses: economic, organizational, psychological, and sociological (Braxton \& Hirschy, 2005). Persistence and retention have become much more important in the last few decades as enrollment and the goals of degree attainment have increased; as a result, retention has also become more nuanced, focusing on the specific characteristics of students and institutions (Berger \& Lyon, 2005). Tinto (2007) posited that while retention is the most widely studied area in higher education, significant improvements in persistence and graduation rates have not occurred and theory has not always resulted into effective practice, largely due to the complexity and the fact that institutions now serve many different constituents. Furthermore, student departure is an ill-structured problem, one with no singular solution, and thus requires a multi-theoretical approach (Braxton \& Mundy, 2001-02).

All of the methods in the previous section are designed to strike at the root of departure. According to Tinto (1987), the primary roots of departure were intention, citing that about $75 \%$ of college students will at some point experience a level of uncertainty with their stated educational goals (Tinto, 1993), goal commitment, and institutional commitment. Goal commitment refers to a student's willingness to work toward a certain goal, while institutional commitment is one's dedication to completion of the degree at a specific school (Tinto, 1987). Tinto (1987) asserted that departure was typically the result of one or more events: adjustment, or the ability for the individual to break away from the home environment and acclimate to the collegiate environment with new social and intellectual demands; difficulty, where the student struggled to meet the 
academic demands of the institution usually as a result of poor academic preparation; incongruence, a mismatch between the individual and institution in regards to needs, interests, and preferences; and isolation, where the student does not establish a contact with the academic and social communities of the college.

Tinto (1987) referred to the transition to college as a "rite of passage" and outlined a model of college withdrawal having students moving from separation, where they left home to attend college, to transition, where they may not feel as if they have a place in either the home or college environment, to incorporation, where they have been fully integrated into their new environment (Tinto, 1993). According to Tinto (1993), how well a student moves through and adjusts to each stage is impacted by five factors: pre-entry attributes, such as family background and prior schooling; goals and commitments to the institution; experiences at the institution (both academic and those involving extra-curricular activities/peer networks); external commitments; and finally, integration both academically and socially. Reason (2009) reviewed of the extensive literature on persistence and retention and found that despite the large amount of research, students from a lower socioeconomic status have been underrepresented which can be problematic given how a student's background and life experience influences persistence.

Many reasons have been given for students' lack of persistence. In one study, even when academic preparation is strong, students can still be at risk for dropping out when they lack academic self-confidence and goals as well as lack institutional commitment, social support and involvement; furthermore the same study found that the academic factors of one's high school GPA and socio-economic status had a positive 
relationship to retention and that this was strongest when combined with ACT scores, explaining about $17 \%$ of the overall variability of college retention across all students (Lotkowski, Robbins \& Noeth, 2004). The same study found when those three combined with the non-academic factors of self-confidence and achievement motivation had the largest relationship to overall college performance (Lotkowski et al., 2004).

Furthermore, in her single case study, Bergerson (2007) asserted that campuses need to re-think how they improved persistence, particularly with low-income and firstgeneration students and efforts to sever ties with home communities in the process of strengthening the bonds to the institution may not be the best approach. Tinto (2007) would later point out a litany of research against his original point that students needed to "break away" from their families and communities in order to persist and be successful, instead asserting for many students, maintaining that connection was paramount to their success and persistence (Attinasi, 1989; London, 1989; Nora, 2001; Terenzini, Rendon, Upcraft, Millar, Allison, Gregg \& Jalomo, 1994; Tierney, 1992; Torres, 2003; Waterman, 2004).

As with any scholarly research, Tinto's work is not without criticisms. Braxton and Hirschy (2005) stated that despite the value of Tinto’s theory, it does not take into consideration whether or not a student resides on campus or commutes, and that students come to college with a wide range of other characteristics influencing their persistence such as family background, academic ability, high school academic preparation, and gender. Of the two, academic preparation and family background could be particularly salient issues for low-income and first-generation students. Tierney (1992) also took issue with Tinto's reference of college as a "rite of passage," and asserted that a "rite of 
passage” implies an innate cultural rite of passage and is one that Tierney posited was that of the dominant, mainstream culture which may be foreign to populations outside of this culture. Tierney (1992) was also critical of Tinto's notion of "departure” from the ritual, a non-existing concept in certain cultures, Tinto's reference of the process as individualistic while many cultures are collectivist, and the process implying that shifting from one culture outside of academia to another within academia is unfamiliar with regard to rites of passage in some cultures. It is important to note Tierney's research here focused specifically on Native American students, however, it could certainly be applicable to other cultures outside of the mainstream, particularly as it relates to separating from one’s family and community for first-generation students (London, 1989; Piorkowksi, 1983; Van Galen, 2000; Hsiao, 1992). Tinto’s (1988) transition stage does point to the greater challenges and obstacles faced by those students who come cultures that are "very different" from of a college or university. Tinto (1988) stated that "their past experiences are unlikely to have prepared them for the new life of the college in the same way as have those of persons who come from families that are themselves college educated" (p. 445). While Tinto does not use the term "first-generation" here, it is strongly implied.

\section{Focus on Completion and Graduation}

Despite increasing access to higher education for low-income students, a significant gap still exists between low and high income students in terms of four-year degree completion as well as part-time versus full-time enrollment, with low-income students being much more likely to enroll part-time and much more likely to start at a two-year institution than their higher income counterparts (Tinto, 2007). Also, while 
much of the retention literature has been focused on students persisting from the first to the second year, the consideration to drop out can be considered a cumulative effect and persistence to second year does not guarantee persistence to graduation (Nora, Barlow, \& Crisp, 2005). While globally significant, researchers and scholars typically find it important to focus on specific groups to locate and suggest ways to make a positive impact, and those at-risk in a variety of categories seem to make the most sense in these areas. Another reason for focusing on first-generation and low-income students, particularly those who don't complete their educations, is they may be harmed the most. According to Gladieux and Swail (2000) students who start and don't complete may be worse off than those who never began in the first place because they have no degree, yet have still incurred a great deal of debt. The emphasis on disadvantaged students and those at-risk in higher education has been well researched. In one of the earliest studies of low-income youth, Goetsch (1940) found that low-income students had far fewer opportunities than their higher income peers and that in addition to economic constraints, there was also a relationship between high school attended and level of preparation with college attendance.

While Brock (2010) pointed out that access has greatly improved since the 1960's, persistence and completion rates have not dramatically improved, particularly among the most disadvantaged and at-risk students. First-generation and low-income college students are certainly one group falling under this description. Additionally, while the study focuses specifically on Hispanic students, Harrell and Forney (2011) asserted that parents with even some college can assist their children with navigating through the college landscape, helping with course selection, avoiding poor instructors, 
and selecting an appropriate course load for the semester and that first-generation parents often have the most minimal understanding of college with one mother believing a 12 credit hour semester meant her son would be in class 12 hours a day, to illustrate a rather extreme example given by the pair.

Lynch (2013) further suggested that even if a first-generation college student manages to get through college, his or her parents will often lack the life experience to guide their child to succeed in the college-educated workforce. Furthermore, Hirudayana (2011) found that even with a college education, first-generation students were more likely to use terminologies such as "work" and "job" as opposed "career" and posited that "there appears to be a distinct gap between the understanding of these students about the world of work they wish to enter and its actual expectations, demands, and what it takes to enter and survive there” (p. 6). Hirudayana (2011) also called for further research that identify barriers preventing first-generation students from fully reaping the economic benefits of their educations and creating systems that would allow for a smoother transition into the labor market.

The question and issue continues to remain as to what factors influence student persistence and completion. In one qualitative study, while first-generation students did not believe that involvement in extra-curricular activities was a critical factor in their persistence, that which goes against a great deal of research such as that of Astin (1984), they did believe that one's persistence was largely due to self-motivation and selfdetermination (Mueller, 1997). Another factor is most likely academic preparation. In one study, reverse transfer from a four-year to a two-year community college was more common among less educated families due to poor academic performance during the first 
year, particularly disturbing given that the researchers also found that reverse transfer students were 3.5 more times likely to stop out and had extremely low rates of bachelor degree completion (Goldrick-Rab \& Pfeffer, 2009).

\section{Obstacles, Challenges and the Importance of Higher Education}

The obstacles and challenges facing students from a lower socioeconomic background have been known for some time and are cumbersome as well as numerous. Obstacles and challenges extend beyond the financial and in order to achieve our postsecondary education goals, states will need to focus on low-income students, as well as other at-risk populations of students, to ensure they are academically prepared, aspire to attend college early, and have the necessary supports as they navigate through the college experience (Spence et al., 2010). As early as 1938, a high correlation was found between parental occupation and the child's level of education obtained (Bell, 1938). The reasons as they relate specifically to financial capital are relatively clear, as the median earnings for someone with a college degree are about $\$ 15,000$ more per year than someone with only some college course work and the amount doubles to about $\$ 21,000$ more per year versus someone with only a high school diploma (Julian \& Kominiski, 2011). Locally, Kentuckians with a college degree typically earn over $\$ 16,000$ more per year than those with only a high school diploma (Double the Numbers, 2007). In addition to income differences alone, college graduates are less likely to be unemployed for long periods and less likely to miss work for extended periods due to illness (Hossler, Schmit, \& Vesper, 1999). For society at large, estimates have suggested that if the gap in college completion between the highest and lowest income Americans was significantly reduced, 
it could potentially add as much as $\$ 250$ billion to the gross domestic product and $\$ 80$ billion in tax revenue (Advisory Committee, Access Denied, 2001).

Beyond the economic benefit of a college education, college is where many people form their closest and most lasting friendships and are also more likely to report "excellent" or "very good" health as opposed to those with only a high school diploma (Brock, 2010), while about $43 \%$ of college graduates reportedly volunteer for community organizations compared to only about 19\% of high school graduates (Kentucky Council on Postsecondary Education, 2007) and incarceration rates for U.S. adults with some postsecondary education is only about a quarter of that compared to those with only a high school diploma (Baum, 2004). Additionally, Astin (1977) found students underwent a variety of changes in attitudes, values, and self-concept after entering college, which led to a more positive self-image reflected in a greater sense of interpersonal and intellectual competence. Furthermore, Pascarella and Terenzini (1991) found a positive association between educational attainment and perceptions of global happiness, life satisfaction, and subjective well-being. This was in addition to their finding that throughout college, students make statistically significant gains in both general and specific subject matter knowledge and that exposure to higher education lends itself to greater learning beyond college into adult years (Pascarella \& Terenzini, 1991).

According to Gladieux and Swail (2000), "the odds are increasingly stacked in our society against those with the least education and training” (p. 688) and opportunities for education beyond high school remain unequal for low-income youth between the ages of 18-24 as they attend college at much lower rates. Not only do they attend at much lower rates, but while about $40 \%$ of those from the top income quartile go on to complete 
college, only about $6 \%$ from the bottom quartile do so (Gladieux et al., 2000). The reasons for this are often disputed, but there has been found to be a high correlation between quality of high school curriculum and degree completion (Adelman, 1999). Furthermore, only about 53\% of low-income high school graduates are considered academically qualified and prepared vs. about $86 \%$ of their high-income peers and this is often based on high school tracking policies, school resources and quality or lack thereof, along with societal conditions and expectations (Gladieux et al., 2000). Many critics of the P-12 school system are critical of the "deficit model” approach, which often characterizes low-income and first generation students as lacking the necessary skills and abilities to be successful in an academic setting, an approach that some would argue has set these students up for failure and led to low expectations which is at least a partial cause for low achievement (Green, 2006).

Furthermore, Van Galen (2000) posited that inequities due to social class differences are practically ignored in many of our P-12 schools throughout the country. Simply blaming the P-12 school systems, however, for college completion rates "let’s colleges and universities off the hook too easily, according to Brock (2010). One study discovered that when compared to their higher income counterparts, students from low income backgrounds were much more likely to be enrolled at post-secondary institutions with lower levels of financial resources to help students persist to graduation (Titus, 2006A), yet another significant obstacle. To strengthen Brock’s assertion, higher education professionals to this date have little impact on the P-12 setting, and can only seriously impact circumstances of students upon matriculation. That being stated, a 
multitude of approaches have been attempted with limited and varying degrees of success.

While great efforts and legislative action have helped level the playing field for ethnic and racial minorities, women, those of varying religious affiliation, or those with mental or physical disabilities, one’s socioeconomic status remains the largest determinant force of whether or not one will attend college and universities (Nidiffer, 1999). Additionally, in one study comparing survey data from 1979 to 1997, Belley and Lochner (2007) found that family income had become a more important determinant for going to college, particularly among those of lesser academic ability, for completing college, and that those students in the highest wealth quartile were $24 \%$ more likely to attend college than those in lowest wealth quartile by 1997. A large part of this may be that, as aforementioned, government has done little since the initial establishment of need-based aid. While one study did find that receiving financial aid not only increased opportunities for access for low-income students, but also facilitated interaction with other students on campus, allowing students to spend extra time on social and academic activities in lieu of working a greater number of hours, it is also important to note that the study is well over two decades old (Cabrera, Nora, \& Castaneda, 1992), and has aforementioned need-based aid has not kept up with the cost of tuition since. Also, unfortunately, reductions in state appropriations have led to dramatic increases in public sector tuition rates and governmental shortfalls in grant aid has led to students working greater number of hours (particularly off campus and those who are low-income), taking out more in student loans to increase levels of debt, and enrolling only on a part-time basis, which not only extends one's time to completion and lowers chance of persistence 
and graduation, but further decreases the amount of grant aid students can receive in subsequent years (Advisory Committee on Student Financial Assistance, 2002). Firstgeneration status can often be overlooked and is not as visible a status as race or gender, but can be an equally challenging identity in certain environments. In regard to firstgeneration status, Orbe (2008) stated: “making this aspect of his or her identity known to others may result in (mis) perceptions that the student is ill prepared for college-level academics, without substantial educational aspirations, socially or communicatively inept, and less committed to participating fully in the learning process” (p. 92).

\section{Considerations Other Than Financial}

To ignore the fact that finances play a significant role for most Americans when it comes to college enrollment would be foolish. Paulsen and St. John (2002) posited that the federal government has shifted away from using grants to using loans as the primary means for promoting postsecondary opportunities and that among poor and working class students, there is a substantial amount of unmet need that goes both unidentified and unmet by existing policies and practices at both the institutional and governmental levels. Additionally, Pascarella, Cabrera, and Bernal (2001) asserted that research consistently shows a significantly negative relationship between tuition increases and college enrollment. When this was reported, public institutions in the United States were entering a significant boom period, with enrollment growth of about $30 \%$ over the next ten years (Hicken, 2013). The year 2012, however, saw the first drop in a decade with a decline of enrollment at public institutions of about .7\% (Lewin, 2013). In fact, for lowincome students who desperately rely on Pell Grant funding, it only typically covers about 36\% of their overall cost of attendance (Haycock, et al., 2010). 
Furthermore, in 2002, the Advisory Committee on Student Financial Assistance predicted that over the course of the first decade of the $21^{\text {st }}$ century, 4.4 million high school academically prepared and qualified low-income graduates would not be able to do so at a four-year institution, and that a total of 2 million of these students would not be able to attend college at all. The committee also found that low-income parents are almost five times as likely to be very concerned about college costs, financial aid, and unmet need as higher income parents and low-income students were three and half times as likely to be concerned as their higher income peers (Advisory Committee on Student Financial Assistance, 2002). In a later separate report, the same committee concluded that large scale mismatches exist between the number of academically qualified students and their ability to afford expenses at many four-year institutions leading to many of these students lacking access and when they do enroll, a lack of persistence to graduation (Advisory Committee on Student Financial Assistance, 2010). The Advisory Committee on Student Financial Assistance (2010) attributed much of this gap to grant aid not keeping pace with increases in tuition and they call on federal policy to ensure that states and public institutions "hold Pell Grant recipients harmless against increases in cost of attendance.” The committee finally asserted that initiatives to improve academic preparation, access, and persistence void of also focusing on financial concerns will not adequately address the problem (Advisory Committee on Student Financial Assistance, 2010).

Additionally, often, even when a student is able to have his or her direct school costs such as tuition, room and board, and books covered, the first-generation student may be expected to contribute to their families' finances as was the case with many 
students interviewed by Cushman (2006) in her "First in the Family" report. So, to reiterate, finances do play a role and make a difference clearly. That being stated, while many may assert the economic hindrances as the primary challenge for this group of students, there is some research that points to financial constraints as being far from the only concern and that which would lead to a student dropping out or failing to be academically successful.

While financial aid was found to be one major issue impacting low-income and minority students’ ability to succeed, the Institute for Higher Education Policy (2001) also found that pre-college preparation, involvement in campus activities and feeling connected to their institutions, and attendance patterns were also significant issues of impact as well. Also, despite the litany of evidence and common knowledge that finances create a major obstacle for a low-income student, there is also significant evidence that students face a number of other academic, cultural, and social challenges in obtaining a college education (Fitzgerald \& Delaney, 2002; Levine \& Nidiffer, 1996; London, 1996; Rodriquez, 2001). Gladieux and Swail (1999) asserted that while federal policy has primarily focused on removing financial barriers, academic preparation, family and cultural attitudes, motivation and awareness of opportunities all play key roles in who goes to college and also who succeeds and persists. Additionally, Levine and Nidiffer (1996) posited that while financial aid is obviously necessary for low-income student to matriculate, it is far from sufficient and does little to improve access for such a student. In fact, Bean (2005) pointed out that it is not money alone that gives higher income students an advantage, but also they are much more likely to have higher levels of social and human capital. 
One study examined students who matriculated to Berea College between 1989 and 1997 (Stinebrinkner \& Stinebrinker, 2002). For those unfamiliar with Berea College, every student admitted is offered full tuition subsidy and generous room and board (dependent upon family income and resources) funding. Therefore, theoretically at least anyway, financial issues and challenges should comparatively be of minimal concern to these students. The study, however, revealed that about half of the students left the institution without graduating and the researchers determined based upon their analysis that the attrition rates were primarily due to family environmental differences (Stinebrinkner \& Stinebrinkner, 2002). Additionally, a separate study found finances had no significant effect on institutional fit, which can be a contributor to student retention and success, for first-generation students (Bouchard, 1994). Also, Ellwood and Kane (2000) found after controlling for other variables that income differences alone explained very little of why low-income youth were less likely to attend college, finding that parental education had a strong influence with better educated parents more encouraging of college attendance and better able to convey a college going expectation as well as provide information regarding the process. Hossler, et al. (1999), also found in his longitudinal study of Indiana high school students that in the early stages of college planning and preparation, that parental encouragement had the greatest influence of any factor. Ellwood and Kane (2000) also surmised that the lack of expectation and encouragement first-generation students often received caused them to put forth lesser effort in academics and also found that levels of academic achievement were correlated with college enrollment. 
Furthermore, Hossler, et al. (1999) found in his study that while 91\% of students with an A average attended college, only $28 \%$ of those students with a C average did. Also, desire to increase income alone was found to lead to a decrease in GPA and intrinsic motivation a much greater contributor to academic success for first generation students (Prospero, 2007). Additionally, according to Tony Robinson (personal communication), who is the Coordinator of the Cardinal Covenant program, when the program was first initiated in 2007, student persistence was a major concern and finances seemed to not be the only factor influencing student persistence and achievement; even with the generous financial aid package and program administrators soon learned that students faced threats to persistence and academic aside separate from financial considerations. In another study, although finances were a top consideration of low income students when attending a private institution, it was not among one of the top three factors when enrolling at a public college or university, with academic factors instead fully comprising the list (Terenzini et al., 2001). Beegle (2000) also found that for students in poverty it was not just about the availability of financial aid but rather the knowledge of the availability, learning how to gain access, understanding the scarcity of resources available, and managing those financial resources once they have secured. These findings being stated, one cannot ignore the financial concerns of this population. To illustrate this point, one study found financial aid was a significant concern for lowincome students, who acknowledged their enrollment in college was largely contingent upon funding of their education (Arnold et al., 2008). Also, while it should be duly noted that Tinto's work (1987) was well over two decades ago prior to dramatic increases in tuition and other costs, he concluded finances are not a long-term factor in persistence. 
Finally, upon systematic review of numerous studies, it was found that financial aid considerations do not play a dominant role and that other factors such as academic resources, ability, and academic as well as social integration also play significant roles (Terenzini et al., 2001). While financial and economic capital is certainly a concern for this group of students, it is definitely not the sole issue or possibly even the most important issue.

\section{Further Exploration}

As examined and witnessed in the second chapter of this work, there is a large amount of research related to this particular topic yet. There is a dearth of research on rural students specifically. Thus, I chose in the last section of this chapter to focus more in-depth on studies that primarily focus on rural students, with a couple of exceptions that warrant further exploration: London’s (1989) study that was monumental and groundbreaking in regard to qualitative research on first-generation students, and Engle and O’Brien’s (2007) work which focuses on low-income students specifically at large, public universities similar to the one examined in my study with a host of implications for policy and practice.

The first study I will examine here is that of Leanna Blevins whose purpose was to examine the completion rates of students from rural Virginia at public colleges throughout their Commonwealth over a six-year span from 1992 through 1997. Similar to my current study, Blevins (2004), also used Bourdieu’s concepts of social and cultural capital in framing the theoretical framework for her study. Unlike my current study, she approached this from a quantitative methodological standpoint using an existing data set to determine which variables impacted baccalaureate degree completion by comparing 
rural students to other non-rural students from Virginia (Blevins, 2004). The study found that non-rural students (66\%) were more likely to complete a baccalaureate degree within a six-year timeframe than were rural students (63\%), and while the difference was only three percentage points, the results were statistically significant at the .001 level (Blevins, 2004). Additionally, Blevins' study (2004) found, not surprisingly, that as family income increased among rural students, they were more likely to graduate. Finally, perhaps the most pronounced was that only $11 \%$ of high school graduates from rural areas in Virginia went on to matriculate at public four-year institutions and only $7 \%$ of those high school graduates would go on to graduate from college (Blevins, 2004).

In a somewhat similar fashion, the purpose of the second study was to learn about the experiences of rural college-going students in order to formulate hypotheses regarding how decisions on whether or not to persist are made by these students (Elliott, 1989). Similar to my current study, Elliott (1989) also relied upon Tinto’s work and more specifically his Longitudinal Model of student retention as well as Spady’s Interdisciplinary Model in the theoretical framework of her study. Unlike the study by Blevins (2004), however, and similar to my current study, Elliott (1989) took a qualitative approach and also relied upon in-depth interviews as her method of data collection. The setting of Elliott's (1989) study was also a large, research university, similar to the setting of my current study. The study found that persistence existed more along a continuum rather than as a dichotomous phenomenon, identifying six different points along the continuum (Elliott, 1989). Furthermore, Elliott (1989) found that two major factors, what she referred to as "making the grade,” or such concepts as high school preparation and college study skills, among others, and establishing what she 
referred to as "a home away from home," differed along the continuum. Finally, she conceptualized that students had to perform a "balancing act” between their social and academic demands (Elliott, 1989).

Unlike the first two studies mentioned, Engle and O’Brien (2007) focused more on institutional attributes, which related to my current study, also focusing on what practices in which the institution in question can thus engage and more specifically, as related to the current study, Engle and O’Brien (2007) focused on large, public colleges and universities that serve large numbers of low-income students. The study built upon the work of a previous study that examined what smaller institutions did to retain and graduate low-income students and the specific purpose was to determine if similar practices could be replicated at larger institutions. The study was quantitative in methodology and specifically used regression analysis in order to control for student and institutional "inputs" in order to determine if they were significant differences between "higher" and "lower" performing institutions that served high numbers of low-income students.

By comparing ten institutions that graduated higher than expected numbers of low-income students to four institutions of lower than expected numbers, the study found that institutions that have higher than expected graduation rates offer a wide range of support programs and services and placed a high degree of responsibility on students themselves. Furthermore, Engle and O’Brien (2007) divided institutions into different types based upon whether the institution was higher or lower than expected in graduation rate given the number of low-income students enrolled and the institutions comparison to the national average. Finally, Engle and O’Brien (2007) found that "high performing" 
large, public institutions designate faculty and staff members as "first responders," have relatively high levels of student involvement and engagement, have well developed firstyear programs, and have special programs for at-risk students.

In returning to focusing on students, the purpose of Grcich’s (2008) study was to examine how students from low socioeconomic backgrounds navigated through their educational experiences at the University of Pennsylvania, an elite, Ivy League school. Similar to my current study, and like other studies examined in this section, Grcich (2008) also used Bourdieu's theory in forming his conceptual framework, focusing specifically on Bourdieu's notion of habitus. Also, similar to the current study, Grcich (2008) took a qualitative methodological approach in conducting individual in-depth interviews in an attempt to gain an understanding of students' intersections of the socioeconomic status and educational experiences. The study found that based upon their low socioeconomic background, students often felt alienated, marginalized, and frustrated at the university. It is important that this was in some contrast to my findings, possibly due to the fact that although the University of Pennsylvania and the University of Louisville are both large universities, the University of Pennsylvania is a much more elite institution with likely a much different culture than that of the University of Louisville. Finally, a finding that was similar to my current study was that participants in Grcich’s (2008) study were also cautious and guarded about opening up regarding their low socioeconomic background.

In another similar study, Hodsden (2012) examined the experiences, beliefs, and people that impacted rural students to attend college. Furthermore, similar to my study, she also used Bourdieu's theory in establishing her conceptual framework for her study. 
More specifically, she want to look at how first-generation students from rural areas within the state of Colorado define and describe their path to college enrollment. Similar to my current study, Hodsden (2012) also used a qualitative methodological approach, although she examined her study through a narrative inquiry lens while I use a grounded theory. Hodsden (2012) found that pre-collegiate programs are instrumental along with a mentor in high school in guiding a student during their college application process. Finally, Hodsden (2012) also found that participants acknowledged and attributed a strong sense of connectedness within their rural communities that drove them to seek out a similar environment within their collegiate environment and thus was instrumental in their success as well.

In another break from the dissertation studies, the focus shifts to London's (1989) groundbreaking work on first-generation students. In this qualitative study, London (1989) focused on the family histories of students who were "the first in their families to go to college” (p. 144). The purpose of London's study was to explore how multigenerational family dynamics was linked to college matriculation for these students and also how these students navigated the conflicting demands between their families and their educational pursuits. One key difference here was that London (1989) was focused on urban youth as opposed to rural, however, his findings were in some ways similar to those in my current study in regard to the challenges and obstacles they faced in their matriculation. London (1989) found that first-generation students often experience great conflict between their two worlds and can have a rough transition in navigating between the two experiences. I believe it is significant, however, to point out that London's study was conducted a generation ago and at least amongst the participants I interviewed, the 
transitional experience to post-secondary education was not as traumatic or dramatic as what was uncovered in London's interviews.

In shifting the focus back to rural students, Maples (2000) examined the interaction between the size of the high school a student attended, the size of the college or university attended, the extracurricular activities engaged in while in high school, and the student's level of satisfaction with his/her collegiate environment. Unlike my current study, Maples (2000) used a quantitative measure using archival data from ACT between 1989 through 1999. In analyzing the survey data, Maples (2000) ran an ANOVA to determine effects and results. First, Maples (2000) found that rural students were more likely to be engaged in extracurricular activities if they were enrolled at smaller high schools. Perhaps, and finally, however, the most significant finding from Maples (2000) study was the extracurricular involvement does not necessarily equate to overall satisfaction with their high school. This may perhaps be a finding that could be carried over to collegiate experiences. Maples (2000) carefully and quickly pointed out that academic requirements, curriculum, and curriculum related factors also played a significant factor. I would posit this should also be duly noted for post-secondary student affairs professionals who need to recognize that the collegiate experience is also a combination of curricular, co-curricular, and extra-curricular experiences.

The study by Schutz (2003) was pivotal in review as it prepared for my current study. Schutz (2003) examined the experiences of first-generation students, who were rural and more specifically from agricultural backgrounds. Schutz (2003) sought to use his findings to assist with retention strategies for this particular population as well. While Schutz's (2003) study is somewhat different in regards to the student population, those 
who are in their first semester versus more seasoned juniors, seniors, and graduate level students, he also focused on a select few in a qualitative methodological approach. Schutz (2003) found that students from a rural, agricultural background faced obstacles and challenges related to their lack of knowledge about campus and collegiate culture, large class enrollment sizes, the academic expectations place upon them, as well as the academic rigor inherit within the collegiate culture. Schutz (2003) surmised that an agricultural background may compound some of the differences between themselves and classmates. Finally, Schutz (2003) asserted, however, that the students' agricultural backgrounds may have positive consequences in regard to work ethic, which was also found in my study, as well as self-esteem.

Another study by Whiting (1999) also diverges from the dissertational foci of this review. Whiting (1999) conducted a year-long study focusing on the interaction between a rural students and his English composition professor at a public, state university. Whiting (1999) examined both the general university environment of state universities as well as pedagogical concerns within the classroom itself. Similar to my current study, Whiting's (1999) study was of a qualitative methodological nature, but dissimilar because it was a case study as opposed to interviewing multiple participants, allowing her to go further in-depth and in detail with one particular individual. Through this intense experience, Whiting (1999) learned that while rural students have to adapt and become immersed within the culture of the institution, that the institution and faculty and staff within the confines also have to be amenable to change and transformation.

Finally, similar to the majority of the other studies here as well as my own, Yoder (2007) evaluated the extent to which rural students are admitted to a public, state 
institution, North Carolina State University, and once matriculated a comparison of the their completion rates as compared to other, non-rural students at the university. Unlike my current study, Yoder (2007) used a quantitative methodological analysis, more specifically that of logistic regression analysis to ascertain the influence of the independent variable of geographical origin on dependent variables such as admission to the university, graduation within a four-year period, and graduation within a five-year period. Yoder (2007) found that fewer rural students made application to the university and thus posited that this may be due to a lack of information to which rural students have access in regard to post-secondary enrollment options. He also found that rural students' parents lacked the level of education of their non-rural counterparts and that rural students trailed the other students in both academic and non-academic indicators of future success. Finally, Yoder (2007) found that there was no significant difference between rural and non-rural students in odds of graduating in four years and rural students were actually more likely to graduate within a five year period than non-rural students.

This section was provided to offer further, more extensive illumination on the underpinnings of my current study on first-generation, low-income students from rural backgrounds. While there is limited research on this population of students specifically, what research that has been done provides important context and a significant contribution to my study. In concluding the literature review on this issue, there is now a shift to discussion on the methodological approach and technique used in the data collection and analysis. 


\section{CHAPTER 3}

\section{METHODS}

This study explored the actions, attributes, behaviors and strategies of firstgeneration, low-income students from rural areas as related to their persistence and academic success at a large, research, urban public university. The information gleaned from this qualitative study adds to the knowledge base concerning the academic success and persistence of these first-generation, low-income students from a rural background to degree attainment. The participants in this qualitative study were purposefully sampled to highlight successful behaviors in the face of challenges and obstacles where much of the literature indicates these students should not have persisted. While there is a lack of research explaining why these students should succeed in the face of overwhelming obstacles, Gladieux and Swail (1999) indicate much of this may be due to what occurs prior to college matriculation through the influence of a certain individuals as a neighbor, teacher, counselor, or tutor who made a difference in their lives. This may lend some argument to these students having a certain degree of social capital as posited by Coleman (1988) and Bourdieu (1986). I also posit that a similar influence can be made through experiences and relationships upon matriculation on campus, also advocated by Tinto (1987). 
As mentioned in the first chapter, this issue is significant because colleges and universities are increasingly challenged with engaging and developing minority, lowincome, and first generation students, and while students whose parents went to college often have the social, cultural, and financial capital that promote success within a collegiate setting, those students who are the first in their families to go may be deficient in such resources (McGregor, et al.,1991; Lohfink \& Paulsen, 2005; Terenzini, Springer, Yaeger, \& Pascarella, 1996; Ramos-Sanchez \& Nichols, 2007; London, 1989; Tierney \& Venegas, 2009; Khan, 2008). Often, many of those students may also originate from a rural background. There are several purposes of this study. The first is to shed light on the specific challenges and obstacles these students face in pursuing their degrees. The second is to provide suggestion through identification of actions and behaviors that students with similar characteristics can practice for the purpose of being successful and completing college. The third is to add to more research specifically on rural, firstgeneration, low-income students in higher education. Finally, the fourth purpose is to better understand the relationship between the needs and university obstacles of firstgeneration, low-income students from a rural background in order to inform and strengthen the university administrative efforts in working with this population of students.

\section{Qualitative Approach}

A qualitative approach was utilized in this study for several reasons. First, due to the specificity of the population, a reasonably adequate sample could likely not be obtained that would create generalizability to a larger population of students. While generalizability is not the goal in a qualitative study, and is not the goal with this study, 
there is a strong possibility of a degree of transferability and adding information to the knowledge base. Second, since a focus of this study revolves around Tinto's theory, in order to truly understand how each participant navigated through and dealt with each of Tinto's stages and events, in-depth responses and thus a qualitative approach is necessary. Additionally, while quantitative methods certainly have their place and can often be beneficial, my view is to truly understand the experiences of first-generation and low-income students a qualitative approach is needed. One of the primary goals for this study is to obtain the richness and thickness in detail that could only be acquired through a qualitative study. In fact, one way we can both enrich the student's experience as well as the institutional setting, is to draw upon these students' cultural capital, instead of viewing them as deficient in some way, by bringing their stories and lived experiences into the discussion (Jehangir, 2010). Furthermore, Oldfield (2007) stated that: "personal narratives can also help faculty and administrators see why it is necessary to change the campus environment so that first-generation college students with humble economic backgrounds feel more at home there” (p. 3). In other words, information obtained qualitatively can often have a deeper impact than quantitative data alone.

Also, qualitative studies are highly beneficial in a number of studies in obtaining a deeper understanding of the struggles, challenges, and experiences of first-generation, low-income college students (Beegle, 2000; Bergh, 2008; Lask, 2008; Cole, 2008; Martin, 2012; London, 1989; Bukoski, 2012). The study by Beegle (2000) relates particularly well to the proposed study here. In her study, Beegle (2000) examined strategies and experiences that contributed to the success for students who came from poverty finding that in addition to securing necessary financial aid, other key themes 
were establishing a connection with mentors who may include family, friends or professionals, a need to maintain determination, and expanding one's social capital which helped them to better make connections and thus assimilate to the college culture. Finally, according to Marshall and Rossman (1995) the type of research questions one is asking is really the determining factor for whether or not a qualitative study is appropriate, and based upon my research questions, I determined a qualitative study was the best way to adequately answer my questions.

A large, urban, public university was chosen as the setting for this study for a couple of reasons. First, being urban, the community environment is considerably different from the hometown communities of the participants. Second, Tinto (1987) pointed out that involvement and the ability for students regardless of background to establish connections may be much more challenging at a large public institution due to the remoteness of faculty and staff and greater vulnerability to isolation. Finally, Kentucky primarily identifies as a rural state and it is anticipated that most of the participants will be from in-state as the total student population at the university is comprised of over 73\% in-state students (U of L Institutional Research, 2014), while the University of Louisville is situated in an urban setting.

\section{Nature of Design}

As first addressed in chapter one, the interviews were conducted with four research questions in mind:

1. What specific obstacles and challenges to their persistence and academic success do first-generation, low-income students from a rural background face at an urban research institution over the course of their enrollment? 
2. What assets or strengths do first-generation, low-income students from rural backgrounds possess that could help them to be academically successful at an urban research institution?

3. What specific attributes of a large, urban research institution can be particularly challenging from a negative aspect or particularly beneficial from a positive aspect for a low-income, first-generation student from a rural background?

4. What actions and behaviors do first-generation, low-income students from a rural background engage in in combination with the practices of an urban research institution to promote and benefit transition and integration into the campus community?

To reiterate, first-generation students have been defined as both those where neither parent has obtained a college degree, but may have enrolled in college, (Engle \& Tinto, 2008; US Department of Education, 2011) and those where neither parent has attended college (Chen, 2005; Nunez \& Carroll, 1998). For the purposes of this study, firstgeneration college students were defined as those where neither parent had graduated from college. Students whose older siblings may have attended or graduated from college were eligible to participate in the study, however, this was taken into account when the data is coded, analyzed, and interpreted for any significant differences from those first-generation students whom did not have older siblings who either attended or graduated from college. Furthermore, while focusing on older siblings who may have attended or graduated from college could certainly be an important consideration for study, the common definitions within the literature on first-generation students pertain to parental status (Engle \& Tinto, 2008; US Department of Education, 2011; Hicks, 2003; 
Chen, 2005; Nunez \& Carroll, 1998; Barnett, 2004; Hertel, 2002; York-Anderson \& Bowman, 1991).

The methodology underlying this study is that of a grounded theory approach, originally espoused by Glaser and Strauss (1967). Grounded theory was developed by Glaser and Strauss (1967) as a way to bridge the gap between theory and practice with the purpose of identifying major categories, relationships between the categories, the context as well as the process in order to illustrate a descriptive account of a certain phenomenon. Glaser and Strauss (1967) used the process of comparative analysis in constructing their theory, believing the key purposes of comparative analysis to validate through accurate evidence by the creation of conceptual categories, to provide empirical evidence for generalizations, to specify concepts, to verify theory, and ultimately, perhaps most importantly, in generating theory (Glaser \& Strauss, 1967). According to Glaser and Strauss (1967), a well-constructed grounded theory meets four central criteria for judging the applicability of theory to the phenomenon:

- Fit, where the theory is faithful to the everyday reality of the substantive area and carefully induced from the diverse data

- Understanding, meaning the theory should be comprehensible and make sense both to the persons who were studied and to those participating in that area

- Generality, that the theory should be abstract enough and include sufficient variation to make it applicable to a variety of contexts related to that phenomenon

- Control, referring to the conditions to which the theory applies should be clearly spelled out and should apply specifically to a given situation 
I chose grounded theory because it was the best fit for the aims of the study. According to Creswell (2007) grounded theory is an appropriate design where there is no theory available to explain a process and the research questions focus on understanding how individuals experience a process. In this case there has been no theory developed to explain how rural, first-generation, low-income students overcome significant challenges, navigating through their experiences at large institutions of higher education to be academically successful and this study certainly strikes at the heart of how the participants have experienced their processes as college students.

According to Strauss and Corbin (1990), the purpose of any grounded theory study is to generate or discover a theory and is generated or "grounded" in data from participants who have experienced the process and generates a theory shaped by the views of a large number of participants. An underlying assumption with grounded theory is that all of the elements pertaining to the given phenomenon have not yet been identified or that relationships between these elements are poorly understood or conceptually underdeveloped (Strauss \& Corbin, 1990). As mentioned previously, there is a lack of research on low-income, first-generation students from a rural background, and even less when you consider those that have matriculated and found success at a large, urban research institution. Therefore, this topic is very appropriate for the grounded theoretical framework. Also, to this date, no theory has been posited, even when it concerns first-generation and low-income students in general, as to how they successfully navigate the terrain of higher education. Finally, Creswell (2007) examined several criteria for judging a grounded theory study: the study of a process, action or interaction as the key element in the theory, a coding process that works from the data to 
a larger theoretical model, the presentation of the theoretical model in a figure or diagram, a story line or proposition that connects categories to the theoretical model, a reflexivity or self-disclosure by the researcher about his or her stance in the study. Considerations of all of these points was a given in pursuit of this study.

\section{Data Collection}

While qualitative inquiry and grounded theory can be approached using a number of methods from focus groups to observations to document analysis, the method I chose for this study was that of interviewing. There was one significant reason for this, according to Patton (2002): "we cannot observe feelings, thoughts, and intentions. We cannot observe previous points in time. We cannot observe how people have organized the world and the meanings they attach to what goes on in the world” (p. 341). While each one of his assertions is poignant and applicable to the heart of this study, I primarily gathered information about previous behaviors and actions, which clearly cannot be captured through observation alone. Furthermore, according to Rubin and Rubin (1995), interviewing can serve to capture how people understand the world they live and the culture they create, and per Rossman and Rallis (2003), "interviewing takes you into the participants' world, at least as far as they can (or choose to) verbally relate what is in their minds” (p. 180). Additionally, while focus groups were a serious consideration, I had serious concerns about how open, honest, and comfortable participants would be with other students present. While the University of Louisville is a large institution, it is very possible for participants to know one another, and interviewing, therefore, would be more conducive to my aims. 
According to Patton (2002) there are three types of interviews: the informal conversation interview, the general interview guide approach, and the standardized openended interview. Patton (2002) is quick to point out, however, that these three approaches are not mutually exclusive and that researchers can combine approaches if needed. I opted to use a combination of an interview guide approach and the standardized openended interview. Patton (2002) stated a researcher may decide to use these two in combination when wants to ask "certain key questions exactly as they must be asked while leaving other items as topics to be explored at the interviewer's discretion” (p. 347). Since I was searching for some level of potential commonalities across participants, it is essential to ask some specific questions. I also wanted to allow for a degree of flexibility given that each participant's story is unique, while also deciding to order my interview questions very strategically, asking zero to low-risk questions, enabling me to establish a level of rapport with the participants and put them at ease (Glesne, 2006; Creswell, 2007).

Questions for this study were created with several considerations in mind. First, related dissertations and studies were examined. When appropriate, questions were directly borrowed from some of these studies that I believed fit my study. Note that the questions are not a complete replication from any one study, but rather a combination of several studies and also some original questions for specific aim toward the student participants in mind. I have attached a list of my interview questions in Appendix C. In developing my questions, I contemplated what Errante (2000) referred to as "watershed questions" or those questions that would unlock one's memory and allow the participant to open up sharing and telling rich and detailed information. Also, Errante (2000) 
referenced the previous work by Kaufman (1974) and this notion of establishing an “interpersonal bridge,” which is akin to an emotional bound of trust between the interviewer and the participant. According to Errante (2000), such a bridge can often not be established prior to the interview, so the interview itself must not only be an informational gathering opportunity, but also a chance to build such a bridge and establish trust.

A pilot interview was conducted of a recent graduate who met the participant criteria in order to review interview questions for accuracy and clarity. Participant criteria will be discussed in greater depth in a later section in this chapter. Slight changes were made based upon the results of the pilot interview. Finally, interview questions were analyzed against the conceptual framework and research questions to ensure there was compatibility among the three and that the interview questions addressed the embedded concepts. Once questions are firmly established, however, other concerns can still exist. One of these is the concern that I will project my own memories, thoughts, feelings, and beliefs on to the experiences of others. Errante (2000) referenced this when speaking of her own memories and grief with the concern she had projected these upon on the villagers of Mozambique. Furthermore, Errante’s background was very different from those she was interviewing, whereas my background is similar in many ways to the participants in my study, so my concern may even be greater. Also, Hurst (2008), in coming from a similar background as those she interviewed, stated that this can influence certain judgment calls over the course of interviewing. In order to guard against this, I was continually mindful and vigilant of these concerns as well as utilizing committee 
members and potentially others to review and check my interpretations. Once again, the interview questions asked can be seen in Appendix C.

Most interviews lasted no more than one hour in length, with the exception of three, which were slightly over an hour in length, and took place on the campus of the University of Louisville with the specific location left to the decision of the participant. Interview locations included my office, the library, private conference rooms, and in one instance, a private office at the location of the participant's on-campus employer. The interviews were audio-recorded for accuracy and the researcher took notes on significant statements or comments by the participant primarily for the purpose of potential unplanned follow-up questions as previously mentioned. Minimal note-taking was also employed in order to maintain eye contact with the participant and engage him or her as much as possible during the course of the interview. The primary purpose of taking notes was to quickly capture any significant words or phrases used by the participant that may have led to follow-up questions for clarification or further explanation. The researcher transcribed each interview and once transcription was complete, the transcript was shared directly with the participant, known as member checking, in order to ensure accuracy of the transcription. It was anticipated that anywhere from 15-25 participants would be interviewed (there were a total of 18), however, the goal in number of participants interviewed is to achieve saturation (Patton, 2002). Participants were also informed that once transcribed, they would be sent a copy of transcription as asked to verify for the purpose of accuracy. Participants were also told upon the conclusion of the interview that if at any time they decide not to continue involvement, even after the interview, they should let the researcher know and the transcript and recording will be destroyed. 
Participants were also informed that when the study was completed and fully analyzed they could read the findings should they so desired.

\section{Epistemological Stance}

Crotty (1998) defined epistemology as “a way of looking at the world and making sense of it” (p.8). Similar to Martin (2012), I chose a constructivist epistemological stance while also viewing through the lens of critical theory framework. Part of the epistemological orientation is based upon a constructivist philosophical paradigm. According to Guba and Lincoln (1994), a paradigm can best be defined as "a worldview that defines, for its holder, the nature of the 'world,' the individual's place in it, and the range of possible relationships to that world and its parts” (p. 107). More specifically, a constructivist paradigm posits people construct their own realities and their own perceptions and that “no one perception is 'right' or more 'real' than another” (Glesne, 2006, p. 7). The constructivist paradigm is further described by Guba and Lincoln (1994) as "understanding and reconstruction of the constructions that people (including the inquirer) initially hold, aiming toward consensus but still open to new interpretations as information and sophistication improve” (p. 113). Furthermore, Crotty (1998) defined constructivism as: "the view that all knowledge, and therefore, meaningful reality as such, is contingent upon human practices, being constructed in and out of interaction between human beings and their world, and developed and transmitted within an essentially social context” (p. 42). I focus on "social context” here, for a first-generation, low-income student from a rural background, thriving in their natural home environment, constructing meaning from experiences that are natural and of the familiar is a given, but 
place that student in an alien, foreign "social context" that is far from what he or she is used to, a different set of consequences emerge.

Abes (2009) pointed out that the combination of multiple perspectives creates a “hybrid theoretical perspective” revealing new approaches to understanding participants’ experiences, and further elaborating that using more than one perspective can be of particular significance in addressing ways in which "inequitable power structures have shaped student development theory” (p. 141). Similar to Martin’s (2012) study, I also employed these multiple, and as she points out, often conflicting perspectives for to illuminate participants' experiences in such a way that both acknowledges inequities related to social class and within higher education. Unlike Martin’s study (2012) however, which focuses solely on white students and does not specify their geographic origin, mine is not racially exclusive with a heavy focus on geographic origin.

Constructivism alone, however, is not sufficient for the aim of my study. In addition to the constructivist paradigm, critical theory is also used. While constructivism may explain how low-income, first-generation students from a rural background have socially constructed their environments, it does not, by itself, advocate for change to make improvements to those environments. Furthermore, Martin (2012) stated that critical theory "acknowledges that human existence is situated within a society where systems of privilege and oppression exist and systematically advantage some while disadvantaging others” (p.48). Patton (2002) also posited that critical theory goes beyond that of just attempting to understand society and make sense of it, but also to impact change with an “explicit agenda of elucidating power, economic, and social inequities” and to "critique society, raise consciousness, and change the balance of power in favor of 
those less powerful” (p. 548). Additionally, Crotty (1998), in reflecting upon the work of Horkheimer in 1937, stated that critical theory is, in essence, "a theory that instead of "reflects the current situation” solely, also “seeks to change the situation” (p. 130). Combining both of these perspectives makes senses when one considers that 1) the environment and one's constructed perspective is of utmost importance in this study, and 2) there is something inherently wrong when a student has a diminished chance of success within such an environment based upon personal characteristics and attributes beyond his or her control. Finally, the combination of the viewing a study through the lens of both is not an alien or drastic notion.

\section{Description of the University of Louisville and the City}

The University of Louisville is the Commonwealth of Kentucky's second largest institution of higher education within the state's largest metropolitan area of just over one million people, advertised as the nation's $17^{\text {th }}$ largest city (U of L web site, 2014) with just over 22,000 students according to 2013-14 figures (U of L Institutional Research, 2013-14). The university's mission statement is that it "shall be a premier, nationally, recognized metropolitan university" and is comprised of 12 colleges and schools housed on three separate campuses, with the main 287-acre Belknap campus housing seven of those colleges and schools where the vast majority of undergraduates attend ( $\mathrm{U}$ of $\mathrm{L}$ web site, 2014). Colleges and schools housing undergraduate students on campus include the College of Arts and Sciences, College of Business, Speed School of Engineering, School of Nursing, College of Education and Human Development, Kent School of Social Work, School of Music, and the School of Dentistry. In 2013, the university awarded just over 2700 baccalaureate degrees and the six-year graduation rate for students entering in the 
fall of 2007 was 53.5\% (U of L Institutional Research, 2014). In the fall of 2013, the university was comprised of just over 16,000 undergraduate students with a little less than 6,000 graduate and professional students (U of L Institutional Research, 2013-14).

While Kentucky primarily identifies as rural, more than half of the in-state students $(9,819)$ originate from Jefferson County, the county in which the university is located, and among the top ten counties from which in-state students originate, all are surrounding counties or more urbanized counties than is generally the case throughout the Commonwealth (U of L Institutional Research, 2014). I point this out only to illustrate that a further challenge for rural students is their minority status on campus.

\section{Characteristics of Participants and Participant Selection}

According to Strauss and Corbin (1990), participant selection is "very directed and deliberate with conscious choices made about who and what to sample in order to obtain the needed data” (p. 187). My targeted sample was found using a purposeful sampling method, which according to Merriam (1998): “is based on the assumption that the investigator wants to discover, understand, and gain insight about a phenomenon and therefore must select a sample from which the most can be learned” (p. 61). While firstgeneration status plays a key role in this study, it should be duly noted that firstgeneration is only one characteristic of the students involved in this study and that income level plays a significant role as well. To make matters more complicated, firstgeneration identity is often complex and not uniform, depending upon situational context and other factors such as socio-economic status, race/ethnicity, age, and gender (Orbe, 2004). 
The first specificity for selection was low-income. While the primary selection criterion is the student's identification as a low-income student, ideally participants were also at or below $150 \%$ of the federal poverty level, a definition that is used by the Cardinal Covenant program on campus, a special program for incoming freshmen who meet the predetermined criteria, one of those being the income threshold, to: "award enough gift assistance from federal, state, private, and institutional sources to cover their direct costs (tuition, room, board, and books)” (University of Louisville Student Financial Aid Office web site, 2014). The same definition is also used by the Federal TRIO programs for eligibility to participate in their programs (US Department of Education web site, 2014). A table of the federal poverty guidelines, as published by the Department of Health and Human Services, along with a table provided by the University of Louisville's Office of Financial Aid indicating the 150\% levels are included in Appendix G. The second important point of selection criteria is college going generational status. First-generation students have been defined as both those where neither parent has obtained a college degree, but may have enrolled in college, (Engle \& Tinto, 2008; US Department of Education, 2011) and those where neither parent has attended college (Chen, X., 2005; Nunez \& Carroll, 1998). For the purposes of this proposed study, to emphasize the importance of obtainment of a college degree, as well as to use the definition of the US Department of Education (2011), first-generation (2011) was defined as those students where neither parent has graduated from college, however, an older sibling may or may not have previously enrolled in or graduated from college. Third, in order to be eligible for the study, the participant must have earned a minimum of 60 credit hours, having been at the university in a higher education setting long enough 
to have demonstrated success. The level of 60 hours was chosen because it is anticipated by the university that students successfully progressing toward their degree will have earned 60 hours by the end of year two, when many students will have hopefully chosen a major and shifted from a professional academic advisor to a faculty advisor within their specific academic discipline. Graduate level students are also potentially eligible for participation in this study and a total of two participated.

Fourth, academic success was determined for the purposes of this study as having a minimum of a 2.5 cumulative GPA Grade Point Average (GPA). While various GPA levels could have been used for cutoff, a 2.5GPA is considered the average or universal cutoff point for undergraduate students in good standing at the University of Louisville. Finally, rural status is necessary for selection, which can be to a degree subjective in a sense. For each participant, how he or she identified in terms of their childhood or adolescent upbringing was of primary importance. For example, if a student now identified as a resident of Louisville, but his or her upbringing was in rural Kentucky, he or she would still be considered for the study. While U.S. Census Bureau data were examined in regard to the population figures, this was used only to supplement and verify the participants' assertions regarding geographical identification. Needless to say the aforementioned research points to an important challenge higher education administrators and student affairs professionals face for students from first-generation and low-income backgrounds, as well as rural status. It is important to note that age was a serious consideration as a factor, with the aim of initially limiting the study to traditional aged college students in their late teens and early twenties. After this serious consideration, however, I decided that non-traditional aged students who are older may also have 
important stories to tell that could add to information obtained in the study. Furthermore, while their experiences could be anywhere from slightly to vastly different from the younger participants, this was taken into account during the analysis and interpretation of the data and noted in the findings. Finally, while gender and race/ethnicity were not controlled for in this study, background of home community (rural vs. urban), age (traditional age only), and institution (large, public and urban) are.

Recruitment was done primarily by e-mail by having program coordinators in Cardinal Covenant and TRIO, staff from a variety of colleges and units, and student leaders on campus distribute my request for participation. Recruitment was also conducted by posting flyers around campus. While I did not limit participation in the study for anyone other than the established set of criteria, the hope was to have a diverse mix of students in regard to gender, ethnicity, and those who participated in programs such as Cardinal Covenant and TRIO and those who do not. Participants were entered into a drawing for $2 \$ 25$ Kroger gift cards to encourage participation. Willing participants were asked to sign a consent form. Prior to contacting the students and conducting the interviews, IRB (Internal Review Board) approval was obtained, which will be discussed in more detail in the Ethical Considerations section. Pseudonyms of students were used to protect confidentiality. Hand-written notes were taken during the interview as well as recorded digitally. The recordings were then transcribed in print, with electronic data stored on a password protected computer with any paper copy data or notes stored in a locked file cabinet in a locked office. The cumulative stories of the participants were then compiled with the individual narratives sorted into themes with the purpose of discovering themes across the participants' stories. 
According to Lincoln and Guba (1985), data should be collected "to the point of redundancy” (p. 202) or enough to saturate the data. Furthermore, although Strauss \& Corbin (1990) suggest as many as 20-30 participant interviews for saturation, given the specific nature of this student population I believed that 15-25 would likely be enough for

saturation. In fact, saturation, defined by Glaser and Strauss (1967) as the point where no additional data can be found to develop categories within a particular property, can certainly vary given the nature of the study.

\section{Ethical Considerations}

While death or serious injury can occur much more often within medical trials, there are also serious ethical concerns within social and behavioral research as well. According to Gallant and Bliss (2006) risks can range from: "breaches of confidentiality, violations of privacy, validation of inappropriate or undesirable behaviors, presentation of results in a way that does not respect the subject's interests, possibly harm to individuals not directly involved in research but about whom data are obtained, or harm to subject's dignity or self-image” (pp. 397-398). There are also several ethical issues in qualitative research that must be considered from recruiting participants, informed consent, confidentiality, and protection from harm (Cieurzo \& Keitel, 1999). Furthermore, Patton (2002) states that qualitative inquiry, particularly if it involves in-depth interviewing, is often much more intrusive for participants than simply having them respond to items on a survey in a quantitative study. Additionally, ethical concerns can revolve around costs and benefits for both the researcher and participants, any harm and risk involved to participants, and issues of privacy, confidentiality, and anonymity (Miles, Huberman, \& Saldana, 2013). Therefore, within ethical considerations, there are several aspects that 
will be directly addressed in this section: confidentiality, consent forms, potential risks, precautions from risks, and potential benefits. It is important to note that for each participant, a pseudonym was established in order to safeguard identities as much as possible. It is also important to note that IRB (Internal Review Board) approval was obtained prior to conducting this study and obtaining any information from participants.

\section{Confidentiality}

Gallant and Bliss (2006) contend protecting participant identity can be challenging since you are obtaining information and sharing details in much more detail than would normally be the case in a quantitative study. While anonymity is not a promise for this study, since identifiers were maintained, there was every effort reasonably possible to maintain participant privacy and confidentiality. Throughout the

study, not only were pseudonyms used, but other identifying information was masked and disguised as much as possible in order to protect identities. Other information that was also protected and not revealed was student age, although the participant may be identified as a traditional age or non-traditional age student, exact location of one's home town, physical description beyond race and gender, and the exact nature of any traumatic incidents which may have occurred. In regard to pseudonyms, participants were initially given the option to choose their own pseudonyms so that the researcher did not project any particular bias. In some cases, participants opted to choose their own pseudonyms, and in some instances they did not.

\section{Consent Forms}

According to Miser (2005), even in exempt research with minimal risk, the researcher must inform participants what they will be asked to do as part of the study, 
how long the research will take, and how their confidentiality will be protected. Prior to the first interview, all participants received a consent form and were given ample time to read, review, ask questions, and ask for clarification regarding providing consent to be interviewed. The consent form outlined the purpose and details of the study, the rights of the research participants, and any potential risks they may incur from the study.

Permission to audio-record each interview was also obtained. Participants were also told that consent was on-going and that they could end participation in the study at any time or refuse to answer certain questions if they cause them to feel uncomfortable. A copy of the consent form is available in Appendix E.

\section{Potential Risks}

While the risks for the study are anticipated to be minimal, it was possible that some could occur such as feelings of anger, sadness, embarrassment, etc. while being interviewed. These were thoroughly explained to each participant and once again, he or she had the opportunity to end participation at any time or refuse to answer a question.

\section{Precautions from Risk}

Although there is no way to eliminate risk entirely, I took several precautions to avoid risk as much as possible. First, in addition to participants being provided with the consent form ahead of time, the consent form was reviewed by the participant prior to each interview, allowing participants an opportunity to ask for clarification or ask any questions. Second, the participant was reminded that he or she could end his or her participation at any point as well as refuse to answer certain questions if needed. Third, permission to audio-record the interview prior to the start of the interview was requested. Fourth, each participant was notified of any potential risks both through the consent form 
and then also, verbally prior to each interview. Fifth, the data are housed in a password protected computer. Sixth, participants made the decision of where the interviews tool place so that they felt the utmost comfort level. Finally, participants were provided with the contact information for the university's counseling center in case they needed to speak further with anyone regarding any emotional issues that may have arisen during the course of the interviews and the study.

\section{Benefits}

While participants received no direct benefit based upon the results of the study, they were informed that their responses would add to the knowledge base on firstgeneration, low-income students from rural areas and may potentially help other similar students in the future.

\section{Data Analysis}

According to Creswell (1994) there is no one "right” way to analyze data and that “data analysis requires that the researcher be comfortable with developing categories and making comparisons and contrast” (p. 153). Glaser and Strauss (1967) advocated for the use of constant comparison in data analysis, which includes the four key steps of: comparing incidents applicable to each category; integrating categories and their properties; delimiting the theory; and finally, writing the theory. Glaser and Strauss (1967) also posited that within comparative analysis, conceptual categories and properties are first discovered, which then lead, second, to the development of hypotheses or "generalized relations among the categories and their properties" (p. 35). According to Merriam (2000), data analysis is ongoing throughout data collection and states that "to wait until the end is also to court disaster, as many qualitative researcher has found 
himself or herself facing hundreds of pages of transcripts and field notes without a clue where to begin” (p. 14). Finally, McCracken (1988) offered the following steps for conducting data analysis: initial sorting out of important from unimportant data; examination of the slices of data for logical relationships and contradictions; rereading of transcripts to confirm or disconfirm emerging relationships and beginning recognition of general properties of the data; identification of general themes and sorting of the themes in a hierarchical fashion, while discarding those that prove useless in the organization; and finally, a review of the emergent themes for each of the transcripts and determination of how these can be synthesized into larger themes.

After typing my notes, I analyzed the transcripts and coded based upon words, thoughts or concepts which personally resonated, which is typical within qualitative studies. According to Saldana (2009), “a code in qualitative inquiry is most often a word or short phrase that symbolically assigns a summative, salient, essence-capturing, and/or evocative attribute for a portion of language-based or visual data” (p. 3). Saldana (2009) also pointed out that how we code can be impacted and influenced by our own biases, perceptions, and judgments and it is possible that a different researcher may code differently. That being stated, while initial codes may differ among qualitative researchers, I feel confident that similar conclusions would have been derived from the data obtained.

According to Strauss and Corbin (1990), analysis proceeds in a series of four calculated steps: first, open coding, which forms categories with several properties and evidence from data; second, axial coding, which identifies a central them and explores causal conditions, specific strategies, context and intervening conditions and 
consequences; third, selective coding, where the researcher writes a story-line that connects the categories; and finally, the researcher(s) develop(s) a matrix which illustrates social, historical, and economic conditions influencing the central phenomenon. Saldana (2009) followed a similar pattern, focusing primarily on the first two steps, which he refers to as first-cycle and second-cycle coding. Within first-cycle coding, Saldana (2009) referenced more than twenty different types of first-cycle codes, with some of the most common being in vivo coding, or "a word or short phrase from the actual language” (p.74), descriptive coding, which essentially summarizes the language of the participant(s), and process coding, using gerunds to describe an action. Also, according to Saldana (2009), the type(s) of first-cycle codes employed vary depending upon the nature and goals of the study as well as the experience of the researcher. Since I am still a relative beginner in the field of qualitative study, I chose to stick primarily with elemental methods such as in vivo, initial, descriptive, process, etc. that are considered foundational approaches. For my second-cycle coding method, I choose to employ what Saldana (2009) referenced as focused coding, focusing on the most frequent or significant initial codes in developing "the most salient categories" from the data and that which “requires decisions about which initial codes make the most analytic sense” (Charmaz, 2006, pp. 46, 57). Finally, Saldana (2009) also discussed analytic memos, also known as reflective coding. Saldana (2009) posits that the purpose of analytic memos are: "to document and reflect on: your coding process and code choices; how the process of inquiry is taking shape; and the emergent patterns, categories, and subcategories, themes and concepts in your data - all possibly leading toward theory” (p.32). As I will discuss 
in further detail in my researcher's role section, I kept a reflexive journal throughout the experience.

The coding process went according to an organized pattern from open coding (or first cycle), to second cycle coding, and then to selective coding. Open coding forms categories with several properties and evidence from data, second cycle coding identifies a central theme and explores causal conditions, specific strategies, context and intervening conditions, and consequences, and finally selective coding, where the researcher writes a story-line that connects the categories. After coding, I created a data matrix in word, inserting a table, where codes were housed from particular participants that fell under a certain category. According to Miles, Huberman, and Saldana (2013), a data matrix can be a highly beneficial way of beginning to organize the data and visualize relationships.

\section{Quality Control}

Patton (2002) asserted that both reliability and validity are two considerations about which any qualitative researcher should be concerned. Other researchers further define reliability as dependability in qualitative research (Lincoln \& Guba, 1985; Clont, 1992;). In other words, while quantitative research may endorse the notion of reliability as the extent to which results are consistent over time and represent a total population under study (Golafshani, 2003), qualitative research is more concerned with the consistency of the results, which depend in large part on the consistency of the application of the methods' decisions, but not necessarily in relation to the population. Credibility is another oft mentioned phrase within qualitative studies. According to Patton (2002), credibility depends upon three elements: rigorous methods, credibility of 
the researcher, and philosophical belief in the value of qualitative inquiry. To the best of my ability, I ensured that the methods employed in this study. Pertaining to the credibility of the researcher, I am well versed in the literature on low-income and firstgeneration college students. Finally, I fully believe in the value of qualitative studies, and would not be embarking on this journey if I did not.

Validity in quantitative research is determined by whether or not an instrument measures what is supposed to measure (Patton, 2002). In contrast, in qualitative methods, validity depends upon the nature of the researcher as opposed to the instrument and might include aspects such as competence, bias of the researcher, or other external influences (Patton, 2002). Creswell (2007) posited that validity is really concerned with the credibility and trustworthiness of the researcher. Creswell (2007) focused on eight strategies for enhancing qualitative study: prolonged engagement and persistent observation, triangulation, peer review, negative case analysis, clarifying researcher bias, member checking, thick description, and external audits. Creswell (2007) further recommended that any qualitative study should have at least two of these strategies. Furthermore, Miles, Huberman, and Saldana (2013) further posited that issues of instrument validity and reliability of the skills of the researcher and can be measured in several ways: good familiarity with the phenomenon and the setting under study ${ }_{2}$ a multidisciplinary approach, as opposed to a narrow grounding or focus in a single discipline, good investigative skills, the ability to draw people out, and meticulous attention to detail, being comfortable, resilient, and nonjudgmental with participants in the setting, a heightened sense of empathetic engagement, balanced with a heightened sense of objective awareness 
Lincoln and Guba (1985) posited there were four primary ways in which a qualitative researcher could establish trustworthiness, essential for any high quality qualitative study: credibility through prolonged engagement, persistent observation, and triangulation; peer debriefing, negative case analysis, and member checks. They further asserted that while qualitative findings were not meant to be generalizable, that the aim was for transferability, referring to the extent to which one's research findings may be applicable in a context other than the one which the research was conducted but similar, and that the best way to obtain this was through "thick description” (Lincoln \& Guba, 1985). According to Whitt (1991), thick description can best be described as "rich in details about the setting, its context, and its people” (p. 413). Furthermore, Lincoln and Guba (1985) would go on to advocate for dependability and confirmability. According to Lincoln and Guba (1985) dependability is based upon thorough examination of the findings, interpretations, and recommendations which are consistently supported by the data. Also, according to Lincoln and Guba (1985) confirmability can be established through triangulation. Merriam (1998) also suggested that qualitative researchers can strive to achieve dependability through triangulation and an audit trail. According to Denzin (1978) triangulation consists of four types: data triangulation, investigator triangulation, theory triangulation, and methodological triangulation.

Theory triangulation was employed by looking through the lens of Tinto and Bourdieu, as well as consideration on their theories from other authors, in understanding student retention, various forms of capital, and self-efficacy issues, while also merging the concepts of a constructivist and critical theory framework. Lincoln and Guba (1985) 
and Creswell (2007) also strongly advocate member checking, which was employed by having participants review the transcripts from their interviews. 


\section{CHAPTER 4}

\section{FINDINGS}

In Chapter 4, I will provide an overview of the participants involved, briefly discuss the process of coding an analysis of the data, and provide a thorough discussion of the emergent themes. First, there will be an explanation of how participants were selected including the process involved. After that, I will give a description of each participant who was interviewed as part of the data analysis. Next will be an explanation of how the process of coding was conducted upon conclusion of the interviews and transcription. Finally, I will address the five emergent themes that were discovered as a result of an analysis from the interviews. The five themes included: significance of the environment of the institution; how first-generation and low-income status impact collegiate experiences; rural strengths and assets that contribute to success; importance of building one's own support network as a first-generation college student; and finally, the support to attend college.

\section{Participant Selection and Process}

In October of 2014, I posted several fliers throughout campus to recruit potential participants for the study. Also, I distributed e-mails through various faculty and staff contacts on campus that had access to student lists, some of which were more general, 
while some student lists were specific groups whom more closely met the criteria for the study such as through TRIO and Cardinal Covenant. From these recruitment efforts, a total of 21 students contacted me interested in participating in the study. Of those 21, 18 were ultimately interviewed between October $16^{\text {th }}$ and November $7^{\text {th }}$. Of the three students who were not interviewed, one misinterpreted the study, believing it to be a survey only, and for the other two, there were no agreed upon mutual convenient times between myself and the potential participants. Although the number of interviews did not reach the 20-30 that Strauss and Corbin (1990) advocated, I feel saturation was achieved because of the repetition of responses and lack of unique information gleaned toward the conclusion of the interviews. Interviews took place at multiple locations on campus, including the library, tutorial center lounge area, my office, and participant's place of work on campus. One interview also took place via e-mail exchange since the participant was involved in an internship in another state. Participants were diverse in regard to gender; there were 12 females interviewed and 6 males. Participants were primarily Caucasian with only two identifying as African-American and three participants openly identified as members of the LGBT (Lesbian, Gay, Bisexual, and Transgender) community. Three of the participants grew up outside of Kentucky, while the other 15 grew up in Kentucky. The following chart in Table 1 offers a comparison and contrast on some of the characteristics of the participants involved in this study (other identities column refers to those other than the focus of the study: low-income, first-generation, and rural status, as well as those identified in the table): 
Table 1

Overview of Participants

\begin{tabular}{|c|c|c|c|c|}
\hline Name & Gender & Race & Other Identities & Student Support Services Used \\
\hline Ellie & Female & White & Unknown & Cardinal Covenant \\
\hline Michael & Male & White & $\begin{array}{l}\text { LGBT, Military } \\
\text { Veteran, Non- } \\
\text { Traditional age } \\
\text { Student }\end{array}$ & None known \\
\hline Ann & Female & White & Unknown & Cardinal Covenant \\
\hline Cindy & Female & White & Unknown & None known \\
\hline Monica & Female & White & Unknown & Cardinal Covenant \\
\hline Taylor & Female & White & Unknown & Cardinal Covenant \\
\hline Jennifer & Female & White & $\begin{array}{l}\text { Non-traditional } \\
\text { Age student, } \\
\text { parent }\end{array}$ & None known \\
\hline Erica & Female & White & Non-traditional & None known \\
\hline Link & Male & White & Unknown & TRIO \\
\hline Cynthia & Female & Black & LGBT & None known \\
\hline Clint & Male & White & Unknown & Cardinal Covenant \\
\hline Kyle & Male & White & Unknown & Cardinal Covenant \\
\hline Connie & Female & Mixed & Unknown & Cardinal Covenant \\
\hline Diane & Female & White & Unknown & None known \\
\hline Jason & Male & White & LGBT & Other \\
\hline Denise & Female & White & Unknown & None known \\
\hline
\end{tabular}




$\begin{array}{llll}\text { Laura } & \text { Female } & \text { White Unknown } & \text { Cardinal Covenant } \\ \text { Auzmon } & \text { Male } & \text { White Unknown } & \text { None known }\end{array}$

\section{Process of Coding and Analysis}

A key element for any qualitative research, particularly with interviewing, is the process of coding. According to Miles, Hubermann, and Saldana (2014), coding is a “data condensation task that enables you to retrieve the most meaningful material, to assemble chunks of data that go together, and to further condense the bulk into readily analyzable units” (p. 73). Following the interviews, I transcribed each one and then proceeded with my First Cycle coding. According to Saldana (2009) there are a wide variety of First Cycle coding methods. I chose primarily In Vivo coding and Descriptive coding. In Vivo coding was chosen because according to Saldana (2009) not only is it “appropriate for virtually all qualitative studies” (p. 74), but it can also be particularly useful for interviews and works well in prioritizing and honoring the participant's voice. According to Miles, Hubermann, and Saldana (2014), In Vivo coding “uses words or short phrases from the participant’s own language in the data record as codes” (p. 74). Descriptive coding was also chosen because it is also appropriate for a variety of qualitative studies and is a rather straightforward method of coding (Saldana, 2009). According to Miles, Hubermann, and Saldana (2014), descriptive coding “assigns labels to data to summarize in a word or short phrase - most often a noun - the basic topic of a passage of qualitative data” (p. 74).

After the interviews were coded, the initial codes were entered into an excel file with each interview in a separate column. Following the initial coding, I went through 
the excel file engaging in a second-cycle process of recognizing emerging patterns. As Saldana (2009) states "the primary goal during Second Cycle coding, if needed, is to develop a sense of categorical, thematic, conceptual and/or theoretical organization from your array of First Cycle codes” (p.149). After the first four interviews, however, as many as 35 separate patterns emerged, so I collapsed patterns as much as possible for a more manageable 11 patterns by the time I had completed second-cycle coding with all of 18 interviews. Once I had developed the 11 patterns, I then shifted the codes from the excel database to word document organized by each pattern. The next step was to further analyze the 11 patterns down to five prominent themes by collapsing some of the codes and eliminating other codes as outliers.

The five prominent themes that emerged were: strengths of a rural background, the need to develop one's own support network, the atmosphere and the environment of the institution toward low-income students, support to attend college, and impact of firstgeneration and low-income status. Once themes were recognized, I went through each theme and developed several categories within each theme. Once the categories were developed, an outline was constructed organizing the initial codes by theme and by category as the final stage of the prewriting phase. I also did analytic coding both during the initial coding phase, as recommended by Saldana (2009), but also after initial coding as well for two reasons. First, I wanted to separate the words, actions, experiences, and thoughts of the participants from my own feelings and interpretations. Second, there was also the need to provide analysis and feedback on the codes themselves. 


\section{Major Themes}

Five emergent themes were discovered after analysis of the data. The first theme that emerged was the importance of the support needed to attend college. The second theme that developed was the importance of the environment and atmosphere of the institution as it impacts first-generation, low-income students from a rural background. The third theme discovered the impact of one's first-generation and low-income status in regard to their experiences on campus. The fourth theme was the significance of strengths from a rural upbringing. The final theme that emerged was the need for participants to build their own support network. Within each of the five themes, several categories also materialized, which will be addressed in greater depth in this next section.

\section{Support to Attend College}

The final theme that emerged from the analysis of the data concerned the level of support to attend college for first-generation, low-income students from a rural background. Within this theme, three separate categories emerged: the degree of parental and family support to attend college; the level of peer and friend support to attend college; and the amount of community support to attend college. The first categorically area within this theme was the degree of parental and family support for each participant to attend college.

Parental and family support. Overall, the parents and family members of most of the participants were generally supportive of the student attending college. Laura spoke of her experiences growing up: “I think despite the fact my parents didn’t attend college, that it was something that was always very important for them... as early as I can remember college has been the plan.” She also states that despite the fact her mother 
really “doesn't understand” her experiences, "she is supportive nonetheless and it helps tremendously that I am able to call her whether it's a positive or negative day."

Likewise, both Auzmon and Connie indicated their families were both very supportive of them attending college while Diane reported that although her family is supportive they may not show it a demonstrative way:

I feel like they are very proud of me, but they don't say things out loud. Other people come up to me all of the time and say 'your dad brags on you all the time,' but he never brags to my face.

For another participant, Taylor, her family was not only supportive, but also served as a motivating factor for her as well:

My family, my dad was really proud of me, and my little sister, she wanted to one day come here...they were wonderful motivation, but now that they're gone, it's even more of a motivation, even more of a motivation to do what they really wanted me to do.

In similar fashion, Ann shared that while her parents did not push or encourage her to attend, which was common among many of the participants, that her family is very supportive of her effort in college and that her mom is proud of her and her accomplishments. For Erica, however, her experience was slightly different from many of the other participants where her mother gradually began to support her after initially being opposed to her leaving home for college immediately after high school:

My mother was very upset with me. She told me if I went there she would disown me, so I didn’t go there. My mom put a lot of guilt on me for wanting to go away to get an education. 
Similar to many of the participants, Monica's remarks were of a similar theme among many of the others, that of support, but not understanding the process:

So, sometimes when I would be super stressed about writing papers, because I am not good at writing very much, so I would call my mom and be like 'mom, I have no idea what to write for this English paper,' she was like, 'well, you'll get through it,' but she couldn't actually help me.

Parents are not the only ones in the family who can offer support, however. For Cynthia, her sister has also been a significant source of support: "whenever I was having issues coping with the college environment and the people I met, she would be the encourager to me.” She also spoke of what happened just before she arrived on campus: "they threw a party for me and my sister. They had cake, they had barbeque and everything for our going away party. They always speak highly of my sister and I.” Finally, Link shared that while his parents could not help him out much financially for college, they have been emotionally supportive and further stated: "I know that my parents would always try to do the best they could for me.” From these findings, while parents and other family members may lack some of the requisite knowledge to help the participants apply to and adapt to the collegiate environment, they remain supportive throughout the process, and this has been an instrumental factor contributing to the student's success. Parents and family are not the only ones, however, whose support can be paramount during the process, which brings us to the next category of the theme: peer and friend support.

Peer and friend support. Several of the participants also alluded to the fact that friends and peers provided a strong sense of support for them in attending college. While 
many students in low-income rural areas fail to attend college, Laura reported that a major benefit for us was her peer group in high school:

I ended up with a good group in high school, a lot of my high school friends went on to college. We were the AP kids, we were the ones taking dual credit classes...I just ended up with a group of friends that were planning to go to college similar to myself.

Likewise, Jason had a similar experience while in high school as he shared: “my friends were the top-of-the-class overachievers in high school, eager to begin college and making big plans.” For some participants, however, such as Diane, the influence and importance of those peer and friend relationships did not cease to be significant once arriving upon campus, as she stated regarding her first days on campus:

I just remember crying a lot and I remember my parents were upset as well because nobody in my family has ever left my hometown, I was the first. The words that I think of were overwhelmed and shocked, but it was okay. The only reason why I feel like I was okay was I had my friend with me, otherwise, I don't know if I would have made it up there.

Other participants such as Kyle, Cindy, and Taylor, also expressed similar sentiment of supportive friends whom may not have gone to college, but were strongly supportive of their friends' endeavors. Furthermore, Link spoke of how the competitive nature among his friends in high school was a driving force behind his eventually matriculation at the university. He further elaborated:

My friends, it was always a competitive thing, we all knew each other were going to go to college at some point, so I guess some of the competition kind of drove 
me to wanting to pursue a degree that I knew would be prestigious or valuable, so that's a reason why I wanted to become a doctor. Now, it's mostly because I think that is something I would enjoy doing, helping people, but back then, definitely, I wanted to be seen as one of the smarter of my class, so there's that competition.

Therefore, despite the influence of parents and family, peers and friends can also be highly influential toward first-generation, low-income students from a rural background in attending college. The final piece of support to attend college, the level of community support will now be further addressed.

Community support. The degree of community support is clearly not as influential as that of family or peers, however, community support can have an impact on a student attending college, particular within small, close-knit rural communities. Interestingly enough, Denise spoke of how while her home community was generally supportive, they were not as impressed with her choice of institution:

Everyone was really supportive of me going to college. They were not as supportive of me coming here. (My hometown) cheers for the (other state institution), so I would see people I knew just out and about and they would say, ‘oh, do you know where you're going to college?’ I would say, ‘yeah, I am going to the University of Louisville,' and they would be like, 'that's great, but we really wish you were going to (the other state school).'

Another participant, Ann, spoke of while she did not get any local financial support in terms of scholarships, etc., she did experience a degree of general support from her home community: "when the decision was made, and I got acceptance letters, people 
were really, really supportive.” Perhaps even to a further extent, Cynthia exclaimed that those in her home community went beyond support:

They wanted me to go, they wanted me to get out of there (her hometown), that's what they would say 'get out of here,' because I think a lot of people in the community feel very negatively about (her hometown).

In summation, while the influence of family and peers may be more important than that of overall community support to attend college, that support can have an influence. The positive impact of all three variables, however, can assist to overcome the obstacles, barriers, and challenges that first-generation, low-income students from rural backgrounds face during the application and matriculation processes. Furthermore, while student affairs professionals, faculty, and others in higher education administration certainly have a strong degree of influence over whether these students can be successful, we cannot underestimate the influence of those who are close to the lives of the students prior to their enrollment in post-secondary education.

\section{Importance of the Environment and Atmosphere of the Institution}

One of the prominent themes that emerged from an analysis of the data was the importance of the environment and atmosphere of the institution. Within this theme, seven separate categories emerged: the positive nature of the campus environment; the many resources available on campus; the opportunity for involvement on campus; the fact that opportunities can also be limited for those who are low-income; the need for greater knowledge and awareness about and for first-generation and low-income students; the need for greater communication on campus; and the impact on Cardinal Covenant. 
The positive nature of the campus environment. Many of the participants reported overall positive experiences on campus. Laura indicated during her interview that she believes the university has done well in working with low-income students and has done a relatively well in preventing any type of negative stigma or divide among students. Likewise, Jason also reported he believes the university overall is a positive atmosphere and climate for students coming from a low-income background. Similarly, Denise felt the same way:

I think it’s a really great climate and atmosphere for low-income students. I think there are a lot of opportunities for people who come from low-income situations. I know from personal experience and a lot of my friends who came from the same town as me that Louisville offered us more scholarships than almost any other school.

Also, just as Laura indicated, Denise does not believe there is a significant divide among students on campus based upon socio-economic status. Other students such as Connie, Ellie, and Cindy feel the university is generally a welcoming environment for low-income and first-generation students and also do not view any readily apparent biases or disparities based upon socio-economic status either. Furthermore, Jennifer compares her experience to where her husband received his graduate degree, at another large, research university in a neighboring state:

This isn't like that school where my husband got his master's degree. The culture there is very materialistic and so there were a lot of name brands and students driving Jaguars, a whole lot of conspicuous consumption, very obvious who had money and who didn’t and here you don’t really see it as much. 
Other participants, such as Monica offered her perspective: "I think there are a lot of good ways to help pay for college if your parents aren’t going to help you pay for it. I don't think there are any social stigmas.” Finally, Link also echoed these sentiments during his interview stating he does not notice or have a great awareness of income disparities on campus: “I don’t think us college students, or the ones I hand out with at least, are thinking about the money we have now, but we are thinking about the money we could potentially making in the future.” He goes on to state he feels the university is can be a positive environment for low-income students:

For the most part it wasn't unnerving to come here, it wasn't much of a culture shock. I eased in relatively easily. The programs they have here, they have the TRIO program, things like that, I can obviously see that the university is trying to change it for those students so they can do the best they can.

While there were certainly challenges faced by the participants of these interviews, many of which will be addressed later, the general belief from the interviews is that the university presents a generally positive environment for students from disadvantaged backgrounds, particularly in regards to low-income. Obviously, improvements can still be made, and many participants emphasized a lack of emphasis or attention addressed to first-generational or rural status, and also acknowledgement that without their scholarship or financial aid packages, it would be impossible for them to attend due to the high cost of tuition. This leads to discussion of the next category, the many resources available to students on campus.

Many resources available on campus. The vast majority of participants indicated they feel there are more than adequate resources available, not just for the 
general student population, but also for low-income and first-generation students on campus as well. Denise, Connie, Erica, and Cindy all referenced the tutorial center on campus as a place for students to go who needed academic assistance. The career center on campus was also specifically referenced and Kyle had this to say about his experiences: "coming from a smaller area we never really had much on resumes, so they get everyone in touch with (one of the career coaches), so he can help with resume writing.” Kyle also added that there are numerous workshops and seminars on campus to help students who are struggling or just may need a little assistance.

Monica indicated in her interview she strongly believes the resources are here on campus in order for any student to be successful. She further elaborated:

I feel like everything is set up for you to succeed. I don’t think that anyone fails a class if you go to class. Honestly, if you go to class you are not going to fail, and if you do it’s because you didn't try and you didn’t want to pass.

Finally, Link spoke of how he had made use of the counseling center, which was strongly beneficial to him. He stated:

I would say that it was relatively hard my sophomore year because I had a lot of emotional problems, because I was starting to be faced with emotional challenges...my school work started to decline because of that and I didn’t really have a support system. So, I felt isolated a little bit and I could see how that could be very detrimental to someone's experience, because it was very hard for me to get through that. But yeah, I got through it with the help of the university, the faculty, and the counseling center. So, definitely, the resources were all there, but 
that was the challenge I went through, but that was probably my hardest year of college so far.

The overall impression from the interviews from the participants is that the resources are here for students to take advantage of, but that ultimately it is also up to students to reach out and take some of the initiative, which can sometimes be a challenge for students coming from a low-income, first-generation, and rural background. This brings the discussion to the third category within the theme of the opportunities for involvement on campus.

Opportunities for involvement on campus. Involvement on campus is certainly important not only for students from at-risk backgrounds, however, it can be much more significant in providing a needed support network and also provide a degree of accountability. Connie discussed the accountability piece further in her interview:

I am actually a part of sorority. They definitely push you to the limit with your time management and your scholarship. If you don’t have above a 2.5, you get kicked out basically. I obviously have way above a 2.5 , but we meet weekly to do homework. We do community service within campus and outside of campus as well.

Likewise, Cindy echoed the sentiment of the importance of being involved in an organization on campus that holds one accountable: "you have to maintain a certain GPA to stay active in my organization," and stated she feels it is good to be involved with "any group that holds you accountable academically.”

Many participants also believed it was easier to be involved at a large institution than a smaller school. Diane, who had already enrolled at two large research institutions 
asserted: "I feel like that is an advantage of going to a bigger college as opposed to a smaller college where I don’t feel like they really have that much.” Furthermore, Ellie also agreed with this sentiment when she stated the following: “I wouldn’t want a small school, I don’t like small. I feel like it breeds less opportunity and also it's just...I guess it just relates back to opportunity.” Of all of the students interviewed, almost all of them were involved in some group or organization either on campus or within the larger community. Although it is a well-researched area, findings from this study indicate that involvement is important for first-generation, low-income students from a rural background and the findings also indicate there are a wide variety of opportunities for involvement on the university's campus. The next discussion involves the fourth category of the theme, that opportunities can be limited for low-income students.

Opportunities for involvement can be limited. While the university has many opportunities for students to be involved on campus, several participants reported that finances can limit involvement. One participant who indicated this was Laura who addressed her concern:

A big one for me was sorority recruitment. I don't necessarily think I would have been in a sorority, but I never had the option to find out, I never had the money or the resources to do recruitment in any shape.

She further states that this can be frustrating at times: "the university offers a lot of encouragement to participate in those things but very rarely is there any form of financial assistance related to those.” Ann was another participant who took issue with the amount of money it took to participate in activities and within organizations on campus: 
I don't buy season passes (for athletic events) because it’s not really possible to.

Those are very expensive, when you have to make a choice. I didn't participate in Greek life, because when it came in it was close to $\$ 1000$ to rush in a sorority, I don't know what it is now, but that's a lot of money to participate in certain things. I didn’t do Study Abroad because I didn’t think it was possible and I had other priorities for my money to go to.

Limitations for involvement, however, are not necessarily limited only to cost, but it can also be difficult for low-income students to find the time needed to participate. Jason indicated his greatest obstacle was balancing maintaining his grades, often working multiple jobs to survive and afford his education, as well as be involved. Similarly, Cynthia expressed concern of this as well in the following statement:

To be honest, if I am not in school, I am at work, and there are so many things going on in the community right now that I want to participate in, but I can't because I have school and I have to work. So, I would like to participate in voter awareness and I would like to be able to go to LGBT or black friendly resources within the community, but I work and go to school and I am exhausted.

Overall, participants in the study all saw the importance of being involved, however, many of them experienced limitations to this involvement due to both finances and time constraints. This brings us to the next category within the theme of the need for greater knowledge and awareness for and about first-generation and low-income students on campus.

The need for greater knowledge and awareness for and about firstgeneration and low-income students. A very common sentiment among many of the 
participants is while the university focuses a great deal on the issues of diversity on campus, two things are needed. First, a greater knowledge should be provided of the demands and challenges of college for first-generation, low-income, and rural students. Second, a greater awareness is needed of the needs and concerns of these student populations on campus but the larger campus community.

Participants felt that while resources were available, more information and greater knowledge should be imparted to students from first-generation, low-income, and rural backgrounds. Laura asserted that more communication and sharing of knowledge about the experiences of first-generation and low-income students needs to occur at the university. She was also very clear that communication needs to occur early with these students:

If we can even have some programs, get to the students before they get to campus from orientation or earlier and say, 'here are some tips, here are some things they are not going to tell you when you are packing for orientation that you need to know, here are the things you need to know moving in. The university isn't going to say 'sometimes people aren't going to like you because you have work-study,' but there are those people who don't understand what it's like to have to work when you are in college. Someone needs to tell students about that. Denise also expressed similar thoughts stating she feels there needs to be more focus on both first-generation and rural students, stating that her rural identity by itself makes her feel like a minority on campus. She also added that she believes the university assumes all students come with a basic understanding of how college works, which is not 
necessarily the case. She also goes on to explain why she thinks even a separate part of orientation might be needed for first-generation students:

I think maybe a separate part of orientation to talk about ‘hey, your parents aren't going to know what you are going through and that's okay...just kind of explaining some of the difficulties of being a first-generation college student, like you are probably not going to be able to ask your family for help, but there are people here who can help you, or 'your parents aren't going to know how to help you register for classes, but here is someone who can help you.

Diane was another participant who shared her thoughts regarding this: "so, I feel there should be something to just grab a hold of first-generation college students to walk them through how to navigate, things like that.” Likewise, Jennifer also felt a separate orientation for first-generation students might be needed: "or at least a meeting or something and be there to let them know someone is here you can contact to learn how to navigate everything." Furthermore, Kyle stated he felt the university needed to offer more career oriented workshops and budgeting workshops specifically aimed at firstgeneration and low-income students who have challenges with such issues coming into college. Clint asserted that perhaps a freshman orientation class specific to Cardinal Covenant students or other low-income students which would address concerns specific to that population would be helpful and Cindy felt the university could offer more resources specifically for students who are first-generation, low-income, from a rural background. Finally, Monica felt that advising could definitely be improved, particularly for first-gen students who cannot rely upon their parents: 
I took all of these stupid 100 and 200 level classes because they were like 'oh, you have to do this gen ed,' but I should have taken a 300 level class that was actually going to count for something other than a gen ed.

It was not solely concern among the participants, however, that the incoming students be exposed to greater knowledge and information, but also that those already on campus, including faculty, staff, and current students who are not first-generation, lowincome, or from a rural background have a greater awareness of the concerns and needs of these student populations. Jason had concerns initially from his orientation experience feeling already like an outsider: "they repeatedly assumed everybody in the audience had a cell phone." He also added: "the school does not seem to understand how some of us had to finance our own way through our education without help from home.”

Ann shared throughout her interview how low-income students can be at greater risk for mental health concerns and stated: "I think this university, and maybe all colleges take for granted normal functioning families.” She also added the university does not advertise their psychological services to students nearly as well as it should and believes that while resources do exist, navigation, particularly for first-generation, low-income students from rural backgrounds can be particularly challenging. She believes the university is slowly and gradually beginning to recognize students from these backgrounds and that "if you want your university to be successful, you have to recognize these students.” In the same fashion, Michael believes there is a lack of realization among many on campus regarding the sheer number of low-income students on campus: "there is kind of perception that college students come from a more 
privileged background," which Michael states based on his experiences is certainly not always the case.

Finally, Cynthia shared she feels like there needs to be a greater awareness of resources on campus, but also a greater awareness of the challenges and obstacles that many first-generation and low-income students are facing when they come to college. She also states that while she believes the university does a well in addressing other types of diversity on campus, "there needs to be more diversity in the sense of socio-economic status.” Once again, findings here point to two concerns, more knowledge and information to provide to incoming first-generation and low-income students, while also a need for greater awareness among others on campus of the needs, challenges, obstacles, and concerns of these students once they arrive on campus. The continued conversation leads to the next category within the theme of communication campus.

Communication on campus. Unfortunately, one of the significant challenges at a large institution can be the lack of communication on campus, as expressed by several of the participants of the study. Also, unfortunately, while continuing generation students, those who are higher income, or come from more urban and suburban areas may have resources and knowledge to assist them with guidance, this lack of communication can be particularly detrimental to students who are first-generation, low-income, or from rural areas. Ann expressed her concerns, feeling there is a lack of connectivity between various offices on campus and believes more connectedness on campus would benefit all students, but certainly those students who are low-income. Furthermore, Jennifer expresses a similar sentiment, feeling at times she has been given the run around on campus, stating; “the right hand doesn’t know what the left hand is doing all over 
campus, it's very frustrating." She also adds that the lack of communication has made school at times a very challenging and once again frustrating experience for her.

Finally, Monica describes her experiences she has had, feeling that it can at times be difficult to access information on campus:

I think that advising could be better and I think that, I know you are required to meet with your advisor your freshman year and maybe the beginning of your sophomore year, or something like that, but they should do more of that because when I was trying to get into Business school, I didn’t know for a really long time that they changed it from a 3.0 to a 2.8.. So, I could have been taking classes that I needed a semester earlier because I assumed since that is what I read online that I didn't' need to talk to anyone, but that wasn't actually correct. I think making that mandatory would have helped me.

Once again, while in general, most participants were positive with what the university was doing, a need for greater communication was certainly expressed as an area of improvement. This leads to discussion of the final category within the theme, the importance of Cardinal Covenant.

Cardinal covenant. As addressed in the first chapter, Cardinal Covenant is program on campus that covers full tuition, books, room and board for eligible in-state students. It decidedly can provide an advantage to the recipients and alleviate many financial concerns these students would otherwise have. That being stated there were also other participants who were recipients of other forms of financial aid including different scholarships. Through many of the participants' statements, it is apparent that Cardinal Covenant is benefiting students in many ways other than financial by teaching 
them how to budget and manage their aid, as well as provide a sense of community and support.

Laura freely admits that without Cardinal Covenant, she might not be able to attend the university:

This program, this scholarship, it's a beautiful thing that they found that made it possible and I think even on a lower scale if we could find something like that in other universities, in other colleges, it would allow more students to, who are interested to attend some of the larger universities.

Likewise, Taylor reports she has found a family within Cardinal Covenant and spoke of how the program helped her to get through a personal tragedy:

They took me in with wide arms, they helped me through the hardest time of my life. They pulled strings for me, made it to where I could drop below full-time and still keep all of my grants and scholarships, so it's been very accepting, very accepting.

Finally, Monica attributes her comfortable living conditions on campus to Cardinal Covenant in many ways:

I live in one of the nicest housing (units) on campus and some of my friends, their parents had money and they lived in (not as nice) of a residence hall. It was a really good deal for me, but it was kind of like I didn't really earn it, but I like that I got to live in a nice apartment on my own.

As evidenced by many of the participants’ statements, the atmosphere and environment of the campus toward low-income, first-generation students from a rural background have a large impact on their experiences on campus, which was the first 
discovered theme emerging from this study. The second emergent theme will now be addressed.

\section{Impact of First-Generation and Low-Income Status on Campus Experiences}

A second theme developed from an analysis of the data was the impact of firstgeneration and low-income status on the students' campus experiences. Within this theme, four separate categories emerged: their statuses serving as impetus for these students to want to do better and be successful; feeling lost or lacking in direction because of the inability to rely on one's parents for guidance; the noticing of significant differences between themselves and their classmates; and the continual facing of financial challenges.

Statuses serving as impetuses for success. Several of the participants reported that their status as a first-generation college student and their status as coming from a low-income background both served as powerful impetus for the participants wanting to do better than their parents and to be successful. Laura was one participated who stated this directly:

The thing that keeps me going when I am overwhelmed or feel like I don't want to do something, I think about providing a better life for myself and my family than what my parents were able to give me.

In similar fashion, Auzmon reported that a large part of his motivation was fear because he had seen what poverty and low-income are like and that these aspects of his background are pushing him to obtain his degree. Likewise, Diane stated: "I am definitely more driven because I am a first-generation college student,” and Kyle indicated that he learned the value of saving money early, learned to work for what he 
had, and that his experiences as growing up as low-income taught him to be frugal.

Furthermore, Clint asserted that the major asset and strength he developed in coming from a low-income background was money management and his first generation status cultivated a degree of determination he might not otherwise have. Taylor also stated she was motivated a great deal by wanting more than she had growing up in eastern Kentucky, and Ellie made a profound statement regarding her experiences: “I have seen what it is like to underestimate the value of an education, so I consider that to be a huge driving force to do better and to be better."

Similarly, Michael credited his parents with teaching him frugality and said that when he makes purchases, he always questions whether or not the item is necessary. Ann also reports that because her parents did not push or encourage her to attend college, she has always had to rely on her own internal motivation and internal "drive” and that being a first-generation college student means one is "constantly trying to move forward.” Furthermore, Jennifer was motivated to be successful by watching her mother's experiences "having to work ten times as hard" as those who had education, while Erica stressed the desire to do better than her parents has also been an impetus for her. As with many of the other participants, Monica also told of a similar theme: "because my parents didn't go to college, they kind of haven't had good jobs and so it makes me really want to graduate college and want to do better than they did.” Finally, Cynthia indicated a motivating factor for her as been the sense of pride she feels in being the first member of her family to go to college. It was rather clear following the interviews, that most of the participants felt their experiences growing up as a low-income and their status now as a first-generation college student, were motivating factors serving as major impetus for the 
success. The discussion now shifts to feeling lost or lacking in direction because they could not rely upon guidance from their parents.

Feeling lost or lacking in direction. Many of the participants indicated feeling lost or lacking in direction because their parents had not attended or graduated college and they could not rely upon those experiences as other students could. Laura was one who indicated this, stating she felt she "stepped into it blind" in regard to coming to college and notices that compared to other students her lack of knowledge can sometimes be a barrier for her. Likewise, Auzmon described his experiences when he first began:

I didn’t know what I wanted, why I was going to college, it was just what you did...after high school you just went to college, not because you have direction, but that's what everybody tells you that you need to do.

Also, by comparison Jason reported that his family never encouraged or valued education and that his college application process was rather daunting: "nobody in my family had ever made a resume, applied for scholarships, filled out FAFSA, or written admission essays. I felt alone.” Similarly, Denise realized she lacked certain knowledge from the very beginning and that her parents could not prepare her for her experiences in college. She further expounded:

They don’t really understand what I am going through and that I have accepted a co-op offer, and now I have to move and we have lived in the same house our whole lives right next door to my grandparents; we live in the house my greatgrandparents built. So, I have been looking at apartments, trying to get everything settle, opening a new bank account, lots of different things like that to prepare to move and it seems like no one can really help me, just because they don’t know. 
They're as blind as I am, so I think that has been one of the most difficult things to go through, just doing things like that and they have no idea what it's like or what I am going through.

Diane also expressed the same sentiment in regard to her experiences: "I wish I had known how to navigate scholarships and how to navigate the basic college stuff, how to do it. I had to learn that on my own.” In addition, Diane indicated that her family cannot relate to her experiences, and although they are generally supportive, it is difficult for them to provide any significant advice she can apply to her collegiate experiences. She further exclaimed:

I have a professor here that I am really close with and her daughter is in graduate school too. She sat me down one day and said 'you know, I thought about something, when my daughter has trouble she can call me about and she knows I will understand, and I know that you have experienced this because you have told me you have called your parents and they have no idea. I thought about it last night and it kept me awake because here we have this southern girl who is working twenty times harder than anyone here. I just want you to know you are appreciated for not having that support,' and she said, 'but I am here, if you need a college mommy, I am here.”

Other students continued to express similar sentiment as Connie relayed that she also had no one to rely upon during her application process, and added: "it's a good thing and a bad thing when you have to learn how to do stuff like that by yourself.” Taylor added that often being a first-generation college student means fearing the unknown and Ellie clearly stated there has been a lack of understanding from her family regarding her 
collegiate experiences. Ellie added: “they can’t really advise you and they don’t understand fully the experiences for having the good and the bad, the struggles and the happy points, they don’t understand the end game.” Furthermore, Michael reported specifically what challenged him when he first came to college is that he was not familiar with much of the terminology used. Ann was also clear about her experiences as a firstgeneration student:

I have had to figure out a lot of things on my own being first-generation. My parents didn't know how to fill out a FAFSA or admission expectations, or even as simple as something like putting a resume together. I had to figure all of that stuff out on my own. I have continued to have to figure a lot of things out on my own. I haven't gone to my mom or my grandparents to ask them or be like 'hey, how do I do this?' because of them having never done it, they have no idea what is going on.

Another participant, Jennifer, discussed how she initially struggled on her first attempt to college because she had no one to guide her and she has had to educate herself on all of the resources available to her. Likewise, Erica feels the lack of connections for first-generation student can be a significant barrier and also believes first-generation students can be more susceptible to money troubles, credit card offers, and other financial challenges once on campus. In providing a similar perspective, Monica referenced how it was difficult to her to reach out to various resources on campus but she used to relying on her parents. She further elaborated: 
I didn’t want to go to a tutor or ask some random person to help me with a paper, so I think that people, like some of my friends that could go to their parents for help, I wish I had that.

Similarly, Cynthia, who is in her first year of graduate school, relayed her frustrations in feeling unprepared in applying for graduate school. Finally, Link added he feels a certain separation from his family due to his college enrollment, stating that "I am kind of off on my own here.” Additionally, Link stated that college for him was a constant learning process. Although not a surprising finding, the lost feeling and lack of direction in both the application and matriculation college process was certainly a key categorical finding of this particular theme. This brings the discussion the differences noticed between participants and their classmates.

Differences noticed in comparison to classmates. Another key categorical finding of this theme was the differences noticed in comparison to other classmates. Every participant indicated at one time or another significant differences became apparent between themselves and other classmates either continually generation or of a higher income status. First, Laura indicated she can sometimes feel left out due to her finances and that for her, working while in college is a necessity, while she notices that for other students it may just be to earn "extra money." Additionally, Jason stated that he has had a great deal of shame regarding his past which has made it difficult to get close and establish relationships with others. Furthermore, Diane shared her experiences when she first came to college, noticing how different she was from many of her classmates:

All of the students kept talking about how their parents were paying for their college and they didn’t have worries, and they all went out and partied. I was just 
like 'I have to worry about just feeding myself' and I think that's when it hit me 'I don’t really have a fall back and they do.

Also, similar to Laura’s statement about working, Diane added: “I’ve had to work ten times harder than everybody else and nobody else understood why I worked three jobs during undergrad, because I had to.” Other concerns have been related to differences in clothing and also differences in technology used.

On her experiences growing up, Connie elaborated: "I was kind of jealous of the kids in school who got brand new clothes and stuff like that.” Likewise, Clint referenced that he has noticed differences in fashion on campus between those students from a rural background and those who are not. Ellie addressed this issue perhaps even more specifically: “their dress down clothes are better than my dress up clothes.” Technology also stood out as a key difference as Clint, Michael, and Ellie all addressed this specifically in their interviews. Some of the significant differences, however, have been more subtle.

Diane indicated there have been times when she has felt inferior compared to other students based upon her first-generation, low-income, and rural status and Ann added regarding her experiences as a low-income college student: “you don’t want to confirm everyone’s suspicions... we keep ourselves pretty hidden.” Taylor stated she believes a big part of the problem is the lack of understanding by other students about needs of low-income students on campus. Furthermore, Jennifer added that she has had a difficult time being social with others on campus due to her lack of finances. Cynthia addressed the issue and divide between herself and her classmates even further: 
I have a lot of socio-economic stuff going on because I have people in my classes that talk about how their dad is a lawyer, and their dad or mom is a scientist and 'because my dad is a chemist, he helped me with Organic Chemistry.' I am just like, 'what do I even say to that, I don't even know how to relate to that.' Another commonality shared was the lack of appreciation by other students that many of the participants felt existed. Link indicated that he believes his friends often take their finances for granted and don't have the same worries about the combination of academics and finances, believing that his has made him more money conscious than other students because of his background. Similarly, Michael stated he believes that many students whose parents graduated from college think college is easy and do not take their collegiate experience seriously enough. Also, Michael asserted that he notices a sense of entitlement among many continuing generation students and feels firstgeneration students often have a greater awareness of the struggles and demands of attending college. Finally, there can be a negative stigma on campus toward low-income and first-generation students, even if subtle. Kyle asserted the following:

A lot of people don’t usually refer to students who are low-income as lowincome, usually the first word they say is 'poor,' and that has negative connotations in itself there...low-income is a much better word to use, I would like that word to be used more often.

Furthermore, Cindy indicated the need to not stand out as separate and blend into the larger campus community, echoing the sentiments of Ann earlier. In a couple of instances during her interview, Cindy stated that as a first-generation, low-income student 
you often have to "fake it 'til you make it." Finally, a fourth category that developed with the theme was the continual financial challenges while attending college.

Continued financial challenges in college. Many of the participants in the study continued to struggle with their finances even after enrolling in college and even if they are receiving financial aid or scholarships. Laura expressed that her and her mother are facing some financial challenges recently since her mother and been laid off from her position about six months prior and had moved in and out of menial labor jobs since that time. Likewise, Auzmon reported that financial obstacles continue to his greatest challenge in obtaining his education, while Jason indicated this: "at one point, I was working three jobs to keep myself fed, housed, and able to afford the astronomical financial burden of post-secondary education.” Furthermore, Connie described her experiences in college:

I am like the cheapest person ever on top of being low-income, so a lot of the stuff kids do like go out, go to the movies all of the time, I don’t do it just because I don't have the money to do it. Books are also a major thing, so when books are released that makes my budget even tighter, which makes it hard to get by every month.

Similarly, Ellie stated that stressing out about finances impacts her academic success and that even though she is a Cardinal Covenant student, basic necessities can still sometimes be a concern. Additionally, she has found budgeting to be a challenge in coming from a low-income background:

Being from a low-income family seriously affects your ability to budget. I have been a very prime example of that because as much as I try to save money, I just 
don't feel like it happens. I don’t know what my system flaw is, and I have very well crafted the art of saying no. Like, if I want something on a whim, I am like 'no' and still yet there is no money in the account and I don't know what happened. I used to have two jobs, technically three, but I had to stop because it was stretching me mentally thin and I am back to having one income. It's a struggle.

It is important for others to realize that coming from a low-income, and a firstgeneration background, as well as a rural upbringing can still impact students even after matriculation. The impact of low-income and first-generation status cannot be overstated based upon many of the participants' experiences. The discussion now turns to the third emergent theme from this study, participant strengths as a result of a rural upbringing, or rural strengths.

\section{Rural Strengths}

A third theme developed from an analysis of the data was the strengths developed from a rural upbringing. Within this theme, three separate categories emerged: rural social skills; work ethic, and a strong sense of community. The first categorically area within this them was the development of rural social skills.

Rural social skills. Many of the participants reported the development of what I refer to as "rural social skills" as a strength and asset from their upbringing. For Auzmon, this meant often having to make a greater effort to engage with others with "everything not being densely populated, being spread out organized activities were harder.” Denise, however, was more specific in regard to her experiences as it related to this: 
One aspect of my personality is definitely being from a small town is I will talk to anybody, I don't care who you are, where you came from, what your name is, but we can still have a conversation, I am one of those people that says hi to everybody.

She also believes that her rural social skills have helped, particularly when it comes to communicating with faculty: "I am still pretty outgoing and friendly, and I definitely think that has helped me in college. Diane was another participant who attributed a portion of her success to the social skills she learned growing up in a rural area: "the social skills I gained in a small town where everybody knows everybody, so you get good at talking to people and I feel better in small towns. People are so cold in the city." Clint also believed that he was friendlier than others on campus because he is specifically from a rural area. Likewise, Taylor attributes her friendly nature to her rural upbringing and notices differences between rural and urban hospitality. She also adds: "when you meet someone else that's from a rural area, you generally click with them." In a similar fashion, Ann believes she has a "small town charm" that has helped her on campus, as she further elaborates: "so, having that personality where I am open to talk to anyone. I feel like that is a rural thing, you get that sense of community where you are really good at it and you can build it anywhere.”

Additionally, Cindy indicated that growing up in a rural area:

It taught me a lot of perspective, just communicating and interacting with people on campus and my professors; that has been very beneficial and to always stay curious and if I have questions to never accept the first answer. 
Echoing a similar sentiment to the other participants, Jennifer also believes her rural way of life has taught her certain social skills: "it's taught me to be more friendly, to be more outgoing...there everybody knows everybody.” Another participant, Monica, also felt the same way, attributing her social personality to much of her success on campus. Finally, Link indicated that he believes he is able to relate to and connect with people and that is rural upbringing has led to him placing a priority on relationships with others. Unlike many of the other findings from the study, with social skills being somewhat of a surprise and not really something I expected to emerge from the study. This leads the discussion to the second strand within the rural strengths theme: that of the rural work ethic.

Work ethic. While first-generation and low-income status, for many of the participants, contributed to their work ethic, many also attributed that rural upbringing for their work ethic. One such example was Denise, who stated the following:

I wasn't one of those people that always got everything I asked for. I had to work for a lot of things, I have had a part-time job since I was 16 years old. So, just realizing that no one owes me anything, sort of, and I have that small town instilled in me that you have to earn what you get. I think that mindset has really helped me that once I moved to college to know that these people don't owe me anything, I have to earn their respect, their trust, my grades, that sort of thing. I think that has been the most beneficial thing about being from a small town. She further elaborated: "I realize I have to earn everything I get here, I am not guaranteed anything, they don't owe me anything, so I think that's the biggest difference,” when she compares herself to other students from different backgrounds. 
Denise, however, was not only student to attribute her rural background to her work ethic. Diane also believed her parents instilled a strong work ethic in her early from her growing up on a farm. Similarly, Jennifer referenced the self-sufficiency of her family, making their own clothes and making do with what you had, as she stated: "we just grew up that way, you keep using something until there is nothing left of it, you don't just throw something away.” Finally, Erica attributes her hard working mentality as well to her rural upbringing.

Once again, it should be duly noted, that work ethic is often attributed to a working class mentality. The reason I list it here under rural attributes is because first, many of the participants made this connection in their responses, that their work ethic was due in large part to their rural upbringing, and second, Schutz (2003) also makes this connection in his study of one's rural background contributing to his or her work ethic. It would be naïve to suggest that participants' rural background is the only characteristic of their personalities that has contributed to their work ethics, however, based upon their responses, it is certainly a contributing factor for many. In addition to the "rural social skills” and the work ethic from a rural background, these participants from rural areas also gained strength from the strong sense of community from which they came.

Strong sense of community. Another powerful category within the rural strengths theme was this strong sense of community. Many of the participants noticed their home communities came together and provided a sense of support not evidenced or witnessed in urban communities. Auzmon discussed how his community back home commonly comes together to help one another and mentioned specifically how neighbors 
helped he and his father with the roof on their house a few years ago. Additionally, Diane referenced the strong sense community she felt back home:

I love that sense of community, you don't get that in a big city. I walk down the street (here in the city) and people don't know you from Adam. Out there (back home), ...literally at almost every booth I stopped to talk to someone I knew and they told me they were proud of me.

That sense of community Diane feels is also a reason that she wants to return home after finishing her education, a feeling that is not completely understood by certain faculty and physicians in the medical school: "they tell me I am wasting my potential and ask me if I realize the impact I could have on people, and I tell them I do, and that's why I want to go rural.” Other participants, such as Connie and Erica, described themselves as coming from a "tight-knit community," and Taylor still maintains a strong connection with her home. Likewise, Cindy discussed her experiences: "since everyone is so close you have a stronger support system I think than if you grew up in an urban area where everything is really fast paced.” In a similar fashion, Jennifer states one aspect of her rural identity is “you've always got a strong home base to go to," and also further elaborated: "if I ever go down there and needed a place to stay I know I could knock on any of those doors.” While at times it was difficult for participants to attribute experiences as relating more to their first-generation, low-income, rural background, and often other statuses, the findings of the study indicate that one strong theme which emerged was that a rural upbringing attributed to certain strengths divided into "rural social skills," work ethic, and coming from a strong sense of community. The thematic 
discussion now turns to the fourth emergent theme from this study, having to build your own support network.

\section{Building Your Own Support Network}

A fourth theme developed from an analysis of the data was the need for firstgeneration, low-income students from a rural background to build their own support networks once on campus. Within this theme, five separate categories emerged: lack of reliance on family or those back home for support; establishing important connections with faculty and staff on campus; becoming involved in the campus or larger community; establishing significant connections with other students on campus; and taking advantage of available resources. The first categorically area within this them was the lack of reliance on family or those back home for the necessary support.

Lack of reliance on family or others in home community. Several participants in the study indicated they realized early on they would need to reach out to others on campus because they could not rely upon family members, friends, or others from their home community. Laura was one participant who addressed this when talking about one of her major obstacles as a student: "there are a lot of big decisions I have to make on my own...I don’t have that family backing. They aren’t necessarily lacking in encouragement, but lacking in knowledge, that's probably a big one.” Denise also discussed how she has to rely on those on campus for support and resources:

I wanted to minor in Math at one point, that's something you can’t ask your parents, 'hey, dad, what if I minor in Math?' He would be like 'minor in Math, what's that?' Just things like that or if I asked 'hey, dad, what if I took Differential Equations with Work Designs?' He doesn’t know. 
Other participants expressed similar concerns, whether it was Diane worried she would not have the same support system she had back home if she had a car accident, or Connie, who reported having grown distant from her friend back home. Ellie also expressed a similar sentiment, stating: "it's different when you don't have family support and you have to have your own built in support.” Furthermore, both Ann and Jennifer indicated they have had to build their own support network since arriving on campus. Jennifer elaborated by stating the following when asked about her greatest obstacle in being successful as a college student: “just the support, gathering support (that her family has not been able to provide), and I have done that by marrying a college graduate, surrounding myself with friends that go to college, and feel that education is very important.” Finally, Link spoke of his experiences in relationship with his family in relation to his collegiate experience: “they don't know how to relate to me I guess, so a lot of that support came directly from me and those immediately around me here and not just my family." While the participants were not able to often rely on family members or those back home, they would then turn to connections and support on campus.

Important connections with faculty and staff on campus. Of significant connections students can make on campus, those with faculty and staff can be particularly important. Participants such as Laura and Auzmon see the faculty on campus as generally approachable and as great resources, but Jason goes a step further with his praise:

I know the faculty and staff here are unique, genuine, and invested in the lives of the students - that is the reason I chose to come here. I continue to believe it to this day. My mentors are the reason I have been able to study in the National 
Student Exchange in Los Angeles, travel abroad to study in Greece, and begin the process of applying for graduate school.

Additionally, Diane believes there is also a great deal of faculty support within her program, stating the following:

Now that I have been here, my professors have just cultivated me so much, they have really empowered me. They are like 'look at who you're becoming' not that I am better than my family. They even said 'look at how you are embracing this and we wish every student had as much motivation as you.'

Furthermore, Diane also expressed how she had maintained strong personal connections with past faculty from a previous undergraduate major, one in which she did not even persist with:

They really motivated me...they were so glad I dropped out of Architecture and glad I was going into the medical field to work with children, they thought I would make such a wonderful impact and said 'we love you and we support you.' Likewise, Kyle feels he has sources of support on campus he can speak with and meet with, believing it is important to make connections with faculty. He also advises incoming students from a similar background to "get to know your professors background, I feel like that helps because you can find who you relate to the best.” Similarly, Ann mentioned her relationship with a key faculty member on campus:

She really pushed me and she opened my eyes to different cultures, teaching me how to explore and research while being comfortable with having a voice in the academic world, which is something difficult to do, being comfortable with having an academic voice. 
It is not just faculty though, Taylor spoke about her experience with a certain staff member on campus:

If it hadn't been for Tom, I wouldn't have known what to do, so he has been the one person that has really helped me through the transition because he has been there, answered calls and e-mails, sometimes even text messages when I have no one else to ask.

Furthermore, Ellie referenced the importance of relationships she has also established with both, including mentors and role models she has connected to through organizations outside of campus, while Michael has also made connections and places great importance on his relationship with faculty in helping with his future possibilities as he plans to pursue his doctoral degree. Other participants such as Jennifer, Cynthia, and Link also referenced how significant their faculty connections are on campus and how these connections have been paramount toward their successes. The importance of the connections with faculty and staff for students cannot be understated, and based upon the particular findings within this category on this theme, certainly not underestimated for first-generation, low-income students from rural backgrounds. The next category within the theme of developing one's own support network is being involved on campus and, in some cases, the larger community.

Involvement on campus and within the community. While participants in many ways have had very different experiences, one of the primary commonalities shared across participant stories is involvement on campus and in the greater community. Participants such as Connie, Kyle, Laura, and Auzmon have all been involved with local 
community service projects and initiatives, while Jason spoke of a variety of experiences with his involvement on campus and how that has also benefitted him academically: I'm very involved in the campus community (residence life, Greek-letter organization, registered organizations, office advisory boards, hearing council, etc.). This involvement dramatically influenced my educational experience because it encouraged me to remain active within the campus community and focused on my education.

Similar to that, Ellie has a great deal of advice for students from a first-generation, low-income and rural background when she states:

Get involved and stay involved. The more eyes you have on you, the more people you have to impress, the better you are going to perform as an individual because you won't have the support probably, you won't have what everybody else has.

She goes on to say: "there have been a number of other organizations I have been involved with a semester or two at a time. There have been a total of about 10 organizations officially.” One participant, Monica, now realizes in hindsight she should have been more involved than she was as she closes in on graduation: "I realize I should have been in more activities that I could add to a resume.” Other participants have also become involved in various academic clubs on campus. Diane reported she serves as the president of an academic student group which has helped her with her leadership and organization skills. Likewise, Jennifer and Cindy have also found their main outlets for involvement on campus through academic clubs within their majors. In slight contrast, however, Michael, who was very clear throughout his interview that his sole purpose at the university was to obtain his degree and not experience student life, stated his 
involvement in his academic student organization as: "it's more about the networking and less of a distraction.” Finally, although there are many possibilities for involvement and engagement in campus, one drawback Taylor states is: “if you don't have the money or time, it’s going to be difficult to find somewhere to really fit in."

Succinctly, student involvement was reported by many of the participants within this study and most participants found ways to be involved either on campus or within the community, although this is not without limitations for first-generation and low-income students. Also complicating matters can be low-income students having to balance work, school, and involvement in addition to other responsibilities. In continuing through the theme of building one's own network at college, the next categorical discussion focuses on making informal connections with other students on campus.

Making informal connections with other students on campus. While connections with faculty and staff, in addition to involvement in various student groups and organizations on campus, establishing informal connections with other students on campus can be also be beneficial in a first-generation, low-income student from a rural background developing his or her own support network on campus. Diane believed making a connection with students like herself was important when she befriended members of a fraternity of guys with from a similar background when she was an undergraduate: “I fit in, oh my gosh, I fit in, everybody talked like me, had the same background as me, that was little bit of a motivation for me.” Laura stated while she believes it is important for students from a background similar to hers to make connections with students who are both from a similar background but also a vastly different background as well, particularly from rural areas): 
I think students from rural areas need that vastly different perspective. I hear it all the time, 'my high school only had two African-American students and I came here to $\mathrm{U}$ of $\mathrm{L}$ and everyone is different,” and yes, that's how the world is and if you are coming from an area where you don’t understand that, you need to understand that.

Perhaps even more specific, Denise speaks about her experiences in making connections with other students in her academic program:

I think some of the biggest connections for me have been meeting people who are older than me, two of my best friends are master's students in Engineering right now...they know what it is like to co-op, they know what it is like to be in this class and that class, and have this course load, and not have enough time to do anything else.

In a similar fashion Michael stated he actively seeks out the experiences of others in his academic program who are more experienced and makes connections with others in his major that will benefit him academically. Likewise, Jennifer also believes it is important to network and establish strong social connections with others in your academic program. Other participants, however, such as Connie, Kyle, and Clint have made some more general significant connections with other students since arriving on campus, finding a support system and community. Furthermore, Taylor indicated she has made and found a connection as well as a shared understanding with others who are lowincome and also believes, similar to what Diane, Cindy, and Laura expressed, that it is important to connect with others who are from a similar background and have had shared experiences prior to matriculating to college. 
Yet another participant, Ann discussed how she has built a community and a family here on campus and advises other students to do the same: "build relationships and networks and don't be afraid to put yourself with your history out there.” She also believes, similar many of the other participants that establishing and building those key relationships with others from similar backgrounds is essential to success on campus. Finally, Link spoke of how his lack of support system initially hampered his success and that it took some time for him to make those connections with others on campus, finding it imperative that first-generation, low-income students from rural backgrounds develop that support network as quickly as they can. Establishing connections on campus goes beyond relationships with faculty and staff, but also concerns other students as well. The final piece of the discussion regarding students building their own support networks concerns taking advantage of resources on campus.

Taking advantage of resources. Many participants, in addition to making those key connections with faculty, staff, and other students, also pointed out the significance of taking advantage of certain resources on the university's campus. This became particularly apparent when participants were asked what advice that would give to incoming students from a similar background. In response to that question, Denise was rather straightforward:

Don't be afraid to ask questions; don't be afraid to use the resources we have here on campus; whether you need tutoring and it's (the tutoring center) or you don't know what you want to major in and you need the (career center), anything like that. 
Another participant, Cindy, also discussed her experience on campus, coming in as a transfer student: "I researched everything that I could learn so I would be the most informed when I did transfer.” She also believes it is important to take advantage of multiple connections within the university from her professors to studying in groups with other students who grasp materials in a variety ways. Other participants such as Jason and Erica also reported taking advantages of resources, and Cynthia perhaps may have said it the best:

So, I feel like just knowing that those resources are there makes me feel like 'okay, I can focus on school now,' so networking, and also finding people to mentor me and have that encouragement, and knowing what you are going through has been helpful.

While it can certainly be argued that it is important for all students, regardless of socio-economic status, geographical origin, or whether or not their parents graduated from college, the findings reveal that for first-generation, low-income students from a rural background it can be a major factor in whether or not that student persists and is successful. The conversation now shifts from the discussion resources on campus to the conclusion of this chapter.

\section{Chapter Four Conclusion}

Five themes emerged from the findings of the study exploring the strategies, actions behaviors, and influences of academically successful first-generation, low-income students from rural areas at an urban institution. The themes that developed were: the importance of the support needed to attend college; the importance of the environment and atmosphere of the institution as it impacts first-generation, low-income students from 
a rural background; the impact of one's first-generation and low-income status in regard to their experiences on campus; the significance of strengths from a rural upbringing; and the need for participants to build their own support network. Within each of the five themes, once again, several categories also materialized.

Within the level of support to attend college for first-generation, low-income students from a rural background, three separate categories emerged: the degree of parental and family support to attend college; the level of peer and friend support to attend college; and the amount of community support to attend college. Within the importance of the environment and atmosphere of the institution, seven categories emerged: the positive nature of the campus environment; the many resources available on campus; the opportunity for involvement on campus; the fact that opportunities can also be limited for those who are low-income; the need for greater knowledge and awareness about and for first-generation and low-income students; the need for greater communication on campus; and the impact on Cardinal Covenant. Within the impact of first-generation and low-income status on the students' campus experiences, four separate categories emerged: their statuses serving as impetus for these students to want to do better and be successful; feeling lost or lacking in direction because of the inability to rely on one's parents for guidance; the noticing of significant differences between themselves and their classmates; and the continual facing of financial challenges. Within the strengths developed from a rural upbringing, three separate categories emerged: rural social skills; work ethic, and a strong sense of community.

Finally, within the need for first-generation, low-income students from a rural background to build their own support networks once on campus, five separate categories 
emerged: lack of reliance on family or those back home for support; establishing important connections with faculty and staff on campus; becoming involved in the campus or larger community; establishing significant connections with other students on campus; and taking advantage of available resources. The discussion now shifts from attention to the important themes that emerged to a discussion of key findings as well as possible implications for both research and practice in higher education from the themes and from the findings in chapter five. 


\section{CHAPTER 5}

\section{DISCUSSION}

The purposes of this chapter are primarily to address the significant findings from the study and discuss potential implications of the study as well. First, there will be a discussion of some the key findings as they relate to the original research questions of the study. Next, the possible implications of the findings from the study for both practice and research within the field of higher education as it relates to first-generation, lowincome students from a rural background. Finally, concluding thoughts regarding the study and the findings will be addressed.

\section{Research Questions}

To begin the fifth chapter, the original research questions of the study will be restated. Once again the research questions are as follows:

1. What specific obstacles and challenges to their persistence and academic success do first-generation, low-income students from a rural background face at an urban research institution over the course of their enrollment?

2. What assets or strengths do first-generation, low-income students from rural backgrounds possess that could help them to be academically successful at an urban research institution? 
3. What specific attributes of a large, urban research institution can be particularly challenging from a negative aspect or particularly beneficial from a positive aspect for a low-income, first-generation student from a rural background?

4. What actions and behaviors do first-generation, low-income students from a rural background engage in in combination with the practices of an urban research institution to promote and benefit transition and integration into the campus community?

\section{Key Findings from the Study}

One major finding from this study relates to the first research question: what specific obstacles and challenges to their persistence and academic success do firstgeneration, low-income students from a rural background face at an urban research institution over the course of their enrollment? In addition to some the obvious financial challenges for first-generation, low-income students from a rural background, a major finding from this study was these students often lack the support they need to be successful in college and, therefore, must build their own networks of support once on campus. A second major finding from this study relates to the second research question: what assets or strengths do first-generation, low-income students from rural backgrounds possess that could help them to be academically successful at an urban research institution? While certain assets and strengths may also be attributed to first-generation and low-income status as well, one significant finding was that a rural upbringing provides major assets and strengths for these students in being successful.

A third major finding from this study relates to the third research question: what specific attributes of a large, urban research institution can be particularly challenging 
from a negative aspect or particularly beneficial from a positive aspect for a low-income, first-generation student from a rural background? Many participants seemed overwhelmed and in culture shock when they first arrived on campus, and although many felt the university was doing a relatively well in regard to low-income students, there are certainly some needed improvements in working with and focusing on first-generation and rural students. This includes recognition of rural culture, active and engaged discussion regarding socio-economic status and income status, and the intersectionality of at-risk characteristics. Finally, a fourth major finding from the study was related to the final research question: what actions and behaviors do first-generation, low-income students from a rural background engage in in combination with the practices of an urban research institution to promote and benefit transition and integration into the campus community? The key finding here was that participants overall were heavily involved and engaged either on campus or with the larger community, taking advantage of resources and connections to be successful.

\section{Students Built Their Own Networks on Campus}

The first major finding of the study was that once on campus, despite the emotional support provided by family and friends from their home communities, students needed to build and develop their own network on campus to assist them in their

persistence and toward their academic success. As evidenced by many of the interviews, building of one's own support network can certainly aid in persistence and academic success. According to Tinto (1987), departure from college campuses often resulted when one of four events occurred. One of those was the issue of adjustment to the collegiate environment, or lack thereof, and isolation, when the student fails to make 
significant connections with the campus community (Tinto, 1987). Similarly, another later study found that academic and social integration play major roles in a student's persistence on campus (Terenzini, et al., 2001). Unfortunately, while many students can rely on family and college-going peers for the level of support they need, universities may need to provide additional efforts in working with students who are low-income, first-generation from a rural background.

A major reason for this need is often the lack of knowledge and informed support that family and friends cannot provide, a key finding of the study, and it is paramount that much of that support comes from those within the college and university setting for firstgeneration college students (Cushman, 2006). Likewise, Lobo (2001) asserted that often friends and family of first-generation students, while desiring to be supportive, often lack the knowledge needed to provide adequate levels of support. Several of the participants in the study knew early on they would need to seek out resources on campus because they could not rely on friends or family members back home.

To further complicate matters, Pike and Kuh (2005) also found that firstgeneration students were more likely to have unfavorable perceptions of college as well as lower levels of engagement and integration. Additionally, London (1992) found that coming to college can lead to a powerful separation from family members and those in their home communities, which can make the integration to campus all the more difficult. Finally, although reference the income aspect with working-class and poor students, Van Galen (2000) perhaps said it best: "for working class and poor students, success in school often signals their distance and difference from those who love them” (p. 7). Firstgeneration status, however, was not the only factor that could inhibit student integration 
on campus. Those students coming from rural areas may have difficulty adjusting to a larger campus, viewing the process as anxiety-producing and one that can create a division and tension with others on campus (Schultz, 2004). What can further compound the problem for rural students is that many times they originate from communities where education is not seen as a significant asset (Abbott, 2006). Previous literature mentioned, in addition to the findings from the interview point to the strong need for students from a first-generation, low-income, and rural background to build a support network on campus.

A significant aspect to building that support network was involvement on campus, which Astin (1984) made the connection with persistence over thirty years ago and was another significant finding from this study. Brachman (2012) also concluded firstgeneration students are not as involved as other students when it comes to study groups, student organizations, and other support services on campus, so it is imperative that student affairs professionals and others within higher education take additional steps to assist first-generation students in building their support networks on campus. The findings from this study, however, contradict Brachman’s (2012) findings and while each participant had a very different experience from one another, most of the participants reported involvement on both campus and in the larger community, engaging in everything from community service projects, academic clubs, athletic teams, Greek Life, student government, and other types of groups and organizations on campus. That being stated, while many of the participants did report involvement, they also indicated the challenges of balancing employment, course work, and involvement, a concern that may 
not be present for their higher income peers who do not have to work and go to school at the same time.

Another significant aspect to building that support network was the relationship peers and college-going friends. As early as three decades ago, Bean (1985) found that a student's peer groups serve as the primary agents for socialization on campus and Astin (1993) also asserted that peer groups were the most influential source of both a student's academic and personal development. Furthermore, Hertel (2002) posited that the more likely a student is to have friends and social support networks outside of the campus, the less likely the student is to be successfully integrated with the institution. This was found to be imperative for first-generation, low-income students from rural backgrounds in the study, that they form these relationships and informal connections with other students in developing and building their own support network on campus. While many of the participants reported establishing connections with students who were from similar backgrounds was important, they also indicated that forming those relationships with students from diverse and different backgrounds was also paramount. Finally, another essential finding from the study was the importance of making connections with other students in one's academic program and seeking out the perspectives of those in the program who are more experienced.

Colleges and universities today should recognize the importance for all students to be able to build and develop their own support networks on campus, but perhaps more significantly, based upon the results of this study, the degree of importance for students who are first-generation, low-income, and from a rural background. These students face significant challenges and obstacles that other students may not. Unlike other students on 
campus, they cannot or may not be able to rely on family members and those from their home communities for the necessary informed support needed to be successful and persist within higher education. In concluding the discussion of the importance of firstgeneration, low-income students from a rural background, the focus shifts to discussion of the second major finding of the study.

\section{Rural Upbringing Provides Major Assets and Strengths}

The second major finding from the study was that a student's rural background and upbringing provides the student with certain key strengths and assets that assist them with their persistence and academic success once on campus. This is an important finding because many of the weaknesses or challenges for first-generation, low-income, and rural students have been well documented. Both Moss (2003) and Abbot (2006) found that many low-income students coming from rural areas grow up within communities where higher education is not as valued as it is elsewhere, a point that was also made in multiple interviews from the current study. Furthermore, Kalmijn and Kraaykamp (1996) determined from their study that rural residents typically have less cultural capital than do urban residents, and Schutz (2004) concluded from his study that students coming from rural backgrounds often have difficulty understanding the importance of relationship building on college campuses and have difficulty adjusting to the academic rigors and expectations within higher education. In the same study Schutz (2004) asserted the size of campus, breadth of curricular, and financial demands of higher education can be overwhelming to rural students and that these students often viewed themselves as very different from the rest of the student population because they were from rural regions. 
All of this being stated, this study found rural students also bring with them many strengths and assets, also supported by the literature. One of the key findings from the study was that participants expressed a desire to succeed and a tremendous work ethic due to their rural upbringing. This can be immensely important in one's academic success as one study found many first-generation, low-income students express a level of determination that can often exceed their perceived abilities, and Steinmetz (2008) determined many first-generation students felt more qualified than their continuing generation counterparts to be at their college or university due to their hard work. Work ethic was definitely a positive attribute that many participants in the current study contributed to their success and also stated that their rural background was a powerful factor with this.

Also referenced within the findings were the strong social skills that many participants asserted they developed from growing up in small towns and rural areas. This can also be a positive as Settle (2005) found that social capital can be an important valuable contributing to persistence and academic success, such as students developing that contact with faculty members outside of the classroom environment. In fact, many participants throughout the current study referenced their relationships and connections with various faculty members as contributing to their success and benefitting them tremendously. Furthermore, Bouchard (1994) determined that one of the most significant contributors of institutional fit for first-generation students was interaction with staff, not just faculty members. Likewise, many of the participants in the current study also spoke of close connections with academic advisors, staff serving as mentors, and helpful administrators on campus. 
Another strength that emerged from the study due to a rural upbringing was originating from a close-knit community, which provided them with a sense of emotional support even if the community could not provide the intellectual or financial support needed to be successful in college. While not entirely surprising, past research pointed to home communities at times being detrimental to an at-risk student's academic success. As stated in chapter two, according to Astin (1977) a student's religious behavior is likely to decline while hedonistic behavior increases with college attendance. With religion playing such a pivotal role as a socialization outlet in rural areas, and an impression of the college going student turning away from the faith and even a perception of the mores and norms of the home community, there can be a fear by family and friends of the student of he or she being lost to the collegiate environment. Likewise, in Tinto's (1987) early discussion of departure, he cited the need for students to, in fact, break away from their home communities.

Tinto (2007), however, detracted this assertion and instead posited that maintaining their connections with their families and home communities was important to a student’s academic success and persistence. Other researchers (Attinasi, 1989; London, 1989; Nora, 2001; Terenzini, Rendon, Upcraft, Millar, Allison, Gregg \& Jalomo, 1994; Tierney, 1992; Torres, 2003; Waterman, 2004) also echoed the same sentiment, one that was also supported from the findings of the current study. The participants' stories told through the interviews are supportive of the more research as opposed the more traditional inquiry of the 1970's and 1980's, that home communities, and in this case, rural communities, can be heavily supportive and beneficial toward the success and persistence for first-generation, low-income students from rural backgrounds. 
Colleges and universities can make use of this knowledge. First, institutional leaders should bring the term "rural" as well as the concept into the discussion pertaining to diversity on campus, this is true both for the University of Louisville and higher education in general. As mentioned several times by the participants, the institution does a great job addressing diversity when it comes to gender, sexual orientation, and race/ethnicity. What is lacking, however, are conversations that involve not only socioeconomic status, also mentioned by some of the participants, but also geographical diversity. Introducing this and offering workshops, guest speakers, and events that bring rural culture into the university is a necessary starting point. Second, action is required. As addressed in chapter four, rural students come into the university with assets and strengths ranging from a strong work ethic to certain social skills they attribute directly to their rural upbringing. What institutional leaders can do is essential to assisting rural students to feel part of the university community, everything from the establishment of a rural student organization, scholarships specifically set aside for students from specific geographical areas, and just generally assisting rural students to make connections with other students from similar backgrounds. Furthermore, the University of Louisville often provides accolades for student athletes, international students, and those students in certain Scholar programs, it is also strongly suggested that the university highlight students from particular areas within rural locations in Kentucky, presenting examples both to the university community as well as making such testimonials and biographical sketches available within the student's home community as well to serve as an example for other aspiring students. 
Of course, as with any action on a college or university campus, assessment is paramount. With any action or practice geared toward or aimed at rural students, faculty and administrators would need to assess the effectiveness of any such initiative. Assessment might include anything from data reports, surveys, observations, interviews, focus groups, or other methods. Finally, tailoring such approaches to the particular nuances and specifics of each institution is imperative. The current study focused on rural students enrolled at an urban university, however, rural students anywhere should be included regardless of location or institution type. It is important for institutional leaders to take these findings and apply them according to the specific characteristics of their school and student population.

Finally, it is also important to relate the significance of one's rural upbringing back to Bourdieu's concept of social and cultural capital. While initially it could easily be perceived that first-generation, low-income students from rural areas lack the necessary social and cultural capital to be successful academically, socially, or otherwise, the findings from the study perhaps point to something else. In reference to rural social skills specifically, this may be providing rural students with a particular social and/or cultural capital element contributing to their degree of success upon matriculation at the university. Rural social skills or rural attributes in general may mean that originating from a rural background does not automatically result in a deficit of cultural or social capital. While the type of social and cultural capital rural students possess may not be the same as other students and may not automatically be the ideal form for the culture of higher education, it still may provide them with a strength and a degree of confidence to be successful within the confines of academia. 


\section{The University is Generally Positive in regard to Low-Income Students}

A third major finding from the study is that, overall, the university is generally positive in regard to low-income students. Much of the current study focuses on the individual student and the steps he or she can take to be successful, however, students do not achieve or persist in a vacuum. Once again, Lewin (1936) posited that behavior is both a combination of the individual and the environment and that one's actions, or success or lack thereof, is not solely a result of the individual's characteristics, but also the environment, or in this case, the institutional context, as well. In more recent times, institutional fit has become a popular factor in student success and persistence and Reason (2009) stated that a college or university's environmental context was exceedingly important in influencing a student's persistence. In fact, among the thousands of institutions in the United States, college and universities can be classified as small private institutions, community colleges, regional universities, for-profit entities, and large, research universities. Of course, the focus of this particular study is on a large, research university.

There is certainly some literature that points to large institutions having a negative impact on at-risk student populations. First, Pascarella and Terenzini (1991) found that attending a large institution for many students can inhibit their levels of social involvement on campus. This can particularly true for students from rural backgrounds not familiar with the large, expansive environment of an institution with over 20,000 students. Furthermore, another study found that smaller, private schools can be more beneficial for first-generation students because of smaller classes, a greater opportunity to engage with faculty members, and a greater chance for engagement on campus (Saenz, et al., 2007). Finally, further research found that institutions focusing more on 
undergraduate teaching with smaller class sizes, often characteristics of community colleges or private institutions as opposed to large, research universities, tend to have higher graduation rates for low-income students (Muraskin et al., 2004). One of the significant findings from the current study was that many of the participants believed there are more than sufficient resources on campus for first-generation, low-income students from a rural background, which can certainly offset many of the challenges faced at a large, urban institution. Furthermore, while many of the participants understood the challenge for first-generation, low-income students in reaching out to and accessing resources, they also indicated that the resources are definitely there for students to take advantage of, and that some of the onus is on the students themselves to take the initiative in accessing the key resources on campus.

Because of the challenges colleges and universities face with first-generation and low-income students, strategies focused on academic success and persistence without taking into consideration characteristics and attributes of such students are destined for failure, while strategies that take these students' challenges into consideration may benefit all student populations on campus (Thayer, 2000). Additionally, Cole (2008) concluded many first-generation students left primarily because they perceived a lack of support and encouragement from those on campus, lacked a connection with the university environment, and did not have overall, positive feelings toward the institution as a whole. Fortunately, one of the ways that these difficulties can be faced is through student involvement, and also fortunately, one of major findings from the current study was that many of the participants felt there were many ways to be involved on campus, and that in fact, it was easier in some ways to be involved and engaged at a large 
institution than at a smaller school because of the sheer number of opportunities. Ultimately, the findings indicate there are many opportunities for students to be involved on the university's campus.

Despite the positive steps taken, there was some criticism by participants in the study asserting that a greater knowledge is needed by the campus community of the need first-generation, low-income students from rural backgrounds, believing that many faculty, staff, and other students may not have the awareness needed of the challenges and obstacles at-risk populations face on a regular basis. Likewise, many participants also believed that despite the resources and information provided by the institution, that a greater knowledge was not only needed of the many demands, needs, and concerns of atrisk students, but there should also be a greater knowledge and information communicated to students who are first-generation, low-income, and of a rural background. Many of the participants in the current study advocated for a separate orientation, or at least a separate segment of the existing orientation, that would be targeted specifically at first-generation students.

Given the challenges and obstacles faced by first-generation, low-income students from a rural background, there are also many positive steps that colleges and universities can take to improve the situation for these student populations, a significant finding of the current study. Previous studies and past literature on the topic have pointed to the fact that there are a vast array of approaches institutions are engaged with to promote academic advancement and student success, particular as it applies to at-risk populations (Kuh et al., 2005; Oldfield, 2007; Engle \& O’Brien, 2007; Bergh, 2008). Furthermore, some of the more common practices that colleges and universities have undertaken in 
recent years have spanned from learning communities, to service and justice learning, and also summer bridge programs. Similarly, in the current study, Cardinal Covenant was cited by many participants as a highly beneficial program, not only alleviating many of the financial concerns, but also helping them in other ways and providing a strong sense of smaller community on a large campus. The only down side to Cardinal Covenant is that it is limited in the number of students the program can benefit. What is clear is that the last couple of decades have brought about dramatic positive changes benefitting disadvantaged and at-risk student populations.

\section{Participants are Heavily Involved and Engaged}

The final major finding from the study was that participants overall were heavily involved and engaged either on campus or with the larger community, taking advantage of resources and connections to be successful. While the degree of involvement of the participants within this study was briefly alluded to in the first finding regarding building their own support network, the issue of involvement will receive more specific and tailored focus within this section. Research on the topic of student involvement goes back to Astin (1984) who asserted involvement on campus was important for a student's academic success. Furthermore, Tinto (1987) cited isolation, not developing key connections with the academic and social communities on campus, can be a reason for departure. What can be troubling, however, is that first-generation students have often been found to have lower levels of involvement on campus (Pascarella, et al., 2004), and that even when other risk factors are controlled for or addressed, students can still be at significant risk for dropping out of college when they lack involvement on campus 
(Lotkowski, et al., 2004). Additionally, what can additionally be concerning is that large institutions may inhibit levels of involvement on campus (Pascarella \& Terenzini, 1991).

Fortunately, the level of involvement on campus is something where institutions can have an impact. Sometimes it is not the lack of opportunity for involvement on campus, but rather a first-generation or low-income student's lack of understanding of the importance of involvement or awareness of opportunity on campus. Institutions certainly should be more proactive in sharing such information and, as Cushman (2006) asserts, advise first-generation students on better navigation through their collegiate experiences with one key suggestion involvement in student organizations on campus. Findings from the current study indicate that many of these students are heeding these warnings as one of the similar statements made across participant interviews was that participants were involved in a variety of groups from athletics, Greek life, academic clubs, service organizations, other types of recognized student organizations on campus. Furthermore, despite the findings from Pascarella and Terenzini (1991), some of the participants believed it may be easier to find ways to be involved on a larger campus due to the sheer number of groups on campus and the wide variety of opportunities.

While many of the participants indicated that involvement was challenging given their already demanding schedules with work, school, and sometimes family responsibilities, it was apparent from the participant interviews, that it was still important to make time for commitments to different organizations and groups both on campus and within the larger community. It was clear, that most participants found ways to be involved, and they attributed much of their success to that involvement. Finally, it was paramount for student success that the participants not only get involved, but that they 
found one, involvement which was meaningful to them personally, and two, that held them accountable and instilled within them a desire to succeed academically.

\section{Differences among Participants}

The findings and the themes from this study purposefully come from similarities that were discovered as a result of analyzing the data. It is significant to note that although the participants in the study shared many similarities as evidenced through the findings and the themes, there were also key differences among the participants as well. There were several examples of these differences throughout the study. First, a small number of participants experience resentfulness from those within their home communities, which often involved passive aggressive behaviors as well as insensitive comments from former high school friends, family members, or others within the community. One participant in particular, Jason, referenced in his interview his strong dislike for his hometown and that he had no desire to return there. Another example was the challenge a few of the participants discussed in adjusting to an urban lifestyle. While this was not exhibited by all or even most of the participants, some mentioned having to adjust to the degree of diversity within the city and also having parents and other family members who continually feared for the participant's safety. Finally, while involvement and engagement on campus was important for most participants in their success, there were a minority of participants who did not attribute campus involvement to their academic success. One participant, Kyle, was very clear throughout his interview that he was only here to obtain his education and to obtain his degree, and that he had no interest in being involved in activities or groups outside of those experiences. It is certainly 
possible that if more students had been interviewed, these three examples may have become more developed and may even have emerged as separate themes.

A previous study by Allison Hurst (2010) found that working-class students divided themselves into three separate groups: Loyalists, Renegades, and Double Agents. While my study focuses primarily on the similarities among participants, Hurst (2010) focused her energies on some of these important differences. According to Hurst (2010) Loyalists were those students who maintained their connection to their working-class backgrounds and distanced themselves from association with the middle-class. Renegades, on the other hand, are the exact opposite, choosing to break their ties with their working-class background and re-associate themselves with the middle-class, while Double Agents were those working-class students attempted to balance between the two worlds (Hurst, 2010). It is certainly possible, and perhaps likely, that had my study used the lens of Hurst's previous study, the participants could have been divided into these groups as well. It is also likely that even though many similarities were found among the participants in how they approached their challenges, that there were many dissimilarities and unique nuances in their strategies in navigating through the university's environment and the culture of academia.

Finally, it is important to recognize that participants who responded to the invitation to participate in this study and share their stories may share certain commonalities that other students who are first-generation, low-income, and from a rural background may not share. This is always a danger when embarking in any research. It is also possible that a longitudinal study with more time to interview participants and process analysis could have yielded different results and findings. 


\section{Implications}

Once again, the intention of this study is to reveal what strategies, practices, actions, and behaviors low-income, first-generation students from a rural background employ and engage in to persist and be academically successful. The findings from the study revealed that students often lack the support they need to be successful in college and, therefore, must build their own networks of support once on campus. Additional findings were that a rural upbringing provides major assets and strengths for these students in being successful, that the university is doing some things well in regard to low-income students and, that participants overall were heavily involved and engaged either on campus or with the larger community, taking advantage of resources and connections to be successful. Once again, this being stated, there are definitely important areas where the university should and could make improvements, particularly for first generation and rural students. First, rural students have rarely been introduced as part of the equation or discussion on diversity. Typically, the discussion on diversity, from both my previous observation and participant responses, has primarily and sometimes solely focused on race/ethnicity, and often only African-American, or LGBT issues. Certainly these are important student populations to involve in the discussion on diversity, however, they are not the only ones that matter. Participants reported the university did little in regard to their status as first-generations students, and some did not realize the significance of this status until after their arrival on campus. Likewise, rural backgrounds and upbringing are rarely, if ever, acknowledged as an important identity status. The university should improve on recognition of rural students and acknowledge the strengths and assets these students bring to the campus environment. The next section of this 
chapter will focus on the implications from the study for future practice on college and university campuses as well as for future research within the field of higher education.

\section{Implications for Practice}

One does not undertake a research endeavor without the hopes there will also be some implications for practice within the field. In this case, there are several recommendations that could be applied at colleges and universities as they relate to students who are first-generation, low-income, and from a rural background. The implications and recommendations are: to offer financial assistance for involvement in student organizations; to implement a separate portion of new student orientation focused specifically on the needs of first-generation students; to offer budgeting and financial workshops aimed at low-income students; to provide training for faculty, staff, and other students at the institution on the specific needs of first-generation, low-income and rural students; to include and provide more information on financial aid and scholarship searches to prospective students prior to matriculation; to establish an organization on campus specifically for rural students; and to offer greater opportunities for family members of first-generation and low-income students to come to campus.

Offer financial assistance for involvement. Many of the participants throughout the current study expressed that while the university does an excellent job at encouraging students to be involved in various student organizations and groups on campus, some of the organizations can be costly and very little is offered in the form of financial assistance to help low-income students to be involved and engaged with these groups. While Greek organizations are not the only groups where this can apply, they were mentioned most frequently by participants. Ann and Laura both indicated a major reason they did not 
choose to participate in a sorority was due to the cost involved, as Laura asserted: "I never had the money or the resources to do recruitment in any shape.” Ann also expressed the following: “I didn’t participate in Greek life, because when it came in it was close to $\$ 1000$ to rush in a sorority.” While time constraints and other factors also could play a role limiting a low-income student's involvement, it was apparent from the interviews, that finances played a substantial role. One possibility might be for such organizations to charge fees based upon a sliding scale according to income. Yet another thought might be for these groups to work with alumni relations and fundraising to approach alums previously engaged with the organization to donate a small amount to help offset a low-income students' expenses. Whatever the approach, cost associated with involvement in many organizations on campus serves as a hindrance for low-income students and can be a significant barrier to engagement.

Offer a separate orientation for first-generation students. As previous literature indicated, first-generation students often approach the college application process without the parental experience other students may have (Gibbons \& Shoffner, 2004), are less likely to be involved in organizations on campus (Brachman, 2012), and lack a general understanding of the expectations of higher education (Padron, 1992). Furthermore, Collier and Morgan (2007) posited that first-generation students are less likely than students whose parents graduated from college to engage in successful approaches in communicating and managing the relationship with both faculty and administrators. Due to the disadvantage that many first-generation students have upon matriculation, a separate orientation, summer bridge program, or at the very least separate portion of orientation for first-generation students may be needed. 
The need for this was expressed in several interviews throughout the course of the current study. Diane was one participant who was open about this during her interview: "I feel there should be something to just grab a hold of first-generation college students to walk them through how to navigate.” Likewise, Jennifer also expressed there might be a strong need for this during her interview: "at least a meeting...to let them know someone is here you can contact to learn how to navigate everything.” Additionally, Denise was another participant who realized early on she lacked knowledge that other students had, knowledge her parents were not able to give her. While many parents who graduated from college are able to provide a sense of direction and impart words of wisdom from their direct collegiate experiences, first-generation college students often arrive without this inherit benefit, and many of the participants in the current study reported feeling lost or lacking in direction upon initial arrival. A separate orientation, bridge program, or at least workshop within orientation may give first-generation students some of the requisite knowledge not imparted to them by their parents. While the Cardinal Covenant program on campus provides an informational session during orientation, this only amounts to a minority of the incoming first-generation college students. Finally, there is a greater need for providing more information to first-generation students about the resources available on campus, the challenges and obstacles they may face moving forward, and how to appropriately manage those challenges and obstacles.

\section{Offer budgeting and financial workshops aimed at low-income students.}

While many of the participants interviewed for the study were either on scholarship or receiving some other form of financial aid to finance their education, they also reported continued financial struggles. One such example was Ellie, who, while a Cardinal 
Covenant recipient, indicated she still worries over finances a great deal and effectively budgeting can be a significant challenge for him, attributing this to her low-income origins. In a similar fashion, Diane stated that when first began she immediately felt set apart from the other students who shared their lack of financial concerns while she struggled to survive while also maintaining good academic standing. For many of these participants, their low-income status did not become apparent until they arrived on campus and noticed dramatic differences between themselves and others in regard to the clothing they wore or technology they used. The desire to disguise one's self and be similar to other students can be powerful, and according to Erica it can also be a time when low-income and first-generation students are susceptible to financial problems, credit cards offers, and other such challenges. While other students may have the financial ability to obtain material resources or the economic knowledge imparted by parents to manage these situations appropriate, it was clear from many of the participants within this study that those benefits or abilities are not always available for firstgeneration, low-income students. As a result, colleges and universities should take it upon themselves to offer financial and budgeting workshops both at new student orientation and periodically throughout the academic year. The argument could be made that students receiving any type of scholarship based on need, work-study, or grant should be mandated to attend at least one such workshop per year as unfortunately, while some students may voluntarily attend such workshops, many others would not unless required.

Provide training or workshops for faculty, staff and other students. There is more than sufficient literature to assert that first-generation and low-income students are 
at greater risk for attrition than other students (Ishitani, 2003; Tinto, 2012). Despite this many of the participants in the current study believe faculty, staff, and other students on campus need to have a greater awareness of the needs and obstacles faced by firstgeneration, low-income students from rural background. One participant, Jason, stated he realized the lack of awareness by the administration as early as orientation and asserted he believes in many ways the university assumes that all students are receiving financial assistance from parents or other family members, which is certainly not the case for many low-income students. Likewise, Michael argued there is also a lack of realization of how many students are low-income, insisting: "there is kind of a perception that college students come from a more privileged background," however, based upon not only Michael's experiences, but also of the other participants within the study, nothing could be further from the truth of the matter.

Additionally, some research may support the participants' assertions, as Lobo (2001) found that some first-generation and low-income students felt like outsiders on their campuses and had a difficult time forming connections with others at their institution. What colleges and universities choose to do as it relates to first-generation, low-income students from rural backgrounds can be significant as interaction with faculty can be highly influential for a student’s success (Bergh, 2008; Astin, 1993), and strategies aimed at these students can also be more universally beneficial toward the general campus population. What is not being done at the present time is an effort to increase knowledge and awareness of first-generation, low-income students from rural areas. While participants noted the university has been engaged in diversity awareness when it comes to racial and ethnic diversity, as well as LGBT (Lesbian, Gay, Bisexual, 
Transgender) issues, there is a greater need for the conversation to also involve student generational status, geographical origin, and social class.

Include and provide more information on financial aid. While many of the participants indicated during their interviews they were either scholarship recipients or receiving some other form of financial aid, there is still a greater need for awareness among first-generation and low-income students when it comes to available aid. Plank and Jordan (2001) found many low-income prospective students matriculate ill-informed about college costs and financial aid, and another multi-state study later confirmed similar findings (Tierney, 2009). Yet, a third earlier study also found that for many lowincome students the availability of aid was not as much of a concern as it was the knowledge of availability, how to gain access to resources, and then manage those resources (Beegle, 2000). At the present time, the university hosts a regular campus visit and admissions counselors travel the state visiting high schools to impart valuable information about the institution. While only so much can be accomplished when a student visits campus or an admission counselor visits a high school, the university must do a better job of communicating information to first-generation and low-income students on financial aid and scholarship opportunities. Although Diane attended another large university for her undergraduate degree, her statement probably provides the best evidence of this: "I wish I had known how to navigate scholarships and how to navigate the basic college stuff. I had to learn that on my own.”

Establishment of a rural student organization. Although there is not as much research on rural students on first-generation and low-income students in general, what does exist often points to rural students' sense of anxiety in adjusting to the campus 
environment and feelings of a divide between them and others in the campus community (Schutz, 2004). What may help alleviate some of this anxiety and create more of a feeling of inclusiveness would be a student organization on campus specifically designed for students from rural areas, particularly for those students who are also first-generation and low-income. As evidenced by some of the interviews throughout the current study, many of the participants have "rural social skills" with Ann having the personality "to talk to anyone,” and Link indicating he can connect with others easily. While it may seem based upon this evidence that rural students would not need their own organization and could rather assimilate into other groups based upon outgoing natures, further evidence from the interviews pointed to the value of establishing connections with others from similar backgrounds.

Diane spoke of how important it was for her to make that connection with others who were very much like her: "I fit in...everybody talked like me, had the same background as me, that was a little bit of a motivation for me.” Likewise, Laura and Taylor both expressed how important they felt it was for students to establish those relationships with others who had shared experiences and came from a similar background. Finally, another participant, Ann, went a step further, asserting that establishing and building those relationships with similar students was not only beneficial but was essential to one's success on campus. The only potential drawback to such an idea is that for many students who are already heavily involved, it may not be possible to add one more engagement to their already expansive list. That being stated, however, establishment of such an organization on campus could have tremendous benefit to 
students who sometimes feel alienated and marginalized within the greater campus culture and community.

Offer more opportunities for family members to come to campus. Previous literature suggests that family support for first-generation, low-income students from rural areas can be crucial for their success (Schutz, 2004; Logan, 2007; London, 1989;

Piorkowski, 1983; Wells, 2008-09; Cushman, 2006). Furthermore, Becker (1999) found that parents engaged in positive practices that promote success in higher education was more significant than a family's socio-economic status. Another study found that families remain influential for student success after matriculation (Adams, et al., 2000), and despite his earlier assertion for the need for students to break away from their home communities to fully assimilate into the campus community, Tinto (2007) would later posit that maintain the connection to their families and home communities was important to their success and persistence.

Unfortunately, often the perception for first-generation and low-income students from others is there is a lack of support or encouragement to attend college. To the contrary, most of the participants in the current study indicated their parents and other family members were generally supportive of them attending college. What was often the case, however, was that while many of the participants' families were supportive, they may have lacked the knowledge needed to know how to adequately provide needed support. Diane was one participant who indicated that although her family is supportive, they do not often outwardly show their support for her in obvious ways. Much of the research also indicates something similar as Mueller (1997) found many first-generation students believe their parents and other family members to be their strongest support 
systems, and DeLong (2003) concluded many low-income parents made significant sacrifices in helping their children go to college.

Consequently, colleges and universities should be doing more to engage and involve parents of first-generation, low-income students from a rural background. This could be anything from open invitations to attend campus events with their children, or even hosting a special event on campus. This recommendation is nothing new as well over a decade ago Hicks (2002) argued for more programs that involve parents of firstgeneration students. Throughout the interviews, it was often conveyed parents were somewhat isolated from the process, and although this was not expressed by every participant, it certainly seemed to resonate with many of them. In fact, Link openly addressed the issue during his interview, stating he feels a degree of separation from his family since he has matriculated at the university: "I am kind of off on my own here." For many parents and other family members, there may be an intimidation factor, something that institutions could actively strive to remedy. While student affairs professionals and higher education administrators spend a great deal of time concerning with how to engage and involve students on campus, there should be a greater effort to how we can also engage the parents and other important family members as well as this can also have a positive benefit for a first-generation, low-income student from a rural background's academic success and persistence.

\section{Implications for Research}

In a similar fashion, research findings should also have implications for future research in addition to practice. Based upon the findings from this study, several ideas 
for future research emerged. The following implications for research will also be divided into both qualitative and quantitative measures.

Quantitative studies. First, since the current study only involved participants studying at a large, research university, it may be beneficial to study the comparison between a large, research university and other types of institutions (private colleges, community colleges, etc.). Second, of the four major findings addressed earlier in this chapter, further exploration is perhaps needed on which factor has the greater influence.

Comparing research universities to other types of institutions. Although one study indicated that rural community colleges can offer certain advantages for rural students that large, research universities may not provide (Miller \& Tuttle, 2007), additional research shows that those who do attend community colleges may not receive the similar economic rewards as those who have obtained four-year degrees. Furthermore, Dougherty and Kienzl (2006) found that only about 10 percent of lowincome students who begin at community colleges will continue at four-year schools. In contrast, however, large institutions could serve to hinder a student's opportunity at involvement (Astin, 1977), and the location of research, urban universities could limit enrollment for students from rural areas. Additionally, smaller, private colleges may be more preferable for first-generation students due to greater opportunity for campus engagement (Saenz, et al., 2007).

Given the amount of conflicting research regarding the topic, and also the sparseness of literature comparing experiences of students at research universities from first-generation, low-income, and rural backgrounds, there is certainly a need for more research exploring the relationship between institutional type and the nature of these 
experiences for this student population. In fact, while participants often reported throughout the interviews that there are many resources on campus for students to take advantage of, and some participants even believed it was easier to be involved and engaged due to the sheer opportunities on campus to do so, more than one participant expressed concern due to the lack of communication. For example, Ann stated she believes there is of connectivity on campus and Jennifer who asserted that at times she has received conflicting messages from university personnel. Finally, while there can be benefits and drawbacks for all categories of colleges and universities, more can be learned regarding what advantages may exist for first-generation, low-income students from rural areas enrolled at different types of institutions.

\section{Further exploration needed on the greatest or greater factors of influence.}

Previously in this chapter, four major findings were discussed, and it would be important to more deeply examine which of these findings had the greatest influence or impact on experiences of first-generation, low-income students from rural backgrounds. For example, are the support networks participants build for themselves when on campus more significant to their persistence and academic success than the strengths and assets acquired from their rural upbringing? Another possible research question could be: are the positive actions taken by the university more important to the success and persistence for first-generation, low-income students from rural backgrounds than their own initiative to be involved and engaged in organizations on campus? Of course, since all of these findings contribute to the success and persistence of these students, a multiple regression statistical test may be needed to determine which of these factors is contributing the most to the success of first-generation, low-income students from rural backgrounds. Finally, 
while there may be a greatest or may be greater factors of influence with these findings, all of the findings are, of course, important considerations in working with and designing programs and policies aimed at this student population.

Qualitative studies. Because the current study only involved participants who originated from rural areas, a comparison could also be studied between first-generation, low-income students from rural areas and those from urban regions. Next, given the lack of research on rural students, there could be research conducted on the influence of this factor on participants' experiences. Finally, since there are few studies on the impact of older siblings who enroll in college on first-generation students, it may also be beneficial to study the influence on first-generation students of this opposed to those first-generation students who do not have older siblings in college.

\section{Comparing rural, first-generation, low-income students to urban, first-}

generation, low-income students. Another area related to this study deserving of greater research is comparing the experiences, success, and persistence of rural students versus urban students. As addressed previously, while much of the previous research focuses on first-generation and low-income students in general, or those from urban areas or who may meet ethnic and racial minority status, rural students may face additional challenges and obstacles than their urban counterparts do such as geographical and cultural isolation (Abbott, 2006). Geographical barriers can be significant, isolating rural students from information, opportunity, and access, which can serve as a major hindrance in addition to the challenges of being first-generation and low-income. Kalmijn and Kraaykamp (1996) also found that rural residents may have less cultural capital than urban residents do, which means rural students may face further difficulties being successful with an 
academic setting which often relies, at least in part, on such capital. Furthermore, Schutz (2004) found that rural students view themselves as "different from others” on campus because of their rural background.

Throughout the study, while many of the struggles participants reported were due to their first-generational and low-income statuses, there were also challenges based on their rural origins, as even generally supportive parents expressed hesitancy for their children moving away to urban areas and also feelings of being overwhelmed when participants first arrived on campus due to the size of the university and the city. Very few studies exist comparing urban students from first-generation and low-income backgrounds to rural students from the same backgrounds. It may be highly beneficial to examine significant differences or similarities between the two student groups to ascertain specifically what obstacles and challenges can genuinely be attributed to a student's rural origins. Finally, the findings of such a study may be helpful to student affairs professionals and higher education administrators in preparing and planning programs and policies directed at specific groups on campus.

More research on rural students. Currently, while a great deal of research exists on first-generation and low-income students, there is very little published literature focusing specifically on students from a rural background. In fact, often rural students have been excluded in conversations on university campuses about diversity (Whiting, 1999). This is troublesome as what research does exist has found that rural students may face unique obstacles. One study found that rural students were overwhelmed by the large university campus setting, lacked knowledge about college costs and financial aid, and had difficulty adjusting to the academic challenges and demands (Schutz, 2004), 
something that was also found in the current study. Likewise, higher education leaders throughout the country have reported that rural students face several barriers from a lack of academic preparation to cultural differences with the higher education setting, and transportation issues (Chronicle of Higher Education, 2006). Much of the findings from the current study point to the need for a greater focus on rural students, for example, one participant, Denise addressed the issue specifically in stating she felt like a minority on campus due to her rural status.

In focusing on rural students, any of the three key themes could be addressed: social skills, work ethic, and a strong sense of community. As previously mentioned, the work ethic and strong sense of community were not necessarily surprises, however, the social skills aspect was particularly intriguing and surprising to an extent. It could likely be beneficial to further explore this theme to see if this continually seems to be the case and how this skill set more specifically benefits rural students and serves as a potential attribute throughout their collegiate experiences. Finally, further research and findings could be useful to college administrators in tapping into this personality trait and engaging rural students to persist and be academically successful.

\section{Greater focus on the influence of siblings for first-generation students.}

Presently, almost all of the research on first-generation college students focuses on the impact of parents and peers, while very little focuses on what influence older siblings who have matriculated to college previously may have on first-generation students. Throughout the current study, when asked about the support from family members, parents were not the only ones referenced and in multiple studies family support has been found to be highly influential and impactful for first-generation students (Bouchard, 
1994; Rondini, 2010). When asked in the current study, many of the participants either did not have an older sibling or had an older sibling that had not attended college, so it was difficult to determine within the limits of this study what specific influence older college-going siblings may have. One participant, however, Cynthia did reference how beneficial it has been to have a sister also enrolled in college, albeit at another institution:

"whenever I was having issues coping with the college environment and the people I met, she would be the encourager to me.” In contrast, another participant, Clint, referenced his older sister whom he felt had little impact on his own collegiate experiences. While it may make sense that an older college-going sibling could be a strong sense of support and highly beneficial for a first-generation college student, this is not necessarily supported by the existing literature and there is definitely a need for greater research on

\section{Limitations of the Study}

As with any research study, there were a few limitations associated with the study. First, many of the participants in the study had multiple identities not a focus of this research which could have influenced the findings. For example, some participants identified as LGBT, some as non-traditional aged students, and at least one as a parent; some experiences, challenges, strengths, etc. may originate at least partially from those identities. Furthermore, other participants may have other identities or obstacles not related to their first-generation, low-income, or rural status that were not revealed or identified as part of the study.

A second limitation of the study was that many of the participants were recipients of Cardinal Covenant, which may have impacted the results positively. While the study was advertised through multiple avenues throughout the entire campus community, the 
Program Coordinator of Cardinal Covenant forwarded the message out directly, and since he has a close relationship with many of the recipients, although he had no direct involvement with the study, this may have led Cardinal Covenant recipients to be more likely to respond perhaps than other students at the university. Fortunately, I was aware of this limitation from the outset, so throughout the interview, transcribing, coding, and analyzing processes, I was mindful of this and did as much as I could to limit the influence of this factor.

A third limitation of the study was lack of inclusion of students from multiple universities. While findings and results from qualitative studies are not intended to be generalizable to larger populations, but transferability is possible through thick description (Lincoln \& Guba, 1985). According to Lincoln and Guba (1985), transferability can still be difficult to determine, and later studies might involve research at multiple institutions to both compare and contrast student experiences and develop a greater degree of transferability of the findings. Furthermore, while the study does yield some important findings, it is also limited to the extent that other identities may be influencing some of the results, some of the participants may have been more eager or motivated to participate than the average first-generation, low-income student from a rural background at the university, and the transferability of the findings could be potentially strengthened by conducting research at multiple institutions.

Some additional limitations included the fact it was not entirely clear why the participants in this study made use of the resources available to them while other students from a similar background may not and participants’ living arrangements were not discussed as part of the interview either. In other words, it is unknown whether or not 
living in a residence hall on campus or an apartment off campus made a significant difference. That being stated, however, based upon my interviews and conversations with the participants, it did not seem that any of them resided with their parents or other family members and those family members remained in their rural communities as best I could determine from analysis of the data. Finally, while all interview transcripts were sent back to the participants twice for the purpose of member checking, only 11 of the 18 responded. Of those who responded, however, only minor errors were noted and corrected that did not impact the findings from the study.

\section{Conclusion}

This study examined the strategies, actions, behaviors, and influences for academically successful first-generation, low-income college students from rural areas at an urban, research university. Themes that emerged from this study indicate that the environment and atmosphere of the institution toward first-generation, low-income students from backgrounds is paramount to the success and persistence of this student population. Additionally, the study also found that both a student's status as firstgeneration and low-income is heavily impactful in regard to their experiences on campus. Also, a third theme that emerged from the study was that students' rural upbringings provide them with multiple strengths and assets that are useful in being successful at the university. Finally, because many of the participants in the study lacked the support networks needed upon matriculation, they had to develop their own support networks once on campus.

Throughout the study participants both addressed and alluded to the significance and the impact of their first-generation, low-income, and rural statuses as students at a 
large, research university. While participants clearly faced obstacles, challenges, and barriers to attending the university and being academically successful, the vast majority have made use of resources on campus that have benefitted them moving forward. The major findings of the study included the need to build their own support network on campus, that a rural upbringing provides students with many assets and strengths that can be beneficial at the university, that the university is generally doing a positive job for students who are from first-generation and low-income backgrounds, and finally, that participants, overall, were heavily involved and engaged on campus and that this certainly contributed to their persistence and academic success.

Finally, implications for practice include: to offer greater financial assistance for involvement in student organizations, to offer a separate orientation for first-generation students, and to offer more budgeting and financial workshops for low-income students. Implications for practice also include providing training or workshops for faculty, staff, and other students on campus regarding the needs of first-generation, low-income, and rural students, to provide more information on financial aid searches to first-generation students, to establish a rural student organization, and to offer more opportunities for family members to come on campus. Implications for research included: comparing experiences at large, research universities to other types of institutions, comparing rural students to urban students, conducting more research specifically on rural students, exploring the influence of older, college-going siblings on first-generation students, and further research on the greatest factor of influence for first-generation, low-income students from rural backgrounds in regard to their academic success and persistence. 
Research on this topic, hopefully, has only just begun. The need for more research, both that which is qualitative, quantitative, and potentially mixed methods is necessary if first-generation, low-income students from rural backgrounds are to become part of the discussion and part of the solution regarding the issues of diversity on college campuses today. The eighteen participants involved in this study will hopefully one day be only the "tip of the iceberg" in focusing on students of this specific population and potentially an early precursor to an abundance of research focusing on college students from rural areas. 


\section{REFERENCES}

Abbott, S. E. (2006). College material: Tapping rural areas for the next generation of college students. The Journal of the New England Board of Higher Education, 20(4), 28-30.

Abes, E. S. (2009). Theoretical borderlands: Using multiple theoretical perspectives to challenge inequitable power structures in student development theory. Journal of College Student Development, 50, 141-156.

ACT. (2007). The role of nonacademic factors in college readiness and success. Issues in College Success. ACT, Incorporated.

Adams, G. R., Ryan, B. A., \& Keating, L. (2000). Family relationships, academic environments, and psychosocial development during the university experience: A longitudinal investigation. Journal of Adolescent Research, 15(1), 99-122.

Addy, S., Engelhardt, W., \& Skinner, C. (2014). Basic facts about low-income children: Children under 18 years, 2011. National Center for Children in Poverty. Retrieved from: www.nccp.org

Adelman, C. (1999, June). Answers in the tool box: Academic intensity, attendance patterns, and bachelor's degree attainment. Washington, DC: U.S. Department of Education.

Adelman, C. (2006, February). The toolbox revisited: Paths to degree completion from high school through college. Washington, DC: U.S. Department of Education. 
Advisory Committee on Student Financial Assistance. (2001). Access denied:

Restoring the nation's commitment to equal educational opportunity. Washington, DC.

Advisory Committee on Student Financial Assistance. (2002). Empty promises: The myth of college access in America. Washington, DC.

Antonio, A. L. (2004). The influence of friendship groups on intellectual self-confidence and educational aspirations in college. The Journal of Higher Education, 75, 446471.

Arnold, K. D., Fleming, S., Castleman, B. L., DeAnda, M. A., Wartman, K. L., \& Price, P. (2008, March). The summer flood: The gap between college admission and matriculation among low-income students. Presented March 27, 2008 at the annual meeting of the American Educational Research Association, New York City.

Astin, A. W. (1977). Four critical years: Effects of college on beliefs, attitudes, and knowledge. San Francisco, CA; Jossey-Bass.

Astin, A. W. (1984). Student involvement: A developmental theory for higher education. Journal of College Student Personnel, 25, 297-308.

Astin, A. W. (1993). What matters in college? Liberal Education, 79(4), 4-15.

Astin, A. W., \& Oseguera, L. (2004). The declining “equity” of American higher education. The Review of Higher Education, 27, 321-341.

Attinasi, L. C. (1989). Getting in: Mexican American’s perceptions of university Attendance and implications for freshman year persistence. Journal of Higher Education, 60, 247-277.

Bandura, A. (1986). Social foundation of thought and action: A social cognitive theory. Englewood Cliffs, NJ: Prentice-Hall.

Bank, B. J., Slavings, R. L., \& Biddle, B. J. (1990). Effects of peer, faculty, and parental influences on students’ persistence. Sociology of Education, 63(3), 208-225. 
Barnett, A. N. (2004). Examination of the relationship between anxiety and first generation college students.(Unpublished Thesis: Emporia State University).

Baum, S., Ma, J., \& Payea, K. (2013). Education pays 2013: The benefits of higher education for individuals and society. New York, NY.: CollegeBoard.

Bean, J. P. (1985). Interaction effects based on class level in an explanatory model of college student dropout syndrome. American Educational Research Journal, 22(1), 35-64.

Bean, J. P. (2005). Nine themes of college student retention. In A. Seidman (Ed.), College student retention (pp. 215-243). Westport, CT: Praeger Publishers.

Becker, J. (1999). Partnerships with families promote TRIO student achievement. Washington, D.C.: National TRIO Clearinghouse.

Beegle, D. M. (2000). Interrupting generational poverty: Experiences affecting successful completion of a bachelor's degree (Doctoral dissertation). Retrieved from ProQuest.(UMI Number: 9999839)

Bell, H. M. (1938). Youth tell their story. Washington, D.C.: American Council of Education.

Belley, P., \& Lochner, L. (2007). The changing role of family income and ability in determining educational achievement. Working paper 13527: National Bureau of Economic Research: Cambridge, MA.

Berger, J. B. (2000). Optimizing capital, social reproduction, and undergraduate persistence: A sociological perspective. In J. M. Braxton (Ed.), Rethinking the departure puzzle: New theory and research on student retention (pp. 95-126). Nashville, TN: Vanderbilt University Press.

Berger, J. B., \& Lyon, S. C. (2005). Past to present: A historical look at retention. In A. Seidman (Ed.), College student retention (pp.1-29). Westport, CT: American Council on Education and Praeger Publishers. 
Bergh, D. G. (2008). Celebrating the "invisible middle": Successful first-generation and low-income college students (Unpublished doctoral dissertation) The University of Vermont, Burlington, VT.

Bergerson, A. A. (2007). Exploring the impact of social class on adjustment to college: Anna’s story. International Journal of Qualitative Studies in Education, 20(1), 99-119.

Bettinger, E. P., Long, B. T., \& Oreopoulos, P. (2007). Increasing college enrollment among low-and moderate-income families: An intervention to improve information and access to financial aid. New York, NY: The National Center for Postsecondary Research.

Blevins, L. B. (2004). Rural students' baccalaureate degree attainment at public colleges in Virginia (Doctoral dissertation). Retrieved from ProQuest. (UMI Number: 3144625)

Borrego, S. E. (2008). Class on campus: Breaking the silence surrounding socioeconomics. Diversity \& Democracy: Civic Learning for Shared Futures, 11(3), 1-3.

Bouchard, E. E. S. W. (1994). Fitting in at college: A comparison of first-generation and second/subsequent-generation college students (Doctoral dissertation). Retrieved from ProQuest. (UMI Number: 9514260).

Bourdieu, P. (1977). Outline of a theory of practice. (R. Nice, trans.) Cambridge, England: Cambridge University Press. (Original work published 1972)

Bourdieu, P. (1984). Distinction: A social critique of the judgment of taste. London: Routledge.

Bourdieu, P. (1986). The forms of capital. In J. G. Richardson (Ed.), Handbook of Theory and Research for the Sociology of Education (pp. 241-258). New York, NY: Greenwood Press. 
Bowen, W. G., \& Bok, D. (1998). The shape of the river: Long-term consequences of considering race in college and university admissions. Princeton, NJ: Princeton University Press.

Brachman, C. (2012). Improving access and success for first-generation college students. America's Promise Bulletin. Retrieved from: http://cms.americaspromise.org/News-and-Events/News-and-Features/APB2012/Vol-25/First-Generation-College.aspx

Bramston, P., \& Patrick, J. (2007). Rural adolescents experience an urban transition. Australian Journal of Rural Health, 15, 247-251.

Braxton, J. M., \& Mundy, M. E. (2001-2002). Powerful institutional levers to reduce college student departure. Journal of College Student Retention, 3, 91-118.

Braxton, J. M., \& Hirschy, A. S. (2005). Theoretical developments in the study of college student departure. In A. Seidman (Ed.), College student retention (pp. 61-87). Westport, CT: Praeger Publishers.

Brock, T. (2010). Young adults and higher education: Barriers and breakthroughs to success. The Future of Children, 20(1), 109-132.

Bui, K. V. T. (2002). First-generation college students at a four-year university: Background characteristics, reasons for pursuing higher education, and first-year experiences. College Student Journal, 36(1), 3-11.

Byrd, K. L., \& MacDonald, G. (2005). Defining college readiness from the inside out: First-generation college student perspectives. Community College Review, 33(1), 22-37. 
Cabrera, A. F., Nora, A., \& Castaneda, M. B. (1992). The role of finances in the persistence process: A structural model. Research in Higher Education, 33, 571593.

Cabrera, A. F., \& La Nasa, S. M. (2001). On the path to college: Three critical tasks facing America’s disadvantaged. Research in Higher Education, 42, 119-149.

Calkins, M. V. (2005). First generation college students: Family influence and the road to college (Doctoral dissertation) Retrieved from ProQuest. (UMI Number: 3179861)

Charmaz, K. (2006). Constructing grounded theory: A practical guide through qualitative analysis. Thousand Oaks, CA: Sage.

Cheeseman Day, J., \& Newburger, E. C. (2002). The big payoff: Educational attainment and synthetic estimates of work-life earnings. U.S. Department of Commerce: U.S. Census Bureau.

Chen, R., \& DesJardin, S. L. (2008). Exploring the effects of financial aid on the gap in student dropout risks by income level. Research in Higher Education, 49, 1-18. Chen, X. (2005). First generation students in postsecondary education: A look at their college transcripts (NCES 2005-171). U.S. Department of Education, National Center for Education Statistics. Washington, DC: U.S. Government Printing Office.

Choy, S. P., Horn, L. J., Nunez, A. M., \& Chen, X. (2000). Transition to college: What helps at-risk students and students whose parents did not attend college. New Directions for Institutional Research, 107, 45-63. 
Choy, S. (2001). Essay: Students whose parents did not go to college: Postsecondary access, persistence, and attainment. Washington, DC: National Center for Educational Statistics. (ERIC Document Reproduction Service No. ED448899)

Cieurzo, C., \& Keitel, M. A. (1999). Ethics in qualitative research. In Kopala, M. \& Suzuki, L. A. (Eds.) Using qualitative methods in psychology. (pp. 63-75). Thousand Oaks, CA: Sage.

Clauss-Ehlers, C. S., \& Wibrowski, C. R. (2007). Building educational resilience and social support: The effects of the educational opportunity fund program among first-and-second generation college students. Journal of College Student Development, 48, 574-584.

Clont, J. G. (1992). The concept of reliability as it pertains to data from qualitative studies. Paper presented at the annual meeting of the South West Educational Research Association. Houston, TX.

Cole, D. L. (2008). Staying within the margins: The educational stories of firstgeneration low-income college student (Doctoral dissertation). Retrieved from ProQuest. (UMI Number: 3346834)

Coleman, J. S. (1988). Social capital in the creation of human capital. Journal of Sociology, 94, 95-120. Chicago, IL: The University of Chicago Press.

Collier, P. J., \& Morgan, D. L. (2007). “Is that paper really due today?”: Differences in first-generation and traditional college students’ understandings of faculty expectations. Higher Education, 55, 425-446. 
Conley, P. A., \& Hamlin, M. L. (2009). Justice-learning: Exploring the efficacy with low-income, first-generation college students. Michigan Journal of Community Service Learning, 16(1), 47-58.

Creswell, J. W. (2007). Qualitative inquiry \& research design: Choosing among five approaches. $\left(2^{\text {nd }}\right.$ ed.) Thousand Oaks, CA: Sage.

Crotty, M. (1998). The foundations of social research: Meaning and perspective in the research process. Thousand Oaks, CA: Sage.

Cushman, K. (2006). First in the family: Advice about college from first-generation students. Providence, R.I.: Next Generation Press.

DeLong, A. W. (2003). Parents of first-generation college students: Their perceptions on the importance of college (Doctoral dissertation). Retrieved from ProQuest. (UMI Number:3119228)

Dennis, J. M., Phinney, J. S., \& Chuateco, L. I. (2005). The role of motivation, parental support, and peer support in the academic success of ethnic minority firstgeneration college students. Journal of College Student Development, 46, 223236.

Denzin, N. K. (1978). The research act: A theoretical introduction to sociological methods. ( $2^{\text {nd }}$ ed.) New York, NY: McGraw-Hill.

DiMaggio, P., \& Mohr, J. (1985). Cultural capital, educational attainment, and marital selection. American Journal of Sociology, 90, 1231-1261.

DiMaria, F. (2006). Working-class students: Lost in a college's middle-class culture. The Hispanic Outlook in Higher Education, 16, 60-65. 
Dougherty, K., \& Kienzl, G. (2006). It’s not enough to get through the open door: Inequalities by social background in transfer from community colleges to fouryear colleges. Teachers College Record, 108, 452-487.

Duffy, J. O. (2007). Invisibility at risk: Low-income students in a middle-and upper-class world. About Campus, 12(2), 18-25.

Dumais, S. A. (2002). Cultural capital, gender, and school success: The role of habitus. Sociology of Education, 75(1), 44-68.

Dumais, S. A., \& Ward, A. (2009). Cultural capital and first-generation college success. Poetics 38, 245-265.

Dykes, M. (2011). Appalachian bridges to the baccalaureate: Mattering perceptions and transfer persistence of low-income, first-generation community college students (Doctoral dissertation). Retrieved from ProQuest. (UMI Number: 3584058)

Elliott, J. P. (1989). An investigation of the college-going behavior of rural high school graduates with implications for postsecondary persistence (Doctoral dissertation). Retrieved from ProQuest. (Order number: 9009300)

Ellwood, D. T., \& Kane, T. J. (2000). Who is getting a college education? Family background and the growing gaps in enrollment. In S. Danziger and J. Waldfogel (Eds.) Securing the future: Investing in children from birth to college (pp. 283324). New York, NY: Russell Sage Foundation.

Emporia State University. (2013). Project Challenge. Retrieved from: http://www.emporia.edu/prjchlng/

Engberg, M. E., \& Wolniak, G. C. (2010). Examining the effects of high school contexts on postsecondary enrollment. Research in Higher Education, 51, 132-153. 
Engle, J., Bermeo, A., \& O’Brien, C. (2006). Straight from the source: What works for first-generation college students. Washington, DC: The Pell Institute for the Study of Opportunity in Higher Education.

Engle, J., \& O’Brien, C. (2007). Demography is not destiny: Increasing the graduation rates of low-income college students at large public universities. Washington, DC: The Pell Institute for the Study of Opportunity in Higher Education.

Engle, J., \& Tinto, V. (2008). Moving beyond access: College success for low-income and first generation students. Washington, DC: The Pell Institute for the Study of Opportunity in Higher Education.

Engstrom, C. M., \& Tinto, V. (2008). Learning better together: The impact of learning communities on the persistence of low-income students. Opportunity Matters, 1, $5-21$.

Engstrom, C. M., \& Tinto, V. (2008, January/February). Access without support is not opportunity. Change, 40(1), 46-50.

Errante, A. (2000). But sometimes you're not part of the story: Oral histories and ways of remembering and telling. Educational Researcher, 29(16), 16-27.

Federal Communication Commission. (2012). Eighth broadband progress report. Retrieved from: http://www.fcc.gov/reports/eighth-broadband-progress-report 
Filkins, J. W., \& Doyle, S. K. (2002, June). First generation and low income students: Using the NSSE data to study effective educational practices and students selfreported gains. Paper presented at the Annual Forum for the Association for Institutional Research, Toronto, Ontario, Canada. Paper retrieved from: http://cpr.iub.edu/uploads/Filkins,\%20Doyle\%20(2002)\%20\%20first\%20gen\%20 and\%20low\%20income.pdf

Fitzgerald, B. K., \& Delaney, J. A. (2002). Educational opportunity in America. In D.E. Heller (Ed.) Condition of access: Higher education for lower income students (pp. 3-24). Westport, CT: Praeger.

Folger, W. A., Carter, J. A., \& Chase, P. B. (2004). Supporting first-generation college freshman with small group intervention. College Student Journal, 38, 472-476.

Gallant, D. R., \& Bliss, A. (2006). Qualitative social science research. In E. A. Bankert \& R. J. Amdur (Eds.) Institutional review board: Management \& function. (pp.403-414). Sudbury, MA: Jones \& Bartlett Publishers.

Gibbons, M. M., \& Shoffner, M. F. (2004). Prospective first-generation college students: Meeting their needs through social cognitive career theory. Professional School Counseling, 8(1), 91-97.

Gladieux, L. E., \& Swail, W. S. (1999). Financial aid is not enough: Improving the odds For minority and low-income students. In J. E. King (Ed.) Financing a college education: How it works, how it’s changing. (pp. 177-197). Phoenix, AZ.: The American Council on Education and The Oryx Press.

Gladieux, L. E., \& Swail, W. S. (2000). Beyond access: Improving the odds of college success. The Phi Delta Kappan, 81, 688-692. 
Glaser, B. G., \& Strauss, A. L. (1967). The discovery of grounded theory: Strategies for qualitative research. Chicago, IL: Aldine Publishing Company.

Glesne, C. (2006). Becoming qualitative researchers: An introduction. New York, NY: Pearson.

Goetsch, H. B. (1940). Relation of parental income to college opportunity. The School Review, 48(1), 26-33.

Golafshani, N. (2003). Understanding reliability and validity in qualitative research. The Qualitative Report, 8(4), 597-606.

Goldhaber, D., \& Peri, G. K. (2007). Community colleges. In S. Dickert-Conlin \& R. Rubenstein, (Eds.) Economic inequality and higher education: Access, persistence, and success (pp.101-127). New York, NY: Russell Sage Foundation. Goldrick-Rab, S. (2006). Following their every move: An investigation of social-class differences in college pathways. Sociology of Education, 79(67), 61-79.

Goldrick-Rab, S., \& Pfeffer, F. T. (2009). Beyond access: Explaining socioeconomic differences in college transfer. Sociology of Education, 82(2), 101-125.

Gos, M. W. (1995). Overcoming social class markers: Preparing working class students for college. The Clearing House, 69(1), 30-34.

Grayson, J. P. (1997). Academic achievement of first-generation students in a Canadian university. Research in Higher Education, 38, 659-676.

Green, D. (2006). Historically underserved students: What we know, what we still need to know. New Directions for Community Colleges, 135, 21-28.

Grcich, K. D. (2008). Beyond the gates: An exploration of socioeconomically disadvantaged students navigating the University of Pennsylvania (Doctoral dissertation). Retrieved from ProQuest. (UMI Number: 3310480) 
Harrell, P. E., \& Forney, W. S. (2011). Ready or not, here we come: Retaining Hispanic and first-generation students in postsecondary education. Community College Journal of Research and Practice, 27(2), 147-156.

Haycock, K., Lynch, M., \& Engle, J. (2010). Opportunity adrift: Our flagship universities are straying from their public mission. Washington, DC: The Education Trust.

Hearn, J. C. (1984). The relative roles of academic, ascribed, and socioeconomic characteristics in college destinations. Sociology of Education, 57(1), 22-30.

Hertel, J. B. (2002). College student generational status: Similarities, differences, and factors in college adjustment. The Psychological Record, 52, 3-18.

Hicken, M. (2013, March 6). Public college tuition spiked 8.3\% last year. CNN Money. Retrieved online at: http://money.cnn.com/2013/03/06/pf/college/public-collegetuition/index.html

Hicks, T. (2002). Advising the first-generation college student: Effective retention tools for colleges and universities. Faculty Working Papers from the School of Education. Paper 6.http://digitalcommons.uncfsu.edu/soe_faculty_wp/6

Hicks, T. (2003). First generation and non-first generation pre-college students' expectations and perceptions about attending college. Faculty Working Papers from the School of Education. Paper 10.

http://digitalcommons.uncfsu.edu/soe_faculty_wp/10 
Hicks, T. (2005). A profile of choice/responsibleness and goal-seeking attitudes among first-generation and non-first generation college students. Faculty Working Papers from the School of Education. Paper 2.

http://digitalcommons.uncfsu.edu/soe_faculty_wp/2

Hirudayaraj, M. (2011). First-generation students in higher education: Issues of employability in a knowledge based economy. Online Journal for Workforce Education and Development, 5(3), 1-10.

Hodsdon, M. C. (2008). The road less travelled: Tracing the path of first-generation Students from rural areas to college (Doctoral dissertation). Retrieved from ProQuest. (UMI Number: 3523428)

hooks, b. (2000). Where we stand: Class matters. New York, NY \& London, England: Routledge.

Horvat, E. M. (2001). Understanding equity and access in higher education: The potential contribution of Pierre Bourdieu. In J. C. Smart (Ed.) Higher Education: Handbook of theory and research Vol. XVI (pp. 195-238). New York, NY: Agathon Press.

Hossler, D., Schmit, J., \& Vesper, N. (1999). Going to college: How social, economic, and educational factors influence the decisions students make. Baltimore, MD: The John Hopkins University Press.

Howard, A. (2001). Students from poverty: Helping them make it through college. About Campus, November/December, 5-12.

Hoxby, C. M., \& Avery, C. (2012). The missing “one-offs": The hidden supply of highachieving, low income students. Working paper 18586: National Bureau of Economic Research: Cambridge, MA. 
Hsiao, K. P. (1992). First-generation college students. [Washington, DC] : Distributed by ERIC Clearinghouse, 3 p.

Hurst, A. L. (2008). A healing echo: Methodological reflections of a working-class researcher on class. The Qualitative Report, 13(3), 334-352.

Hurst, A. L. (2010). The burden of academic success. Lanham, MD: Lexington Books.

Ingels, S. J., Curtin, T. R., Kaufman, P., Alt, M. N., \& Chen, X. (2002). Coming of age in the 1990’s: The eighth-grade class of 198812 years later. US Department of Education: National Center for Education Statistics (NCES Publication No. 2002-321).

Ingram, D. D., \& Franco, S. J. (2014). 2013 NCHS urban-rural classification scheme for counties. National Center for Health Statistics. Vital Health Statistics, 2(166).

Inkelas, K. K., Daver, Z. E., Vogt, K. E., \& Leonard, J. B. (2007). Living learning programs and first-generation college students’ academic and social transition to college. Research in Higher Education 48, 403-434.

Inman, W. E., \& Mayes, L. (1999). The importance of being first: Unique characteristics of first-generation community college students. Community College Review, 26(3), 3-22.

Institute for Higher Education. (2012). Supporting first-generation college students through classroom-based practices. Washington, D.C.: Institute for Higher Education Policy.

Ishitani, T. T., \& DesJardins, S. L. (2002, June). A longitudinal investigation of dropout from college in the U.S. Paper presented at symposium conducted at the AIR $42^{\text {nd }}$ Annual Forum, Toronto, CA. 
Ishitani, T. T. (2003). A longitudinal approach to assessing attrition behavior among first generation students: Time varying effects of pre-college characteristics. Research in Higher Education, 44, 433-449.

Ishitani, T. T. (2006). Studying attrition and degree completion behavior among firstgeneration college students in the United States. The Journal of Higher Education, 77, 861-885.

Jean, D. (2010). The academic and social adjustment of first-generation college students (Doctoral dissertation). Retrieved from ProQuest. (UMI Number: 3416604)

Jehangir, R. (2010). Stories as knowledge: Bringing the lived experience of firstgeneration college students into the academy. Urban Education, 45(4), 533-553.

Johnson, I. (2008). Enrollment, persistence, and graduation of in-state students at a public research university: Does high school matter? Research in Higher Education, 49, 776-793.

Julian, T., \& Kominiski, R. (2011). Education and synthetic work-life earnings estimates: American community survey reports. U.S. Department of Commerce: U.S. Census Bureau.

Kahlenberg, R. D. (2004). America's untapped resource: Low-income students in higher education. New York, NY: The Century Foundation Press.

Kalmijn, M., \& Kraaykamp, G. (1996). Race, cultural capital, and schooling: An analysis of trends in the United States. Sociology of Education, 69(1), 22-34.

Karp, M. M., \& Hughes, K. L. (2008). Supporting college transitions through collaborative programming: A conceptual model for guiding policy. Teachers College Record, 110, 838-866.

Kaufman, G. (1974). The meaning of shame: Toward a self-affirming identity. Journal of Counseling Psychology, 21, 568-574. 
Kelly, P. J. (2011). Realizing Kentucky's educational attainment goal: A look in the rear view mirror and down the road ahead. Boulder, CO: National Center for Higher Education Management Systems.

Council on Postsecondary Education. (2007). Double the numbers: Kentucky's

Plan to increase college graduates. Retrieved from: http://www.cpe.ky.gov/doublethenumbers/

Kentucky Council on Postsecondary Education. (2009). Kentucky postsecondary education 2008-10 county profiles. Retrieved from: http://cpe.ky.gov/info/county/

Khan, M. (2008). First-generation college students: Finding an identity and fulfilling dreams. Journal of Student Affairs, 4, 12-18.

Kim, K. K., \& Sax, L. J. (2009). Student-faculty interaction in research universities: Differences by student gender, race, social class, and first-generation status. Research in Higher Education, 50, 437-459.

Kim, D. H., \& Schneider, B. (2005). Social capital in action: Alignment of parental support in adolescents' transition to postsecondary education. Social Forces, 84, 1181-1206.

Kuh, G. D., \& Love, P. G. (2000). A cultural perspective on student departure. In J. M. Braxton (Ed.) Reworking the student departure puzzle: New theory and research on college student retention (pp. 196-212). Nashville, TN.: Vanderbilt University Press.

Kuh, G. D., Kinzie, J., Schuh, J. H., \& Whitt, E. J. (2005). Student success in college. San Francisco, CA: Jossey-Bass.

Lamont, M., \& Lareau, A. (1988). Cultural capital: Allusions, gaps and glissandos in Recent theoretical developments. Sociological Theory, 6(2), 153-168.

Lareau, A. (1987). Social class differences in family-school relationships: The importance of cultural capital. Sociology of Education, 60(2), 73-85. 
Lask, T. M. (2008). First generation students: Stories of hope and resilience (Doctoral dissertation). Retrieved from ProQuest. (UMI Number: 3322454)

Lee, S. M., Daniels, M. H., Puig, A., Newgent, R. A., \& Nam, S. K. (2008). A data-based model to predict postsecondary educational attainment of low-socioeconomicstatus students. Professional School Counseling, 11, 306-316.

Lehmann, W. (2007). “I just didn’t feel like I fit in”: The role of habitus in university drop-out decisions. Canadian Journal of Higher Education, 37(2), 89-110.

Levine, A., \& Nidiffer, J. (1996). Beating the odds: How the poor get to college. San Francisco, CA: Jossey-Bass.

Levine, L. (2012). An analysis of the distribution of wealth across households, 19892010. Washington, DC: Congressional Research Service.

Lewin, K. (1936). Principles of topological psychology. New York, NY: McGraw-Hill Book Company, Inc.

Lewin, T. (2013, March 6). Financing for colleges declines as costs rise. The New York Times, Retrieved online at: http://www.nytimes.com/2013/03/06/education/aidfor-higher-education-declines-as-costs-rise.html

Light, R. (2001). Making the most of college: Students speak their minds. Cambridge, MA., London, England: Harvard University Press.

Lincoln, Y. S., \& Guba, E. G. (1985). Naturalist inquiry. Beverly Hills, CA: Sage.

Lobo, C. P. (2001). Tellin' it like it is: Disempowerment and marginalization of firstgeneration, low-income college students: A participatory research (Doctoral dissertation). Retrieved from ProQuest. (UMI Number: 3010142)

Logan, J. Q. (2007). Psychosocial influences on college attendance among first and continuing-generation college students (Doctoral dissertation). Retrieved from ProQuest. (UMI Number: 3263895) 
Lohfink, M. M., \& Paulsen, M. B. (2005). Comparing the determinants of persistence for first-generation and continuing-education students. Journal of College Student Development, 46, 409-428.

London, H. B. (1989). Breaking away. American Journal of Education, 97, 144-170.

London, H. B. (1992). Transformations: Cultural challenges faced by first-generation students. New Directions for Community College, 80, 5-11.

London, H. B. (1996). How college affects first-generation students. About Campus, 1(5), 9-13.

López Turley, R. N. (2006). When parents want children to stay home for college. Research in Higher Education, 47, 823-846.

Lotkowski, V. A., Robbins, S. B., \& Noeth, R. J. (2004). The role of academic and nonacademic factors in improving college retention. Iowa City, IA: American College Testing ACT Inc.

Lynch, M. (2013). It's tough to trailblaze: Challenges of first-generation college students. Diverse Issues in Higher Education. Retrieved from: http://diverseeducation.com/article/50898/

Maples, M. R. (2000). Rural students' satisfaction with college environment: An ecological consideration (Doctoral dissertation). Retrieved from ProQuest. (UMI Number: 9996133)

Marshall, C., \& Rossman, G. B. (1995). Designing qualitative research. ( ${ }^{\text {nd }}$ ed.). Thousand Oaks, CA: Sage.

Martin, G. L. (2012). Getting out, missing out, and surviving: The social class experiences of white, low-income, first-generation college students (Doctoral dissertation). Retrieved from ProQuest. (UMI Number: 3516740) 
McCarron, G. P., \& Inkelas, K. K. (2006). The gap between educational aspirations and attainment for first-generation college students and the role of parental involvement. Journal of College Student Development, 47, 534-549.

McCracken, G. (1988). The long interview. Newbury Park, CA: Sage.

McDavis, R. (2010). Including the needs of poor, rural students in the diversity equation. Diverse Issues in Higher Education, 27(2). Retrieved from: http://www.readperiodicals.com/201003/1980857541.html

McDonough, P. M. (1997). Choosing colleges: How social class and schools structure opportunity. Albany, NY: State University of New York Press.

McGregor, L. N., Mayleben, M. A., Buzzanga, V. L., Davis, S. F., \& Becker, A. H. (1991). Selected personality characteristics of first-generation college students. College Student Journal, 25, 231-234.

McKay, V. C., \& Estrella, J. (2008). First generation student success: The role of faculty interaction in service learning courses. Communication Education, 57, 356-372.

McMahon, W. W. (2009). Higher learning, greater good: The private and social benefits of higher education. Baltimore, MD: John Hopkins University Press.

Merriam, S. B. (1998). Qualitative research and case study applications in education. San Francisco, CA: Jossey-Bass.

Merriam, S. B. (2000). Qualitative research in practice: Examples for discussion and analysis. San Francisco, CA: Jossey-Bass.

Miller, R., \& Tatum, S. (2007). The association of family history knowledge and cultural change with persistence among undergraduate low-income, first-generation college students. Research and Teaching in Developmental Education, 24(2), 3955. 
Miller, M. T., \& Tuttle, C. C. (2007). Building communities: How rural community colleges develop their communities and the people who live in them. Community College Journal, 31(2), 117-127.

Miles, M. B., Huberman, A. M., \& Saldana, J. (2013). Qualitative data analysis: A methods sourcebook. ( $3^{\text {rd }}$ ed.) Los Angeles, CA: Sage.

Miser, W. F. (2005). Educational research - to IRB, or not to IRB? Family Medicine, 37, 168-173.

Moore, N. D. (2003). The relationships of family environment and academic performance to college adjustment of first-generation, low-income college students after a summer program and fall semester transition (Doctoral dissertation). Retrieved from ProQuest. (UMI Number: 3075767)

Moss, K. (2003). The color of class. Philadelphia, PA.: University of Pennsylvania Press. Mueller, K. L. (1997). Involvement as a critical factor in the persistence of seniors who are first generation college students.(Master’s thesis). Retrieved from ProQuest. (UMI Number:1388719)

Muraskin, L., Lee, J., Wilner, A., \& Swail, W. S. (2004). Raising the college graduation rates of low-income students. Washington, DC: The Pell Institute for the Study of Opportunity in Higher Education.

Murphy, C. G., \& Hicks, T. (2006). Academic characteristics among first-generation and non-first-generation college students. College Quarterly, 9(2), n2.

National Association of Independent Colleges and Universities. (2011). Independent colleges and universities: A national profile. Washington, DC.

National Center for Children in Poverty. (2007). Poverty by the numbers: By race, white children make up the biggest percentage of America's poor. Retrieved from: http://www.nccp.org/media/releases/release_34.html

Nichols, L. (2004). Giving students a voice: Learning through autobiography. The NEA Higher Education Journal, 19(2), 37-50. 
Nidiffer, J. (1999). The "poorest" in American higher education. History of Education Quarterly, 39, 321-336.

Nora, A. (2001). The depictions of significant others in Tinto's "Rites of Passage": A reconceptualization of the influence of family and community in the persistence process. Journal of College Student Retention: Research , Theory, and Practice, 3(1), 41-56.

Nora, A., Barlow, E., \& Crisp, G. (2005). Student persistence and degree attainment beyond the first year in college: The need for research. In A. Seidman (Ed.) College student retention (pp. 1-29). Westport, CT: American Council on Education and Praeger Publishers.

Nunez, A., \& Carroll, C. D. (1998). First-generation students: Undergraduates whose parents never enrolled in postsecondary education. U.S. Department of Education.

Oldfield, K. (2007). Humble and hopeful: Welcoming first-generation poor and workingclass students to college. About Campus, 11(6), 2-12.

Olivérez, P. M. (2013). Developing an effective peer mentoring program to support firstgeneration college students. [PowerPoint slides]. Retrieved from: http://www.innovativeeducators.org//v/vspfiles/V4_Backup/03_06_13_Oliverez_ Peer Mentor2013.ppt

Orbe, M. (1996). Laying the foundation for co-cultural communicative theory: An Inductive approach to studying the non-dominant communicating strategies and the factors that influence them. Communication Studies, 47, 157-176. 
Orbe, M. P., \& Groscurth, C. R. (2004). A co-cultural theoretical analysis of communicating on campus and at home: Exploring the negotiation strategies of first-generation college (FGC) students. Qualitative Research Reports in Communication, 5, 41-47.

Orbe, M. P. (2004). Negotiating multiple identities within multiple frames: An analysis of first-generation college students. Communication Education 53(2), 131-149.

Orbe, M. P. (2008). Theorizing multidimensional identity negotiation: Reflections on the lived experiences of first-generation college students. New Directions for Child and Adolescent Development, 2008(120), 81-95.

Padron, E. J. (1992). The challenge of first-generation students: A Miami-Dade perspective. In H. B. London \& L. S. Zwerling (Eds.), First-generation students: Confronting the cultural issues (pp. 71-80). San Francisco, CA: Jossey-Bass.

Pascarella, E. T., \& Terenzini, P. T. (1991). How college affects students. San Francisco, CA: Jossey-Bass.

Pascarella, E. T., Pierson, C. T., Wolniak, G. C., \& Terenzini, P. T. (2003). Experiences and outcomes of first-generation students in community colleges. Journal of College Student Development, 44, 420-429.

Pascarella, E. T., Pierson, C. T., Wolniak, G. C., \& Terenzini, P. T. (2004). Firstgeneration college students: Additional evidence on college experiences and outcomes. The Journal of Higher Education 75, 249-284.

Patton, M. Q. (2002). Qualitative research \& evaluative methods ( $3^{\text {rd }}$ ed.). Thousand Oaks, CA: Sage. 
Paulsen, M. B., \& St. John, E. P. (2002). Social class and college costs: Examining the financial nexus between college choice and persistence. The Journal of Higher Education, 73,189-236.

Payne, K. A. (2007). First-generation college students: Their challenges and the advising strategies that can help. The Mentor: An Academic Advising Journal, 9(1), Retrieved from: http://dus.psu.edu/mentor/old/articles/070131kp.htm

Perna, L. W., \& Titus, M. A. (2005). The relationship between parental involvement as social capital and college enrollment: An examination of racial/ethnic group differences. The Journal of Higher Education, 76, 485-518.

Perna, L. W., Rowan-Kenyon, H., Bell, A., Thomas, S. L., \& Chunyan, L. (2008). The typology of federal and state programs designed to promote college enrollment. The Journal of Higher Education, 79, 243-267.

Phillips, M., \& Chin, T. (2003). School inequality: What do we know? Paper prepared for The Russell Sage Foundation's Social Dimension of Inequality Program, Russell Sage Foundation: New York, NY.

Phinney, J. S., \& Haas, K. (2003). The process of coping among ethnic minority firstgeneration college freshmen: A narrative approach. The Journal of Social Psychology, 143, 707-726.

Pike, G. R., \& Kuh, G. D. (2005). First-and second-generation college students: A comparison of their engagement and intellectual development. The Journal of Higher Education, 76, 276-300.

Piorkowski, G. K. (1983). Survivor guilt in the university setting. The Personnel and Guidance Journal, 61, 620-622. 
Poverty still plagues McCreary: Food stamp usage continues to rise here. (2009, December). McCreary County Record. Retrieved online from: http://www.mccrearyrecord.com/local/x546248088/Poverty-still-plaguesMcCreary

President's Commission on Higher Education. (1947). Higher education for American democracy. Washington, D.C.: U.S. Government Printing Office.

Prospero, M., \& Vohra-Gupta, S. (2007). First generation college students: Motivation, integration, and academic achievement. Community College Journal of Research and Practice, 31, 963-975.

Rager, K. B. (2005). Self-care and the qualitative researcher: When collecting data can break your heart. Educational Researcher, 34(4), 23-27.

Ramos-Sanchez, L., \& Nichols, L. (2007). Self-efficacy of first generation and non-firstgeneration college students: The relationship with academic performance and college adjustment. Journal of College Counseling, 10, 6-18.

Ramsey, K., \& Peale, C. (2010, May). First-generation college students stay the course. USA Today. Retrieved online from: USAToday.com

Rank, M. R. (2005). One nation, underprivileged: Why American poverty affects us all. Oxford, England; New York, NY: Oxford University Press.

Reason, R. D. (2009). An examination of persistence research through the lens of a comprehensive conceptual framework. Journal of College Student Development, 50, 659-682. 
Reid, M. J., \& Moore, J. L. (2008). College readiness and academic preparation for postsecondary education: Oral histories of first-generation urban college students. Urban Education, 43(2), 240-261.

Rendon, L. I. (1992). From the barrio to the academy: Revelations of a Mexican American scholarship girl.” In H. B. London \& L. S. Zwerling (Eds.) Firstgeneration students: Confronting the cultural issues (pp. 55-64). San Francisco, CA: Jossey-Bass.

Rendon, L. I. (1995, March). Facilitating retention and transfer for first generation students in community college. Paper presented at the New Mexico Institute, Rural Community College Initiative, Espanola, NM.

Rodriguez, R. (1974). Going home again: The new American scholarship boy. The American Scholar, 44(1), 15-28.

Rodriguez, S. (2001). Giants among us: First-generation college graduates who lead activist lives. Nashville, TN: Vanderbilt University Press.

Rodriguez, S. (2003). What helps some first-generation students succeed? About Campus, $8(4), 17-22$.

Rondini, A. C. (2010). Negotiating identity: Elite institutions, low-income first generation college students, and their parents (Doctoral dissertation). Retrieved from ProQuest. (UMI Number: 3403348)

Rossman, G. B., \& Rallis, S. F. (2003). Learning in the field: An introduction to qualitative research. Thousand Oaks, CA: Sage. 
Rowan-Kenyon, H. T., Bell, A. D., \& Perna, L. W. (2008). Contextual influences on parental involvement in college going: Variations by socioeconomic class. The Journal of Higher Education, 79, 564-586.

Rubin, H. J., \& Rubin, I. S. (1995). Qualitative interviewing: The art of hearing data. Thousand Oaks, CA: Sage.

Rural students: Common obstacles, different settings. (2006). Chronicle of Higher Education, 53(11).

Saenz, V. B., Hurtado, S., Barrera, D., Wolf, D., \& Yeung, F. (2007). First in my family: A profile of first-generation college students at four-year institutions since 1971. Cooperative Institutional Research Program: Higher Education Research Institute: Los Angeles, CA.

Saldana, J. (2009). The coding manual for qualitative researchers. London, England; Thousand Oaks, CA: Sage.

Schutz, P. F. (2003). Upon entering college: First semester experiences of firstgeneration, rural students from agricultural families (Doctoral dissertation.) Retrieved from ProQuest. (UMI Number: 3092695)

Schutz, P. F. (2004). Upon entering college: First semester experiences of firstgeneration, rural students from agricultural families. Rural Educator, 26, 28-51.

Seider, M. (2008). The dynamics of social reproduction: How class works at a state college and elite private college. Equity \& Excellence in Education, 41(1), 45-61.

Seider, M., \& Aries, E. (2004, August). Pushing class aside: How college students legitimize the class structure. Paper presented at a meeting of the American Sociological Association. San Francisco, CA. 
Settle, J. (2005). The effect of socioeconomic status on year-to-year persistence of firstGeneration and continuing generation college students at two-year and four-year institutions: Developing a conceptual model (Doctoral dissertation). Retrieved from ProQuest. (UMI Number: 3197914)

Sheehy, K. (2011). High-tech tools often lacking for rural students. U.S. News Digital Weekly, 3(49), 15.

Shields, N. (2002). Anticipatory socialization, adjustment to university life, and perceived stress: Generational and sibling effects. Social Psychology of Education, 5, 365-392.

Smith, J. L. (2011). The meaning of college access and persistence for low-income, firstgeneration college students (Doctoral dissertation). Retrieved from ProQuest. (UMI Number: 3459902)

Somers, P., Woodhouse, S., \& Cofer, J. (2004). Pushing the boulder uphill: The persistence of first-generation college students. NASPA Journal, 41, 418-435.

Speirs Neumeister, K. L., \& Rinker, J. (2006). An emerging professional identity: Influences on the achievement of high-ability first-generation college females. Journal for the Education of the Gifted, 29, 305-338.

Spence, D., Blanco, C. D., \& Root, M. (2010). No time to waste: Policy recommendations for increasing college completion. Southern Regional Education Board, Atlanta, GA: Edited by A. Richard.

St. Clair-Christman, J. M. (2011). Family support and institutional support for lowincome, first-generation college students (Doctoral dissertation). Retrieved from ProQuest. (UMI Number: 3479160) 
Steinmetz, C. L. (2008). Negotiating class boundaries: A phenomenological study of the Effects of poverty on the identity development of college students (Doctoral dissertation). Retrieved from ProQuest. (UMI Number: 3312115)

Stephens, H. M., Fryberg, S. A., Markus, H. R., Johnson, C. S., \& Covarrubias, R. (2012). Unseen disadvantage: How American universities’ focus on independence undermines the academic performance of first-generation college students. Journal of Personality and Social Psychology, 102(6), 1-20.

Stinebrickner, R., \& Stinebrickner, T. R. (2002). Understanding educational outcomes of students from low-income families. The Journal of Human Resources, 38, 591617.

Strage, A. A. (1999). Social and academic integration and college success: Similarities and differences as a function of ethnicity and family educational background. College Student Journal, 33(2), 198-205.

Strauss, A., \& Corbin, J. (1990). Basics of qualitative research: Grounded theory procedures and techniques. Newbury Park, CA: Sage.

Strayhorn, T. L. (2006). Factors influencing the academic achievement of first-generation college students. NASPA Journal, 43(4), 82-111.

Sullivan, N. (2003). Academic constructions of "white trash," or how to insult poor people without really trying. In V.C. Adair \& S.L. Dahlberg (Eds.), Reclaiming class: Women, poverty, and the promise of higher education in America. (pp. 5366). Philadelphia, PA: Temple University Press.

Swartz, D. (1997). Culture and power: The sociology of Pierre Bourdieu. Chicago, IL: University of Chicago Press. 
Terenzini, P. T., Rendon, L., Upcraft, M. L., Millar, S., Allison, K., Gregg, P., \& Jalomo, R. (1994). The transition to college: Diverse students, diverse stories. Research in Higher Education, 35, 57-73.

Terenzini, P. T., Springer, L., Yaeger, P. M., \& Pascarella, E. T. (1996). First-generation college students: Characteristics, experiences, and cognitive development. Research in Higher Education, 37, 1-22.

Terenzini, P. T., Cabrera, A. F., \& Bernal, E. M. (2001). Swimming against the tide: The poor in American higher education. Commissioned Report for the College Entrance Examination Board, New York, NY.

Thayer, P. B. (2000, May). Retention of students from first-generation and low-income backgrounds. Paper prepared for the Council of Opportunity in Education, Washington, DC.

The Institute for Higher Education Policy. (2001). Getting through college: Voices of low-income and minority students in New England. The New England Student Success Study. Sponsored by: Nellie Mae Foundation, Quincy, MA.

Tierney, W. G. (1992). An anthropological analysis of student participation in college. The Journal of Higher Education, 63, 603-618.

Tierney, W. G., \& Venegas, K. M. (2009). Finding money on the table: Information, financial aid, and access to college. The Journal of Higher Education, 80, 363388.

Ting, S. R. (2003). A longitudinal study of non-cognitive variables in predicting academic success of first-generation college students. College and University, 78(4), 27-31.

Ting, S. R. (1998). Predicting first-year grades and academic progress of college students of first-generation and low-income families. Journal of College Admission, (158), 14-23. 
Tinto, V. (1975). Dropout from higher education: A theoretical synthesis of recent research. Review of Educational Research, 45, 89-125.

Tinto, V. (1987). Leaving college: Rethinking the causes and cures of student attrition. ( $1^{\text {st }}$ ed.).Chicago, IL: The University of Chicago Press.

Tinto, V. (1988). Stages of student departure: Reflections on the longitudinal character of student leaving. The Journal of Higher Education, 59(4), 438-455.

Tinto, V. (1993). Leaving college: Rethinking the causes and cures of student attrition. ( $2^{\text {nd }}$ ed.).Chicago, IL: The University of Chicago Press.

Tinto, V. (2007). Research and practice of student retention: What next? Journal of College Student Retention, 8(1), 1-19.

Tinto, V. (2012). Completing college: Rethinking institutional action. Chicago, IL: The University of Chicago Press.

Titus, M. (2006a). No college student left behind: The influence of financial aspects of a state’s higher education policy on college completion. The Review of Higher Education, 29, 293-317.

Titus, M. (2006b). Understanding college degree completion of students with low socioeconomic status: The influence of the institutional financial context. Research in Higher Education, 47, 371-398.

Torres, V. (2003). Influences on ethnic identity development of Latino students in the first two years of college. Journal of College Student Development, 44, 532-547.

Tyre, P., \& Scelfo, J. (2003). Falling through the cracks. Newsweek, 142(20).

University of Kentucky. (2014). Robinson scholars program. Retrieved online from: http://www.uky.edu/RobinsonScholars/

University of Louisville. (2014). About UofL. Retrieved online from: http://louisville.edu/about/ 
University of Louisville Office of Institutional Research and Planning. (2014). Just the facts:2013-14. Retrieved from:

http://louisville.edu/institutionalresearch/institutional-research-planning

University of Louisville Office of Student Financial Aid. (2014). Cardinal Covenant:

Student financial aid. Retrieved from: http://louisville.edu/financialaid/cardinalcovenant

University of Louisville TRIO Student Support Service. (2015). Retrieved from: http://louisville.edu/trio

University of Kentucky Undergraduate Housing \& Residence Life. (2014). Retrieved from: http://www.uky.edu/Housing/undergraduate/llp/firstGen.html

U.S. Census Bureau. (2010). 2010 Census urban and rural classification and urban area criteria. Retrieved from: http:/www.census.gov/geo/reference/ua/urban-rural2010.html

U.S. Census Bureau. (2010). Mean earnings by highest degree earned. Retrieved from: http://www.census.gov/compendia/statab/2012/tables/12s0232.xls

U.S. Census Bureau. (2012). Education. Retrieved from: http://www.census.gov/compendia/statab/cats/education.html

U.S. Census Bureau. (2012). Income, expenditures, poverty, \& wealth: Income and poverty—state and local data. Retrieved from: http://www.census.gov/compendia/statab/cats/income_expenditures_poverty_wea lth/income_and_poverty--state_and_local_data.html

U.S. Census Bureau. (2012). State \& county quickfacts. Retrieved from: http://quickfacts.census.gov/qfd/states/21000.html 
U.S. Census Bureau. (2013). Income, poverty and health insurance in the United States: 2011 - tables \& figure. Retrieved from: http://www.census.gov/hhes/www/poverty/data/incpovhlth/2012/index.html

U.S. Department of Education: Office of Educational Research and Improvement. (2001). Bridging the gap: Academic preparation and postsecondary success of firstGeneration students. National Center for Education Statistics: Statistical Analysis Report.

U.S. Department of Education. (2014). Federal trio programs: Upward bound program. Retrieved from http://www2.ed.gov/programs/trioupbound/index.html U.S. Department of Health and Human Services. (2012). 2012 HHS poverty guidelines: One version of the (U.S.) federal poverty measure. Retrieved from: http://aspe.hhs.gov/poverty/12poverty.shtml

U.S. Department of Health and Human Services. (2014). 2013 NCHS urban-rural classification scheme for counties. (Series 2, Number 66).

Van Galen, J. A. (2000). Education \& class. Multicultural Education, 7(3), 2-11.

Vargas, J. H. (2004). College knowledge: Addressing information barriers to college. The Education Resources Institute (TERI): Boston, MA.

Vedantam, S. (2013). Elite colleges struggle to recruit smart, low-income kids. National Public Radio. Retrieved online from: http://www.npr.org/2013/01/09/168889785/elite-collegesstruggle-to-recruit-smart-low-income-kids

Venegas, K. M. (2006). Internet inequalities: Financial aid, the internet, and low-income students. American Behavioral Scientist, 49, 1652-1669. 
Walpole, M. (2003). Socioeconomic status and college: How SES affects college experiences and outcomes. The Review of Higher Education, 27, 45-73.

Wang, C. D., \& Castaneda-Sound, C. (2008). The role of generational status, self-esteem, academic self-efficacy, and perceived social support in college students’ psychological well-being. Journal of College Counseling, 11, 101-118.

Waterman, S. J. (2004). The Haudenosaunee college experience: A complex path to degree completion (Doctoral dissertation). Retrieved from ProQuest. (UMI Number:3132719)

Weis, L. (1992). Discordant voices in the urban community college. In H. B. London \& L. S. Zwerling (Eds.) First-generation students: Confronting the cultural issues, (pp. 13-28). San Francisco, CA: Jossey-Bass.

Wells, R. (2008). The effects of social and cultural capital on student persistence: Are community colleges more meritocratic? Community College Review, 36(1), 2546.

Wells, R. (2008-09). Social and cultural capital, race, and ethnicity, and college student retention. Journal of College Student Retention, 10(2), 103-128.

Whiting, M. E. (1999). The university and the white, rural male. Journal of Research in Rural Education, 15(3), 157-164.

Whitt, E. J. (1991). Artful science: A primer on qualitative research methods. Journal of College Student Development, 32, 406-415.

Wilkins, A. C. (2014). Race, age, and identity transformations in the transition from high school to college for black and first-generation white men. Sociology of Education, 87(3), 171-187. 
Williams, C. R., \& Butler, S. K. (2010). A new retention variable: Hope and first generation college students. Retrieved from http://counselingoutfitters.com/vistas/ vistas10/Article_11.pdf

Wyner, J. S., Bridgeland, J. M., \& Diulio, J. J. (2007). Achievementrap: How America is failing millions of high-achieving students from low-income families. A report from the Jack Kent Cooke Foundation \& Civic Enterprises with Original Research by Westat.

Yarbrough, S. A. (1996). Perceptions of the decision-making process used by rural high school students in regard to higher education. (Doctoral dissertation). Retrieved from ProQuest. (UMI Number: 9721222)

Yeh, T. L. (2010). Service-learning and persistence of low-income, first-generation college students: An exploratory study. Michigan Journal of Community Service Learning, 16(2), 50-65.

Yen, H. (2013). Four in five in U.S. face near-poverty, no work. [USA Today online]. Retrieved from: http://www.usatoday.com/story/money/business/2013/07/28/americans-povertyno-work/2594203/

Yizar, J. H. (2010). Enrollment factors that predict persistence of at-risk (low-income and first generation) students' journey towards completion of a baccalaureate degree (Doctoral dissertation). Retrieved from ProQuest. (UMI Number: 3448146)

Yoder, M. J. (2007). Rural students' access to and success in higher education: A case study (Doctoral dissertation). Retrieved from ProQuest. (UMI Number: 3306663). 
Yosso, T. J. (2005). Whose culture has capital? A critical race theory discussion of community cultural wealth. Race Ethnicity and Education, 8(1), 69-91.

Zinn, H. (1999). A people's history of the United States: 1492 to present. New York, NY: HarperCollins Publishers. 


\section{TARGETED E-MAIL TO CARDINAL COVENANT AND TRIO STUDENTS}

You are being invited to participate in a research study should you meet certain criteria. The purpose of this study is to learn what strategies, practices, actions, and behaviors low-income, first-generation students from a rural background employ and engage in to persist and be academically successful. This study is being conducted to fulfill the requirements for completing my doctoral degree here at the University of Louisville.

You are receiving this e-mail because you have been identified as a student who may meet the additional criteria for this study. In order to be eligible, participants must:

- identify as being from a low-income family background

- having grown up or identify as originating from a rural environment

- not having a parent who has graduated with a 4-year college degree

- have at least a 2.5 cumulative college GPA

- have completed at least 60 credit hours (not all credits need to have been completed at $\mathrm{U}$ of $\mathrm{L}$ )

Any information you provide will be kept confidential, however federal regulatory agencies and the University of Louisville Institutional Review Board (a committee that reviews and approves research studies) may inspect and copy records pertaining to this research. To help protect your confidentiality, I will use a study identification code number and a study name, not your real name, to identify all information collected for the study.

Please note that participation in this study is completely voluntary. You will not have any costs associated with the study, however, you will also receive no payment for the study either. If you participate in the interviews, however, you will be entered into the drawing for one of two $\$ 25$ Kroger gift cards. If you have any questions regarding the study, don't hesitate to contact me, Aaron Phillips at: 502-852-3214 or aaron.phillips@louisville.edu; or the chair of my dissertation committee and principal investigator of the study, Dr. Amy Hirschy at: 502-852-0625, or via e-mail at: amy.hirschy@louisville.edu

Sincerely, 
Aaron Phillips

PhD Candidate, College Student Personnel Program

University of Louisville 


\section{E-MAIL TO THE GENERAL U OF L POPULATION}

You are being invited to participate in a research study should you meet certain criteria. The purpose of this study is to learn what strategies, practices, actions, and behaviors low-income, first-generation students from a rural background employ and engage in to persist and be academically successful. This study is being conducted to fulfill the requirements for completing my doctoral degree here at the University of Louisville. You are receiving this e-mail because you are an undergraduate student at the University of Louisville, not because of any predetermined criteria. You have not been singled out based on any personal characteristics, but are receiving this because I am attempting to reach as many potential participants who may meet certain criteria. In order to participate in this study, participants must identify as

- identify as being from a low-income family background

- having grown up or identify as originating from a rural environment

- $\quad$ not having a parent who has graduated with a 4-year college degree

- have at least a 2.5 cumulative college GPA

- have completed at least 60 credit hours (not all credits need to have been completed at U of L)

Any information you provide will be kept confidential, however federal regulatory agencies and the University of Louisville Institutional Review Board (a committee that reviews and approves research studies) may inspect and copy records pertaining to this research. To help protect your confidentiality, I will use a study identification code number and a study name, not your real name, to identify all information collected for the study.

Please note that participation in this study is completely voluntary. You will not have any costs associated with the study, however, you will also receive no payment for the study either. If you participate in the interviews, however, you will be entered into the drawing for one of two \$25 Kroger gift cards. If you have any questions regarding the study, don’t hesitate to contact me, Aaron Phillips at: 502-852-3214 or aaron.phillips@louisville.edu; or the chair of my dissertation committee and principal investigator of the study, Dr. Amy Hirschy at: 502-852-0625, or via e-mail at: amy.hirschy@louisville.edu 
Sincerely,

Aaron Phillips

PhD Candidate, College Student Personnel Program

University of Louisville 


\section{APPENDIX C \\ INTERVIEW QUESTIONS}

\section{Tell me about yourself and your background.}

- Tell me about your first day on U of L's campus. As best you can recall, what were some of your feelings and thoughts?

- Tell me a story about any experiences you had during the transition to campus when your status as a first generation student impacted you or became apparent.

- What do you feel are some aspects of your personality related to your first-generation status that have been assets to you as a student here at the university? What about aspects in relation to that status have been obstacles to you as a student here at U of L?

- Have you had any siblings that have graduated from college? If so, how has this impacted your experience? If not, what does it mean to be the first in your family to graduate from college?

\section{Tell me about your hometown, your home community, where you are from.}

- How supportive were your friends, family, and home community been regarding your attending college in general? What about in regard to $U$ of L specifically?

- Is there anything about being from a rural area that has benefitted you and helped lead toward your success?

- I come from a small town myself, so I can very much relate to moving from a rural to an urban area, is there anything about coming from a rural area specifically that you feel has made your transition here more difficult? Is there anything that you think is a positive from a rural standpoint in your being here?

- How have any of your experiences here at U of L influenced or affected your relationships with your home community?

3. What are your thoughts and feelings when some students are described as low-income? What does that mean for you personally? 
- Please describe your experiences growing up as related to your family's finances.

- Now, if you could please describe your experiences on campus in relation to being low-income.

- From your perspective, what is the climate and atmosphere here at $\mathrm{U}$ of $\mathrm{L}$ toward low-income students?

\section{Explain/describe your greatest challenges/obstacles in being successful as a college student.}

- Did you have any challenges in attending the University of Louisville specifically? Explain a little bit about that. Have you personally found anything about $\mathrm{U}$ of $\mathrm{L}$ that is advantageous for a student from a first-gen, low-income, rural background?

- How did you work to overcome those obstacles?

- From your perspective or based on your experiences, has the university done well to help students from a similar background as yourself (firstgen, rural, low-income) to overcome those challenges? What could the university be doing differently?

5. What assets and strengths have you relied upon most based upon your background as low-income, first-generation and being from a rural background in being successful as a college student?

- What about your personality do you think has helped you to succeed?

- What advice would you give to another first-generation, low-income student, particularly one from a rural background?

- What has been your biggest motivation to complete your degree?

6. What have you been involved with here at $U$ of $L$ that you feel has benefitted you academically and contributed toward your persistence? Also, in addition, that has helped you to feel part of the campus community?

- What activities or organizations are you involved with on campus? Do you believe this involvement has helped you to be successful as a student academically or in other ways? If so, how?

- What about any academic connections you have made on campus (to instructors, tutors, in study groups, academic advisor, etc.) that have led to your success? Could you tell a little about that?

- Also, have you made any social connections on campus that have led to success as a student here? 
- Have you made any connections, academically, socially, or otherwise in the Louisville area, but off campus? Could you tell me a little about that?

7. Is there anything else you would like to add that I haven't asked about? Or, when you first heard about the study, is there anything you thought I would ask you that I haven't?

Notes regarding interview: This is an interview guide and I will ask probing sub-

questions related to the questions in this guide as necessary for a more in-depth interview. In other words, there may be certain follow-up questions asked over the course of the interview not revealed here based upon participants' responses. There may be minor alterations (including additions) as the interview proceeds and develops. 
APPENDIX D

\section{Subject Informed Consent Document}

$10 / 13 / 2014$

IRB EXPIRATION DATE:

09/14/2015

\section{Strategies, Actions, and Behaviors of Academically Successful First-Generation, Low-Income Students from Rural Areas at an Urban Institution}

Investigator(s) name \& address: Dr. Amy Hirschy, Room 325 College of Education of Human Development University of Louisville, Louisville, KY 40292 Mr. Aaron Phillips, Room 140, Education Advising and Student Services, College of Education and Human Development, University of Louisville, Louisville, KY 40292

Site where study is to be conducted: Belknap campus

Phone number for subjects to call for questions: 502-852-3214 or 502-852-0625

\section{Introduction and Background Information}

You are invited to participate in a research study. The study is being conducted by Dr. Amy Hirschy and Aaron Phillips PhD Candidate in College Student Personnel in the College of Education and Human Development. The study is sponsored by the University of Louisville, Department of Educational \& Counseling Psychology, Counseling, and College Student Personnel. The study will take place on the Belknap campus of the University of Louisville with the specific location to be determined by the participant. Approximately 20-25 subjects are anticipated to participate.

\section{Purpose}

The purpose of this study is to find out what strategies, practices, actions, and behaviors low-income, first-generation students from a rural background use to be academically successful.

\section{Procedures}


In this study, you will be asked to participate in at least one interview lasting approximately 60 minutes, and another possible follow-up interview lasting no more than 60 minutes. The participant will also have the option to answer follow-up questions via email if he or she so chooses to do so. The participant may decline to answer any question that makes him or her uncomfortable and participation in a second interview is not a requirement for participation in the study. Interviews will be audio recorded to ensure for accuracy.

\section{Strategies, Actions, and Behaviors of Academically Successful First-Generation, Low-Income Students from Rural Areas at an Urban Institution}

\section{Potential Risks}

There are no foreseeable risks other than possible discomfort in answering personal questions.” There may also be unforeseen risks.

\section{Benefits}

The information collected may not benefit you directly. The information learned in this study may be helpful to others.

\section{Compensation}

For your participation in this study, you will be entered into a drawing for two \$25 Kroger gift cards. If you are selected to receive a gift card, the University of Louisville must collect your name, address, social security number, as you to sign a W-9 form, and keep records of how much you are paid. You may or may not be sent a Form 1099 by the University. This will only happen if you are paid $\$ 600$ or more in one year by the University. We are required by the Internal Revenue Service to collect this information and you may need to report the payment as income on your taxes. This information will be protected and kept secure in the same way that we protect you other private information. If you do not agree to give us this information, we can't pay you for being in this study. You can still be in the study even if you don't want to be paid.

\section{Confidentiality}


Total privacy cannot be guaranteed. Your privacy will be protected to the extent permitted by law. If the results from this study are published, your name will not be made public. While unlikely, the following may look at the study records:

The University of Louisville Institutional Review Board and Human Subjects Protection Program Office.

Office for Human Research Protections (OHRP)

Office of Civil Rights

Any information received from you will be stored in a locked file cabinet in a locked office. Electronic information will be stored on a password -protected computer. Your study name and your study identification will be stored in a separate location that is accessible only to the researchers. When I write a report about this study or share the study data with others, I will do so in a way that you cannot be identified.

\section{Strategies, Actions, and Behaviors of Academically Successful First-Generation, Low-Income Students from Rural Areas at an Urban Institution}

\section{Voluntary Participation}

Taking part in this study is voluntary. You may choose not to take part at all. If you decide to be in this study you may stop taking part at any time. If you decide not to be in this study or if you stop taking part at any time, you will not lose any benefits for which you may qualify.

You will be told about any changes that may affect your decision to continue in the study.

\section{Research Subject’s Rights, Questions, Concerns, and Complaints}

If you have any concerns or complaints about the study or the study staff, you have three options.

You may contact the principal investigator at: 502-852-0625 and the co-investigator at: 502-852-3214

If you have any questions about your rights as a study subject, questions, concerns or complaints, you may call the Human Subjects Protection Program Office (HSPPO) (502) 
852-5188. You may discuss any questions about your rights as a subject, in secret, with a member of the Institutional Review Board (IRB) or the HSPPO staff. The IRB is an independent committee composed of members of the University community, staff of the institutions, as well as lay members of the community not connected with these institutions. The IRB has reviewed this study.

If you want to speak to a person outside the University, you may call 1-877-852-1167. You will be given the chance to talk about any questions, concerns or complaints in secret. This is a 24 hour hot line answered by people who do not work at the University of Louisville.

\section{Strategies, Actions, and Behaviors of Academically Successful First-Generation, Low-Income Students from Rural Areas at an Urban Institution}

This paper tells you what will happen during the study if you choose to take part. Your signature means that this study has been discussed with you, that your questions have been answered, and that you will take part in the study. This informed consent document is not a contract. You are not giving up any legal rights by signing this

informed consent document. You will be given a signed copy of this paper to keep for your records.

Signature of Subject/Legal Representative

Signature of Person Explaining the Consent Form (if other than the Investigator)

Signature of Investigator
Date Signed

Date Signed 
UofL Institutional Review Boards

IRB NUMBER: 14.0701

IRB APPROVAL DATE:

APPENDIX E

10/13/2014

IRB EXPIRATION DATE:

POSTED FLIER TO RECRUIT PARTICIPANTS

09/14/2015

Strategies, Actions, and Behaviors of Academically Successful First-Generation, Low-Income Students from Rural Areas at an Urban Institution

\section{ARE YOU A FIRST-GENERATION COLLEGE STUDENT?}

If so, you may be eligible to participate in an important study researching strategies, techniques, actions, and

behaviors of academically successful students from the se backgrounds.

In addition to the above criteria you must also have:

- at a least a 2.5 cumulative GPA and

- be Junior or Senior in academic standing

- identify as being from a rural area

- identify as low-income

IF YOU THINK YOU MAY BE INTERESTED, PLEASE CONTACT AARON PHILLIPS, PHD CANDIDATE IN THE COLLEGE STUDENT PERSONNEL PROGRAM HERE AT U OF L AT: aaron.phillips@ouisville.edu You may also call Aaron at: 502-852-3214 if you have questions. You may also contact Dr. Amy Hirschy at: 
amy.hirschy@ouisville.edu or at: 502-852-0625 should you have questions.

Participation in the study will involve one (possibly two) face to face interviews lastly no more than 60 minutes. All interviews will take place on the main Belknap campus at a location to be determined by the participant.

The purpose of this study is to find out what strategies, practices, actions, and behaviors low-income, firstgeneration students from a rural background use to be academically successful.

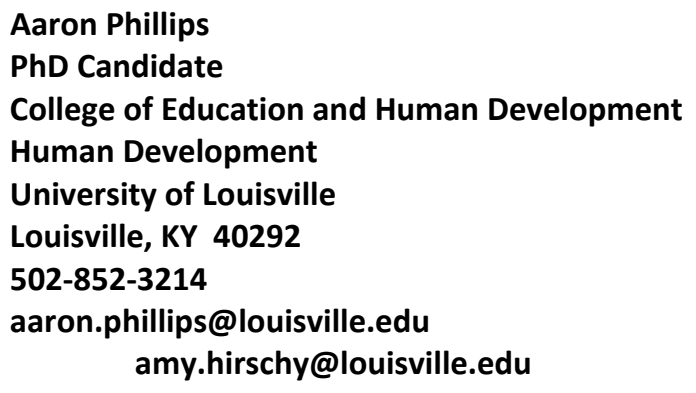

Dr. Amy Hirschy Assistant Professor College of Education and University of Louisville Louisville, KY 40292 502-852-0625 


\begin{abstract}
APPENDIX F
Poverty Guidelines and TRIO Low Income Guideline Tables
\end{abstract}

Table 2

2014 Poverty Guidelines for the 48 Contiguous States and the District of Columbia:

\begin{tabular}{cc}
\hline Persons in Family/Household & Poverty Guideline \\
\hline 1 & $\$ 11,670$ \\
2 & $\$ 15,730$ \\
3 & $\$ 19.970$ \\
4 & $\$ 23,850$ \\
5 & $\$ 27,910$ \\
6 & $\$ 31,970$ \\
7 & $\$ 36,030$ \\
\hline
\end{tabular}

Note: For families/households with more than 8 persons, add \$4,060 per each additional person. Retrieved from: http://aspe.hhs.gov/poverty/14poverty.cfm 
Table 3

Current-Year Low-Income Levels for the Federal TRIO Programs

\begin{tabular}{|c|c|c|c|}
\hline$\underline{\text { Size of Family Unit }}$ & $\begin{array}{l}48 \text { Contiguous States, D.C., } \\
\underline{\text { and Outlying Jurisdictions }}\end{array}$ & $\underline{\text { Alaska }}$ & $\underline{\text { Hawaii }}$ \\
\hline 1 & $\$ 17,505$ & $\$ 21,870$ & $\$ 20,130$ \\
\hline 2 & $\$ 23,595$ & $\$ 29,490$ & $\$ 27,135$ \\
\hline 3 & $\$ 29,685$ & $\$ 37,110$ & $\$ 34,140$ \\
\hline 4 & $\$ 35,775$ & $\$ 44,730$ & $\$ 41,145$ \\
\hline 5 & $\$ 41,865$ & $\$ 52,350$ & $\$ 48,150$ \\
\hline 6 & $\$ 47,955$ & $\$ 59,970$ & $\$ 55,155$ \\
\hline 7 & $\$ 54,045$ & $\$ 67,590$ & $\$ 62,160$ \\
\hline 8 & $\$ 60,135$ & $\$ 75,210$ & $\$ 69,165$ \\
\hline
\end{tabular}

Retrieved from: http://www2.ed.gov/about/offices/list/ope/trio/incomelevels.html

Note: For family units with more than eight members, add the following amount for each additional family member: \$6,090 for the 48 contiguous states, the District of Columbia and outlying jurisdictions; $\$ 7,620$ for Alaska; and \$7,005 for Hawaii. The term "low-income individual" means an individual whose family's taxable income for the preceding year did not exceed 150 percent of the poverty level amount. The figures shown under family income represent amounts equal to 150 percent of the family income levels established by the Census Bureau for determining poverty status. The poverty guidelines were published by the U.S. Department of Health and Human Services in the Federal Register on January 22, 2014. 


\section{CURRICULUM VITAE}

\section{Aaron Phillips}

502-852-3214 or 502-810-8539

awp2112@gmail.com

\section{ACCOMPLISHMENTS}

- Established and coordinated graduate student orientation for the College of Education and Human Development at the University of Louisville

- Supervise staff for over 5 years

- Developed and manage Graduate Student Visit Program, arranging for a meeting with a faculty member, current student, and provide a tour of campus

- Initiated and developed promotional print materials to advertise and market graduate programs within the College of Education and Human Development

- Oversee graduate application process for the College of Education and Human Development

\section{CURRENT EXPERIENCE}

\section{University of Louisville $\quad$ October 2009 to present}

Assistant Director for Education Academic Services/Graduate Admissions Coordinator

- Provide overall leadership and direction for the admission process for graduate admission in the College of Education and Human Development (CEHD) (largest graduate college at the university with over 1000 graduate students)

- Coordinate retention efforts and admission initiatives by tracking enrollment, following up with those not enrolled, and troubleshooting registration problems and issues

- Employ advising strategies with students on policies and procedures to support student retention

- Oversee advisement of prospective students regarding admission requirements

- Oversee accuracy of admission data and current student records maintained in PeopleSoft

- Lead and support registration, admission, and other processes

- Provide guidance to and oversee annual budget of \$1500 for the CEHD Graduate Student Association

- Collaborate, plan, and implement with university partners on admission, recruitment, and enrollment initiatives 
- Collaborate with and advises the Assistant Dean of Student Services and Department Chairs on potential problem areas and make recommendations to improve the admission process

- Monitor degree programs' web sites and works closely with IT professionals to ensure information is accurate, complete, and compelling

\section{EDUCATION}

University of Louisville

May 2015

$\mathrm{PhD}$ in Counseling and Personnel Services with an emphasis in Louisville, KY College Student Personnel (focus on disadvantaged and at-risk student populations) Dissertation: “"I Had to Learn That on My Own: Successful First-Generation, LowIncome College Students from Rural Areas at an Urban Institution”

3.983 GPA

University of Louisville

Master of Education in College Student Personnel Services 3.954 GPA

Eastern Kentucky University

Bachelor of Science in Middle Grade Education

Certification in social studies \& language arts, grades 5-9, 3.78 GPA

Eastern Kentucky University

Bachelor of Arts of Sociology: 3.74 Overall GPA, 4.0 GPA in major
December 2006

Louisville, KY

December 2003

Richmond, KY

July 2009

\section{PREVIOUS EMPLOYMENT EXPERIENCE}

University of Louisville

Admissions Counselor/Admissions Counselor Sr
July 2007-October 2009

- Evaluated 300-500 transfer and freshman applicants for admission per semester

- Established and cultivated partnerships with various academic units on campus including the Office of Athletics, College of Education and Human Development, College of Business, etc.

- Coordinated scholarship program for students transferring from KCTCS

- Coordinated monthly visit for prospective transfer students

- Presented to high school students and their parents through the "Campus Visit Program”

- Counseled and discussed with prospective students and their parents regarding admission policies and procedures

- Represented the university at corporate and community college fairs

- Assisted with special events on campus such as preview days, orientation, and others as needed 
- Taught remedial writing/reading and life skills' course content to beginning college students

- Designed lesson plans around book content

- Designed student assessments to indicate if content objectives were met

- Facilitated student interaction and participation in involvement and discussion

- Maintained attendance and grade records for enrolled students

- Provided emotional support and encouragement for students facing academic and personal challenges

Ivy Tech Community College, Office of Enrollment Services ～August 2005-July 2007 Assistant Director of Enrollment Services

- Represented Ivy Tech at college and other educational fairs

- Answered questions by current/potential students and parents via phone and email

- Registered and tested local high school students for dual credit courses, working closely with academic affairs and external secondary school personnel

- Welcomed and met with prospective student and their parents in person

- Served on interview committees for prospective employees

- Supervised two work-study students

- Administered and facilitated school and other group visits on campus

- Established and maintained positive relationships with high school personnel including school guidance counselors and administrators

- Planned, organized, and assisted with events on campus such as open house, orientation, etc.

University of Louisville, Office of Admissions December 2004-July 2005

Graduate Assistant

- Represented university at five local high schools in Jefferson county

- Gave presentations to potential students and parents on campus visits

- Read and evaluated undergraduate applications for admission

- Reviewed and input data into PeopleSoft database system

- Answered questions concerning the university and admission's policies to parents and student via telephone and in person

- Responded to e-mail inquiry from transfer students and scheduled appointments for students with Transfer Credit Specialists 
- Responded to general questions regarding financial aid regulations

- Assisted students and parents with account information via phone

- Input and verified student information via the PeopleSoft system

- Managed and organized hard copies of student files

- Assisted with other duties and projects as assigned

\section{PROFESSIONAL DEVELOPMENT AND AWARDS}

Presentations, Professional Associations, and Activities

- "Dual Credit Opportunities for High School Students" Presentation: CPAK and KASCAC 2006 conferences in Louisville, KY

- NACADA, National Academic Advising Association, Regional Conference, May 2010 in Lexington, KY: Co-presented on delivering graduate students services within an advising office geared toward an undergraduate student population

- ACPA, American College Personnel Association, Case Study team competition, Competed April 2005

- CPAK, College Personnel Association of Kentucky, Case Study team competition, Winner, March 2005

Professional and Collegiate Associations and Memberships

- SACSA (Southern Association for College Student Affairs) 2014 Conference, Member of the On-site planning committee

- University Judicial Hearing Board, 2014-15 academic year

- U of L Staff Senate, August 2013-present, member of Policy and Economic Development Committee 2013-14 and Staff Morale Committee 2014-15

- IACAC, Indiana Association for College Admission Counseling, Congress Planning Committee for 2006 Congress, Member

- KACRAO, Kentucky Association of Collegiate Registrars and Admission Officers, Member 2007-09

- KASCAC, Kentucky Association for School Counselors and Admission Counselors, Member 2005-07

- EKU Middle School Association Treasurer, 2002-03

Teaching and Publication

- Taught session of ECPY 661, Theory of College Student Development, March 2014 \& March 2015

- Taught session of ECPY 664, College Student Subcultures, September 2014

- Cardinal Covenant Program: Internship as part of doctoral course work (MarchDecember 2013)

o Produced article for possible publication

o Conducted an assessment on campus involvement of students 


\section{Awards}

- Received Graduate Dean's Citation “in recognition of excellent achievement as a candidate for an advanced degree,” December 2006

- Awarded “Outstanding Sociology Graduate” for 1998-99 academic year 